\title{
Early-Middle Pleistocene transitions: linking terrestrial and marine realms
}

\author{
Martin J. Head ${ }^{\mathrm{a},{ }^{*}}$, Philip L. Gibbard ${ }^{\mathrm{b}}$ \\ ${ }^{a}$ Department of Earth Sciences, Brock University, 500 Glenridge Avenue, St. \\ Catharines, Ontario L2S 3A1, Canada \\ ${ }^{\mathrm{b}}$ Cambridge Quaternary, Department of Geography, University of Cambridge, \\ Downing Place, Cambridge CB2 3EN, UK \\ * Corresponding author \\ E-mail address: mjhead@brocku.ca (M. J. Head)
}

Key words: Early-Middle Pleistocene, terrestrial climate, paleoceanography, hominins, integrated review

\begin{abstract}
Marked by a progressive increase in the amplitude of climate oscillations and a shift towards a quasi-100 kyr frequency, the Early-Middle Pleistocene transition (EMPT), previously known as the Mid-Pleistocene Transition (or Mid-Pleistocene Revolution) (1.4-0.4 Ma), represents a fundamental shift in the Earth's climate state. The physical and biotic responses to this transition, amplified by the growth of Northern Hemisphere ice sheets, have been profound. Two important paleomagnetic episodes characterize the EMPT, the Jaramillo Subchron (1.07-0.99 Ma) and the Matuyama-Brunhes Chron boundary $(\sim 773 \mathrm{ka})$. The latter has been chosen as the primary guide for the LowerMiddle Pleistocene Subseries boundary, as it lies at the approximate midpoint of the EMPT and aids in global recognition both in marine and terrestrial deposits. The Jaramillo Subchron has received less attention, but the late Early Pliocene is important in Europe because it saw the progressive transition from the Villafranchian to Galerian mammal faunas, and expansion of hominins into western and northern Europe. The Jaramillo Subchron is represented by Marine Isotope Stages (MIS) 31 to 28, with MIS 30 already showing the asymmetrical (saw-tooth) pattern characteristic of the Middle Pleistocene. Indeed, while variation in the 40-kyr band (obliquity) remains strong throughout the EMPT, low frequency variability begins at around 1250-1200 kyr, which coincides with a progressive increase in global ice volume.

The early phase of the EMPT is characterized by important glaciations beginning with MIS 36 and continuing to MIS 22, a major intensification of the East Asian monsoon system, intensification of loess deposition in northern Europe, development of open landscapes in western Siberia, increased fluvial incision, higher amplitude sea-level change, and spread of large mammals across northern Eurasia, and a strong reduction in the North Atlantic thermohaline circulation. In Europe, the loss of thermophilous plant taxa during the EMPT and indeed throughout the Quaternary is a reminder of the progressive cooling that took place in this region.
\end{abstract}




\section{Introduction}

A fundamental transition in the Earth's climate state took place during a 1.4-0.4 Ma interval that spans the Early-Middle Pleistocene boundary (Ruddiman et al., 1986). It was largely marked by a progressive increase in the amplitude of climate oscillations, a shift from 41-kyr to quasi-100 kyr orbital rhythym, increasing long-term average global ice volume, and the establishment of strong asymmetry in global ice volume cycles. This interval, known as the Early-Middle Pleistocene transition (EMPT), essentially begins at 1.4 Ma with a relative decrease in the duration of interglacials and a change in the climate's sensitivity to orbital focing (Lisiecki and Raymo, 2007). It is taken here to terminate around Marine Isotope Stage (MIS) 12/11 transition at $420 \mathrm{ka}$, given that from MIS 11 onwards the Earth's climate experienced much higher-amplitude interglacials than earlier in the EMPT (Lang and Wolff, 2011). Changes during this transition are perhaps most intense near to its midpoint at around MIS 24-22 (900 ka) which is also close to the Matuyama-Brunhes boundary at $\sim 773 \mathrm{ka}$. For reasons of expediency, the Matuyama-Brunhes boundary has been taken as the primary guide for the Early-Middle Pleistocene boundary (Head and Gibbard, 2005; Head et al., 2008). The term EMPT is therefore most apt for the present situation.

The EMPT essentially equates to the "mid-Pleistocene Revolution" or "midPleistocene Transition" of earlier authors (e.g. Maasch, 1988; Saltzman and Maasch, 1988; Berger and Jansen, 1994; Berger et al., 1994), although these terms initially referred primarily to the change in frequency of the climate signal. These terms, while still in use, are no longer appropriate because the lowering of the base Pleistocene (and Quaternary) from 1.8 Ma to 2.58 Ma (Gibbard and Head, 2010; Gibbard et al., 2010) has shifted the middle part of the Pleistocene to well below the midpoint of the transition. Nor is the term Middle Pleistocene transition (e.g. Clark and Pollard, 1998) appropriate because this interval is not confined to the Middle Pleistocene, but evenly straddles the Early-Middle Pleistocene boundary.

Regardless of its name, the importance of the EMPT cannot be overstated. The glacial stages, progressively increasing in strength and duration, represent a series of ecological filters from which many species eventually succumbed while others adapted in response to change. Increasingly extensive glaciation of the Northern Hemisphere affected atmospheric and oceanic circulation, with impacts on the physical as well as biological realms (Head and Gibbard, 2005). Increasing levels of ice-rafted debris in the North Atlantic and changes in palaeosol-loess deposition on the continents provide stark evidence of physical changes during this time. Evolutionary turnovers and migration events among the large mammal fauna, as evidenced for example by the endVillafranchian-Galerian mammal age transition in Europe, and corresponding changes in vegetation, all reflect dramatic upheavals (Head et al., 2008).

For all these reasons, the EMPT has long been regarded as the natural divide between the Lower and Middle Pleistocene. Interest in this interval has been furthered by efforts to select a global boundary stratotype section and point (GSSP) for the LowerMiddle Pleistocene Subseries boundary (Head et al., in prep.). Three candidate sections are under consideration: the Valle di Manche in Calabria (Capraro et al., 2005, 2015), and Montalbano Jonico in Basilicata (Ciaranfi et al., 2010; Marino et al., 2015), both in 
southern Italy; and the Chiba section in Japan (Pickering et al., 1999; Kazaoka et al., 2015; Suganuma et al., 2015). As mentioned, the Matuyama-Brunhes boundary (at 773 ka) will serve as the primary guide for the boundary (Head et al., 2015).

Additional impetus for studying the EMPT comes from the progressive occupation of the genus Homo across Europe and northern Eurasia during this time. At one of the Atapuerca cave sites near Burgos, northern Spain, a specimen of the genus Homo dated at between $\sim 1.5-1.2$ Ma represents the earliest paleontological evidence of Homo in western Europe, with a second phase of dispersal occurring before $\sim 772 \mathrm{ka}$ (Cuenca-Bescos et al., 2013). The initial migration of Homo into western Europe therefore occurs near the beginning of the EMPT, although expansion of this genus into northern Eurasia and sustained widespread occupation of Europe occurred throughout the interval (Head and Gibbard, 2005; Head et al., 2008 and references therein; Cohen et al. 2012).

Although recently reviewed (Head and Gibbard, 2005, Head et al., 2008), the EMPT has been researched intensely over the past five years or so. This new assessment examines the climatic evolution of the EMPT and its root causes. It critiques the age constraints that underpin this interval, and examines the major paleomagnetic reversals and their estimated ages. Specific events both on land and in the oceans are then identified and characterized, beginning with the oldest and focusing on the earlier part of the EMPT. The marine and terrestrial records are then integrated to yield an updated synthesis of the EMPT. The dating of marine isotope stages and their taxonomy follow Lisiecki and Raymo (2005).

\section{Onset and termination of the EMPT}

The shift to 100 kyr cyclicity, increasing amplitude of climate cycles, and change to a more asymmetrical waveform were all initiated within the early Pleistocene, and have subtle initial expressions. An analysis of the LR04 (Lisiecki and Raymo, 2005) benthic stack by Lisiecki and Raymo (2007) showed that the saw-tooth asymmetry in glacial cycles, which becomes extreme during the EMPT, in fact first appears at around $2.5 \mathrm{Ma}$ and increases progressively thereafter. However, at $1.4 \mathrm{Ma}(\sim \mathrm{MIS} 45)$ there is a stepped decrease in the relative durations of interglacials, and the 41-kyr power of glacial cycles ceases to be modulated by orbital forcing (becoming instead approximately constant and nonlinear), these features collectively pointing to a major transition in climate dynamics (Lisieck and Raymo, 2007). Indeed, between 1.45 and $1.25 \mathrm{Ma}$, low frequency (2-3 bundled obliquity cycles) power has been detected in low-latitude seasurface temperature (SST) records, possibly representing a precursor to later $\sim 100-\mathrm{kyr}$ cycles (Z. Liu et al., 2008).

A long-term average global ice-volume increase occurs between 1.25 Ma and 700 ka (Clark et al., 2006). The onset of low-frequency variability occurs at 1250-1200 ka (around MIS 36) with increased power in the 70-kyr band, based on a wavelet analysis of the LR04 global benthic $\delta^{18} \mathrm{O}$ stack by Head et al. (2008). Long-term SST cooling also begins or intensifies at around 1.2 Ma for most globally distributed records (McClymont et al., 2013).

Indeed the first major build-up of global ice volume during MIS 24-22, the so called 900-ka event, is preceded by various adjustments of the climate system. These 
include the intensification of the tropical Pacific Ocean and atmospheric circulation, evolution of the Asian monsoon system, the cooling and expansion of subarctic and polar watermasses, cooling in upwelling systems and the deep Atlantic Ocean, and changes to the thermohaline circulation (McClymont et al., 2013 and references therein).

The progression of the EMPT can be seen in the wavelet analysis of the LR04 stack (Head et al., 2008) which shows low-frequency variability gaining power in the 85110-kyr band at around 1000-900 ka (late early Pleistocene), and intensifying at around 700-650 ka (MIS 16, early middle Pleistocene). The EMPT has been considered complete by around $700 \mathrm{ka} \mathrm{(e.g.} \mathrm{Clark} \mathrm{et} \mathrm{al.,} \mathrm{2006)} \mathrm{or} \mathrm{at} 640 \mathrm{ka}$ in MIS 16 (Hodell et al., 2008) or $420 \mathrm{ka}$ at the MIS 12-11 transition (Billups et al., 2006). The glacial MIS 12 and peak of the interglacial MIS 11 at $400 \mathrm{ka}$ between them display the high amplitude shift in benthic $\delta^{18} \mathrm{O}$ that characterizes later Quaternary climate cycles, and so the MIS 12-11 (420 ka) transition indeed marks a convenient end to the EMPT. This represents the mid-Brunhes Event (MBE) after which evidence from marine, terrestrial and ice-core records point to an abrupt increase, from MIS 11 onwards, in interglacial temperatures and in reconstructed interglacial $\mathrm{CO}_{2}$ values (Masson-Delmotte et al., 2010; Lang and Wolff, 2011; McClymont et al., 2013 and references therein). However, interglacial temperatures after the mid-Brunhes Event appear generally to have no more than returned to Early Pleistocene values, so the EMPT itself (rather than the MBE) represents the anomaly when viewed within the broader Pleistocene context (McClymont et al., 2013). It has also been noted that the mid-Brunhes Event is not expressed everywhere, challenging the notion that is it is a "global event" (Candy and McClymont, 2013 and references therein). As with the initiation of the EMPT, the mid-Brunhes Event is difficult to explain in terms of orbital forcing, and internal feedbacks seem to be responsible.

\section{Orbital characteristics of climate change during the EMPT}

The benthic foraminiferal $\delta^{18} \mathrm{O}$ record of global ice volume has served as the primary means to characterize climate change through the EMPT. Shackleton and Opdyke (1976) were first to show a change from high- to low-frequency climate cycles at the EMPT from their detailed analysis of a core from the equatorial Pacific Ocean. Ruddiman et al. (1986) showed that the early Pleistocene was dominated by $41 \mathrm{kyr}$ obliquity forcing, and that around $0.735 \mathrm{Ma}$ periodicity shifted to near $100 \mathrm{kyr}$. In detail, early Pleistocene glacial-interglacial cycles have a 41-kyr mean period (Pisias and Moore, 1981), low amplitude, and a relatively symmetrical wave form. This points to an obliquity-forced climate, and a somewhat linear response of Earth climate system. However, asymmetry is present within the 41-kyr cycles (Ashkenazy and Tziperman, 2004), and whether the precise timing of deglaciations was in fact controlled by precession rather than obliquity is an open question (Huybers, 2011).

From late early Pleistocene onwards, glacial-interglacial cycles developed a low frequency ( 100-kyr) mean period, high amplitude, and increasingly "saw-tooth" wave form, characteristic of strong non-linear forcing. It is tempting to explain this pattern through orbital eccentricity forcing, given that eccentricity has strong influence over inter-annual seasonal variations in solar radiation. However, orbital eccentricity has periodicities at 96, 125 and $413 \mathrm{ka}$, and time-series analyses of long benthic foraminiferal 
records show a single peak (rather than a double peak) at around $100 \mathrm{ka}$ and no peak at $413 \mathrm{ka}$. Moreover, glacial-interglacial cycles do not show regular periodicity during this time, but display quasi-100-kyr periodicity (the "eccentricity myth" of Maslin and Ridgwell, 2005). This prompted Maslin and Ridgwell (2005) to propose that each glacial-interglacial cycle represents four or five precessional cycles in which deglaciations are controlled by ice-sheet dynamics and at most "paced" but not driven by eccentricity. In support of this proposal, they noted that even at $65^{\circ} \mathrm{N}$, precession has the dominant influence on solar radiation received, with obliquity dominating only at high polar latitudes (see also Berger and Loutre, 1994).

Nonetheless, Huybers (2006) argued that integrated summer energy (taking summer duration into account as well as insolation intensity) is the primary orbital influence on ice sheet ablation, and is controlled by obliquity. Although precession of the equinoxes, with a periodicity of $21 \mathrm{kyr}$, also has an influence on summer insolation changes, the increased insolation when Earth is close to Sun is nearly canceled by the shorter time spent there. This is because, as known from Kepler's $2^{\text {nd }}$ Law, the Earth accelerates as it approaches the Sun, resulting in shorter summers (Huybers 2006).

Huybers (2007) presented an age model for 17 deep-sea $\delta^{18} \mathrm{O}$ records by combining decompacted sediment depth with the radiometric ages for several paleomagnetic reversals, an approach chosen to avoid orbital assumptions. Using this age model, the $\delta^{18} \mathrm{O}$ records confirmed obliquity forcing in the early Pleistocene, although some cycles were missed such as MIS 36 at 1.2 Ma (Huybers, 2007). Significantly, beginning with the EMPT, the record was found to shift to 80 or 120 kyr cyclicity, and best explained by two or three obliquity $(\sim 41 \mathrm{kyr})$ cycles. Huybers noted that the influence of obliquity increases with latitude; and given that obliquity was already dominant in early Pleistocene, it would be simpler to modulate an existing dominant frequency.

Huybers (2011) used his earlier depth-related age model (Huybers, 2007), with small adjustments, to explore whether precession might have combined with obliquity to pace glaciations of the EMPT and later. Results showed that both obliquity and precession indeed pace $\sim 100 \mathrm{kyr}$ glacial cycles, with eccentricity controlling the amplitude of precession. The two or three ( 80 or $120 \mathrm{kyr}$ ) obliquity cycles of Huybers (2007) are still supported, and obliquity was found to be more fundamental in controlling the length of the glacial cycle, but with precession affecting the precise timing of deglaciation. These results are consistent with an earlier investigation by Head et al. (2008) who used wavelet analysis of a stack of 57 marine benthic $\delta^{18} \mathrm{O}$ records compiled by Lisiecki and Raymo (2005) to reveal strong and consistent power in the 41-kyr obliquity band through and beyond the EMPT as well as some influence of precession during this time. It might be added that the benthic stack of Lisiecki and Raymo (2005) was astronomically tuned, but when a compaction-corrected sedimentation rate age model was applied to this data set, the results were not significantly different from those based on orbitally tuning (Lisiecki and Raymo, 2007). The results of Huybers (2011) indeed also compare with those of Z. Liu et al. (2008) whose analysis of tropical seasurface temperature records across the EMPT suggested that the $\sim 100 \mathrm{kyr}$ cycles of the Middle Pleistocene are probably a nonlinear response to orbital obliquity (bundling of two or three obliquity cycles), but with their timing paced by excentricity/precession. 
Precessional forcing indeed appears to be an influence in climate records, even at the higher latitudes. A detailed record of foraminiferal $\delta^{18} \mathrm{O}$ through MIS 23-20 at a central North Atlantic site has variations that match the second and fourth harmonics of precession, with significant power at 10.7 and $6.0 \mathrm{kyr}$. This site was apparently influenced by the equatorial response to procession-driven insolation, the effects advected northward by tropical convective processes (Ferretti et al., 2010; see Section 7, below). This provides a glimpse of the complexity of the climate system and the interplay between different modes of orbital forcing, including at the millennial scale.

It is evident from the above summary that the early Pleistocene is dominated by $\sim 41 \mathrm{kyr}$ cycles largely driven by obliquity, but with precession possibly influencing the timing of cycles. The $100 \mathrm{kyr}$ glacial cycles characterizing and following the EMPT seem to represent bundles of two $(80 \mathrm{kyr})$ or three $(120 \mathrm{kyr})$ obliquity cycles, but with precession tending to affect the precise timing of deglaciation and also influencing millennial-scale variability. Because eccentricity amplifies the effects of precession, it too has an influence. Orbital forcing combines with feedback mechanisms within the climate system, particularly global ice volume, to control glacial cycles.

\section{Causes of the climate transition}

The unique characteristics of the later Quaternary glaciations largely reflect the interplay between orbital forcing and global ice volume. But Ruddiman et al. (1986) noted that while orbital forcing is the primary cause of these oscillations, it does not alone explain the shift in periodicity because insolation variations at $65^{\circ} \mathrm{N}$ computed for the past several million years show no evidence of a change in state. Numerous researchers have therefore looked for long-term trends that have triggered some form of amplification or threshold response. These are briefly reviewed below.

A secular global cooling trend (Zachos et al., 2001) may have helped Earth's climate to cross a threshold state, allowing ice sheets to survive 41-kyr cycles of high summer energy (e.g. Clark et al., 2006). Sosdian and Rosenthal (2009, 2010) showed evidence of cooling in North Atlantic bottom water across the EMPT but considered this a possible response rather than cause of changing ice sheet dynamics. Lawrence et al. (2010) also found significant decline in North Atlantic sea surface temperatures across the EMPT starting at $\sim 1.5-1.3 \mathrm{Ma}$ and driven largely by progressively cold glaciations, and also an increase in the meridional temperature gradient during this time. A stack of four alkenone-based tropical paleotemperature records and one based on $\mathrm{Mg} / \mathrm{Ca}$ from the major ocean basins (Herbert et al., 2010) for the past 3.5 Ma shows a trend of declining SST in the tropics from about $1500 \mathrm{ka}$. Glacial-interglacial temperature changes of $1^{\circ}$ to $3^{\circ} \mathrm{C}$ are registered over this $3.5 \mathrm{Ma}$ record, with the amplitude of change increasing after about $800 \mathrm{ka}$ (Herbert et al., 2010, fig. 4). An important analysis of 28 global SST records (mostly alkenone and foraminiferal $\mathrm{Mg} / \mathrm{Ca}$ ) by McClymont et al. (2013) revealed a long-term cooling trend through the EMPT in both lower and higher latitudes. This trend usually begins or intensifies at about 1.2 Ma (MIS 35-34), accompanying a longterm trend in higher global ice volume. The cooling trend is confirmed as being mostly attributable to the glacials, with interglacial SSTs showing little if any cooling. An exception is the so called "0.9 Ma event" (MIS 24-22) when both glacial and interglacial maxima register cooling (McClymont et al., 2013). 
In contrast, Elderfield et al. (2012) found no long-term cooling across the EMPT based on their analysis of a deep ocean core east of New Zealand, proposing instead an abrupt reorganization of the climate system during MIS 24-22 initiated by an increase in Antarctic ice volume during MIS 24. MIS 23 coincided with a low insolation maximum in the southern hemisphere, and this may have suppressed ice melting, leading to a massive ice buildup in Antarctica during MIS 22 (Elderfield et al., 2012). It remains to be seen whether the Antarctic, surrounded as it is by ocean, could have accumulated sufficient ice to profoundly influence global climate, and indeed whether a lowered sealevel allowing the grounding of ice on the shelf would have allowed sufficient growth.

Where a cooling trend has been invoked, a long-term decline in atmospheric $\mathrm{CO}_{2}$ has been proposed as the driving force, given the efficacy of $\mathrm{CO}_{2}$ as a greenhouse gas (e.g. Raymo, 1997; Berger et al. 1999; Clark et al., 2006). This would therefore have led to a non-linear response of the climate system. It is indeed likely that $\mathrm{CO}_{2}$ contributed to the amplification of glacial-interglacial alternations over last $800 \mathrm{kyr}$. To give one example, dust (iron) flux to the Southern Ocean may have fertilized the ocean, thereby lowering $\mathrm{CO}_{2}$ and providing a cooling feedback, the so-called "iron hypothesis" (Watson et al., 2000; Ridgwell and Watson 2002). Moreover, Martinez-Garcia et al. (2011) showed from a marine core in the Southern Ocean that dust and iron flux levels increased sharply around 1.25 Ma near the beginning of the EMPT. Nonetheless, Hönisch et al. (2009) using boron isotopes from planktonic foraminiferal tests did not find support for a long-term drawdown in $\mathrm{CO}_{2}$ across the EMPT although glacial $\mathrm{CO}_{2}$ levels did decline after about 1.0 Ma, whereas Tripati et al. (2011) found possible evidence for decline, and van de Wal et al (2011) found only small long-term decline. Hence there is presently no clear evidence for long-term $\mathrm{CO}^{2}$ decline as the trigger for the EMPT.

Increasing size and especially thickness of northern hemisphere ice sheets owing to progressive regolith erosion beneath the Laurentide ice sheet (Clark and Pollard, 1998; Clark et al., 2006; Sosdian and Rosenthal 2009) has also been suggested as a trigger for $\sim 100 \mathrm{kyr}$ glaciations. With erosion allowing ice sheets to rest directly on Precambrian crystalline basement bedrock of the Canadian Shield, with its greater frictional forces, they would develop more mass and therefore resist melting over a 41 kyr cycle, but also become inherently more unstable. The increasing magnitude and duration of IRD events in the North Atlantic, Norwegian-Greenland margins, and Barents Sea after $900 \mathrm{ka}$, along with increased northward advection of heat and moisture during interglacials MIS 25, 21 and 19, is consistent with the growth of large and unstable ice sheets during the EMPT (Hernández-Almeida et al., 2012, 2013, and references therein).

The possibility of mountain range uplift disrupting long-wave (planetary) atmospheric flow and triggering the EMPT was first discussed by Ruddiman et al. (1986) who suggested from modeling experiments that uplift of both the Sierra Nevada (USA) and Himalayan mountains / Tibetan Plateau complex could have created a more meridional (polar-directed) atmospheric flow, favouring cooler summers in central northern North America and hence reduced summer ablation of ice. Such disruption might also have changed the storm path across the North Atlantic, and inhibited the northward penetration of the North Atlantic Current, would have happened later when the Laurentide ice sheet had become well established (Maslin et al., 2001). Further modeling (Kutzbach et al., 1989) produced monsoonlike circulation with increasing uplift. Han et 
al. (2012) studied a loess-paleosol sequence from the Chinese Loess Plateau which provides a sensitive record of the relative strengths of East Asian summer (loess) and winter (paleosol) monsoons. They found a simultaneous strengthening of summer and winter monsoons both at $0.9 \mathrm{Ma}$ and $0.64 \mathrm{Ma}$ along with a shift to $\sim 100 \mathrm{kyr}$ cyclicity. Hence, uplift of the Tibetan Plateau may have crossed a critical threshold during the EMPT, disrupting smooth planetary zonal winds, and replacing them with meridional Asian monsoonal winds and fluctuating enhanced zonal westerlies. Through complex feedback processes this could have given rise to the dominant $\sim 100 \mathrm{kyr}$ cyclicity of the EMPT (Kutzbach et al., 1989; Han et al., 2012).

A consequence both of mountain uplift and increased glaciation is accelerated silicate weathering, which serves as an important $\mathrm{CO}_{2}$ sink (Berner et al., 1983). This leads potentially to a reduction in atmospheric $\mathrm{CO}_{2}$ and hence global cooling. Raymo et al. (1988) and Raymo (1994) have linked Tibetan Plateau uplift to increased silicate weathering and $\mathrm{CO}_{2}$ drawdown, with weathering enhanced by monsoonal precipitation (Tripathi et al., 2011). Similarly, the erosion of crystalline basement rocks by repeated glaciations in North America would have produced finely ground sediment prone to rapid weathering (Vance et al., 2009). In fact, silicate weathering is just one of various ways in which atmospheric $\mathrm{CO}_{2}$ is controlled by the carbon cycle (Tripathi et al., 2011, and above).

Another possible mechanism includes the uplift of the Greenland-Scotland submarine ridge during the EMPT, leading to a southward shift of deep-water production from the Arctic into the Nordic seas (Denton, 2000). Once full glacial conditions had been established, this could have made it more difficult to switch back to an interglacial mode with vigorous thermohaline circulation, thereby allowing ice sheets to build up over a 100 kyr cycle.

A change to more variable intermediate water circulation at the EMPT, causing dissociation of gas hydrates and release of methane on the continental shelf, was advanced by Kennett et al. (2003) to explain the sharp deglaciation of sawtooth curves. This so-called "clathrate gun hypothesis" was supported by the strong similarity between atmospheric methane and temperature variations in ice core records of the later Quaternary. A study examining the hydrogen isotopes of methane in ice cores has since ruled out a clathrate source (Bock et al., 2010). This investigation considered that the methane more likely represented an early climate response from boreal wetlands (Bock et al., 2010), although a study of carbon isotopes of methane suggested tropical wetlands to be the main source especially during glacials (Möller et al., 2013).

In response to a presumed long-term cooling trend, an expansion of the East Antarctic Ice Sheet (EAIS) preventing it from responding to precessionally-forced summer ablation has been proposed by Raymo et al. (2006) to explain the pattern of climate change across the EMPT. While the dominance of 41-kyr obliquity-related frequency in early Pleistocene climate records is well known, Raymo et al. (2006) noted that the weak power in $23 \mathrm{kyr}$ precession-related ice-volume variability is largely unexplained despite its strong influence even at high latitudes. They hypothesized that this subdued response is because precession is out of phase between hemispheres, with each hemisphere cancelling out the other, so long as both hemispheres have dynamic ice sheets. This implies that the EAIS (today the equivalent of $\sim 54-55 \mathrm{~m}$ of sea level), was then small enough in the early Pleistocene to expand and contract within its confined 
geographical limits, i.e. controlled by summer insolation and hence precession. Raymo et al. (2006) proposed that with cooling during the EMPT, the east Antarctica ice sheet expanded so that its margins became marine- rather than ground-based, i.e. bordered by extensive marine ice shelves much as today. This would have changed ice sheet growth from a regime controlled by summer insolation to one based on the destabilization of its marine ice shelves by sea-level fluctuations. With sea-level controlled largely by northern hemisphere ice sheet growth, this will have brought the EAIS in phase with it, and so removing the southern hemisphere cancelling effect of precession. This mechanism explains the in-phase relationship of climate records for both northern and southern ice sheets during the EMPT, and concomitant strengthening of the $23 \mathrm{kyr}$ precession-related ice-volume signal (Raymo et al., 2006). Supporting this view, surface waters surrounding Antarctica warmed about 11,000 years before the peak of MIS 31 in response to southern hemisphere insolation (Scherer et al., 2008). This demonstrates the antiphased nature of Antarctic ice sheet dynamics before cooling later in the EMPT.

The expansion of the West Antarctic Ice Sheet has also been implicated in the onset of the EMPT by increasing the supply of AABW into the North Atlantic (Lawrence et al. 2010). This hypothesis is based on an eastern North Atlantic corehole that is well positioned to detect the interplay between NADW and the AABW which replaces it during glacials. Phase relationships between $\delta^{13} \mathrm{C}, \delta^{18} \mathrm{O}$ and bottom-water temperature estimates imply that the North Atlantic became tightly linked to Southern Ocean processes during the EMPT through an increased export of AABW into the North Atlantic. The West Antarctic Ice Sheet is suggested to have expanded thereby sourcing the increased AABW. Both southern and northern hemisphere processes potentially therefore played a role in North Atlantic climate and current circulation during the EMPT (Lawrence et al. 2010).

Other approaches have explored stochastic processes within the climate system, as distinct from those that are orbitally-controlled and hence deterministic, to assess their role as drivers of climate variability. Meyers and Hinnov (2010) confirmed Pleistocene climate to be largely controlled by deterministic processes but with transient stochastic events that are taken to represent abrupt climate reorganizations both near the beginning and end of the EMPT, at $\sim 1.2 \mathrm{Ma}$ and $\sim 0.7$ Ma respectively.

The Pleistocene climate system has been regarded as having natural oscillatory properties that changed once a threshold ("bifurcation") had been crossed, leading to the $\sim 100 \mathrm{kyr}$ cycles of the EMPT (Saltzman and Maasch, 1988; Maasch and Saltzman, 1990) Orbital forcing paces the rhythms in the model of Maasch and Saltzman (1990). Extending this concept, Rial et al. (2013) proposed that nonlinear internal climate oscillations became synchronized to the $413 \mathrm{kyr}$ eccentricity cycle at 1.2 Ma. Evidence for modulation of climate cycles at the $413 \mathrm{kyr}$ frequency was based on advanced statistical analyses of the LR04 stack. This model gives strong 100-kyr oscillations beginning at around 1.2 Ma via a single mechanism, i.e. phase locking of the climatic response to eccentricity forcing ("master-slave" synchronization). Therefore, since $\sim 1.2$ Ma the climate system has been locked into an externally-forced self-sustained oscillator, with forced phase synchronization culminating with MIS 11 (Rial et al., 2013).

Although the secular changes reviewed above may indeed have triggered threshold responses that led to the EMPT, this is not a requirement for all models advanced to explain the EMPT. Imbrie et al. (2011) created a phase-space model for 
Pleistocene ice volume which, when compared against the LR04 benthic stack, showed how orbital parameters alone could develop $\sim 100 \mathrm{kyr}$ cycles without requiring changes internal to the climate system. This essentially involves precession and obliquity, but with amplitude modulation of the $\sim 100-\mathrm{kyr}$ eccentricity cycle. The model develops $\sim 100$ kyr cyclicity at about $1 \mathrm{Ma}$, as with LR04 benthic stack, and although it does not produce this transition as conspicuously, it does explain the anticorrelation observed between eccentricity and the LR04 benthic stack (Lisiecki, 2010). Precession was found to be more important in glacials, and obliquity more important during interglacials.

Finally, it should be noted that in addition to any primary trigger or crossed threshold, multiple feedback mechanisms are likely at work, including ice-sheet growth, deep-water temperature, surface water currents, atmospheric circulation, iron fertilization of the oceans, and interhemispheric teleconnections.

\section{Magnetostratigraphy and age constraints}

\subsection{Marine realm and ice core record}

Polarity reversals are detectable in marine and continental sedimentary deposits, and in lava flows. They are even reflected in ice core records through the concentration of ${ }^{10} \mathrm{Be}$, a cosmogenic radionuclide whose flux increases when Earth's magnetic dipole field weakens during a reversal (Dreyfus et al., 2008). The sedimentary record is subject to a post-depositional remanent magnetization lock-in depth, this being the depth below the water-sediment interface where the compaction of sediment and other factors combine to preserve the original paleomagnetic signal. Bioturbation of the upper surface of sediment also prevents lock-in, and on average is taken to be $\sim 10 \mathrm{~cm}$ (Bourdreau, 1994, 1998) with the lock-in depth below that. Bioturbation acts as a filter of highfrequency changes, whereas lock-in depth mostly introduces a delay, although some filtering occurs even during lock-in (Suganuma et al., 2011; Roberts et al., 2013). Using pairs of cores with different sedimentation rates but in the same oceanographic region, $\mathrm{Z}$. Liu et al. (2008) deduced that observed Matuyama-Brunhes boundary in marine sediments can be up to $20 \mathrm{~cm}$ lower than its true position due to bioturbation and lock-in depth. Accordingly, marine records with high sedimentation rates tend to be the most reliable (Channell et al., 2004) because rapid deposition accelerates the time to compaction, and the depth of the mixed layer translates to less time. This is well demonstrated by Suganuma et al. (2010) who compared both the ${ }^{10} \mathrm{Be}$ flux and the Matuyama-Brunhes paleomagnetic reversal positions in three Pacific cores with low sedimentation rates $(0.66-1.2 \mathrm{~cm} / \mathrm{kyr})$. While the paleomagnetic signal is affected by delayed lock-in, the ${ }^{10} \mathrm{Be}$ record is not - and bioturbation while blurring the signal should not theoretically shift the stratigraphic position of the peak. They discovered that the paleomagnetic boundary was offset downcore by $\sim 15 \mathrm{~cm}(=\sim 10 \mathrm{kyr})$ relative to the peak ${ }^{10}$ Be flux. In contrast, where sedimentations rates are high, the lock-in depth may be negligible. In an equatorial Indian Ocean core with high $(4.7 \mathrm{~cm} / \mathrm{kyr})$ sedimentation rates, Valet et al. (2014) found the ${ }^{10}$ Be peak, minimum in relative magnetic paleointensity (characteristic of reversals), and the midpoint in the reversal transition, all to be synchronous, indicating no stratigraphic offset for the Matuyama-Brunhes reversal. 


\subsubsection{Matuyama-Brunhes Chron boundary}

The Matuyama-Brunhes Chron boundary is a convenient and widely recognizable mid-point in the EMPT, hence its preferred choice as the primary guide to the EarlyMiddle Pleistocene boundary (Butzer and Isaac, 1975, Richmond, 1996; Pillans, 2003; Head and Gibbard, 2005; Head et al., 2008). It has indeed been recommended that the Early-Middle Pleistocene boundary be placed within one marine isotope stage either side of the Matuyama-Brunhes boundary, although it should obviously represent only one of multiple criteria for local, regional, and global correlation of the boundary (Head et al., 2008).

The most precise dating of the Matuyama-Brunhes reversal in marine sediments derives from astrochronological tuning of the benthic foraminiferal $\delta^{18} \mathrm{O}$ record which serves as a proxy for global ice volume. While this allows the timing of the reversal to be compared around the globe, it needs to be exercised with some caution. Shackleton et al. $(2000,2004)$ have shown for the Portuguese continental margin that the benthic and planktonic foraminferal $\delta^{18} \mathrm{O}$ signals can be out of phase owing to the respective influences of Antarctic and Greenland water masses and hence temperatures. Skinner and Shackleton (2005) found a $4 \mathrm{kyr}$ lead in the Atlantic versus Pacific benthic $\delta^{18} \mathrm{O}$ signal for the last deglaciation, caused by a non-eustatic (local or basin-restricted and probably temperature related) component of this signal. Indeed, Atlantic over Pacific leads of several thousands of years have since been discovered for the past six terminations (Lisiecki and Raymo, 2009). Small asyncronieties therefore potentially exist within the marine isotope record during the EMPT, particularly between ocean basins, but are presently unverifiable as they are beyond the reach of independent (radiocarbon) dating.

An additional feature of geomagnetic polarity reversals is that the duration of reversal is dependent on latitude, with higher latitudes displaying longer durations than at lower latitudes. For the Matuyama-Brunhes reversal, durations were found to vary between $\sim 2$ and $9 \mathrm{kyr}$ with longer durations characterizing the higher-latitude sites (Clement, 2004). A study by Leonhardt and Fabian (2007) that integrates real data with geomagnetic field modeling predicts a similar outcome, but suggests that the timing of onset and duration of the reversal was longitudinally as well as latitudinally variable. This study predicts an average reversal duration of $5.2 \mathrm{kyr}$ and a maximum of up to $10 \mathrm{kyr}$ in the Antarctic, and also variation of up to $9 \mathrm{kyr}$ in the age at which the VGP latitude crosses into the northern hemisphere. It is based on the data set of Clement (2004, table 1) which includes some low-sedimentation-rate cores, and a more even distribution of high-resolution records is needed to validate these results (Channell et al., 2010). Nonetheless, the possibility exists that the Matuyama-Brunhes reversal as measured paleomagnetically is not synchronous, as usually assumed (Leonhardt and Fabian, 2007; Channell et al., 2010).

Shackleton et al. (1990) determined the first reliable astrochronological age for the Matuyama-Brunhes reversal by constructing an age model using the ice volume model of Imbrie and Imbrie (1980) as a tuning target for marine isotope data obtained from eastern equatorial Pacific ODP Site 677. This site lacks a paleomagnetic record, but the age model was applied to North Atlantic DSDP Sites 552 and 607, for which the reversal is documented, using the benthic isotope stratigraphies in both cores. The reversal was dated at $780 \mathrm{ka}$. 
Horng et al. (2002) refined this age to $781 \pm 3 \mathrm{ka}$ based on the astronomical tuning of Philippine Sea core MD972143. The isotope stratigraphy and magnetostratigraphy are both well resolved for this core, but sedimentation rates are low $(1 \mathrm{~cm} / \mathrm{kyr})$. The authors assumed a lock-in depth of only a few centimeters. This age was used by Lourens et al. (2005a) in their widely used timescale ATNTS2004 (Lourens et al. 2005b) which in turn was followed by Hilgen et al. (2012) in their currently popular ATNTS2012 timescale.

In contrast, Channell and Kleiven (2000) and Channell et al. (2004) examined the Matuyama-Brunhes reversal at two high-sedimentation-rate sites south of Iceland, ODP $983(14 \mathrm{~cm} / \mathrm{kyr})$ and ODP Site $984(9 \mathrm{~cm} / \mathrm{kyr})$, and determined the mid-point age of the reversal to be $772.5 \mathrm{ka}$ and $773.5 \mathrm{ka}$, respectively (Table 1). To this study was added a further three North Atlantic sites, with all five satisfying the criteria of highsedimentation rate $(>\sim 5 \mathrm{~cm} / \mathrm{kyr})$ and coupled isotope-paleomagnetic records at highresolution across the boundary (Channell et al., 2010; Table 1, with sedimentation rates based on Channell and Raymo, 2003 for ODP 980; Ferretti et al., 2005 for ODP 1063, and Channell et al., 2008 for IODP U1308). These five records consistently show that the onset of the polarity transition postdates the $\delta^{18} \mathrm{O}$ maximum that represents the MIS 19 peak (MIS 19.3, using the using nomenclature of Bassinott et al., 1994), and the south-north directional shift as indicated by the virtual geomagnetic polar (VGP) latitude occurs in the upper MIS 19 with a mean value of 773.1 ka (Channell et al., 2010; Table 1). The duration of the reversal in these cores was estimated to vary between 2.9 and 6.2 kyr (Table 1). Older published ages were thought to reflect the effects of lock-in on lower sedimentation rates, and imprecision due to low-resolution sampling.

This largely agrees with a study by Z. Liu et al. (2008) based on comparing pairs of cores with different sedimentation rates from the same oceanographic area. After correcting for the combined effects of the surface mixed layer and lock-in, the Matuyama-Brunhes boundary was placed in the upper part of MIS 19.

Valet et al. (2014) demonstrated negligible lock-in for an equatorial Indian Ocean core with high $(4.7 \mathrm{~cm} / \mathrm{kyr})$ sedimentation rates, and dated the Matuyama-Brunhes reversal at $772 \pm 5 \mathrm{ka}$. This is remarkably close to the age of $773.1 \mathrm{ka}$ as determined by Channell et al. (2010) for the North Atlantic cores.

Ice-core records are not subject to paleomagnetic lock-in. However, the EPICA Dome ice core, the only ice core that extends to the Middle Pleistocene, has a chronology based on snow accumulation rates, ice-flow modeling, astronochronological tuning, and event stratigraphy that is subject to uncertainty (Parrenin et al., 2007; Dreyfus et al., 2008). The ${ }^{10} \mathrm{Be}$ flux record shows a peak corresponding to the Brunhes-Matuyama boundary that, when compared directly to atmospheric $\delta^{18} \mathrm{O}$, significantly postdates the peak of MIS 19 and extends across the MIS 19/18 transition (Dreyfus et al., 2008), as observed by Channell et al. (2010) in their high-resolution marine records. A duration of $12 \mathrm{kyr}$ was recorded for the transition. In fact, the highest point of the peak, indicating the reversal boundary, is dated at $766.4 \mathrm{ka}$ based on the EDC3 age model used by Dreyfus et al. (2008), although Channell et al. (2010) pointed out that the earlier EDC2 age model yields an age of $771.7 \mathrm{ka}$ which agrees more closely with the marine records. Dreyfus et al. (2008) detected a precursor event, around $20 \mathrm{kyr}$ before the Brunhes-Matuyama boundary, that had been identified in earlier studies and documented since (e.g. Jin et al., 2012; Valet et al., 2014; Singer, 2014). 
Suganuma et al. (2010) examined the ${ }^{10}$ Be flux in Philippine Sea core MD972143, used earlier by Horng et al. (2002), against the position of the magnetic reversal to avoid assumptions about lock-in depth. An offset of $15 \mathrm{~cm}$ had occurred. Based on the peak in ${ }^{10}$ Be flux, Suganuma et al. (2010) re-dated the Matuyama-Brunhes boundary at $\sim 770 \pm 6$ $\mathrm{ka}$, and consistent with a $770 \mathrm{ka}$ midpoint for the boundary as determined by Dreyfus et al. (2008) in the EPICA Dome $\mathrm{C}$ ice core. The somewhat younger age than that determined by Channell et al. (2010) might be a function of the low sedimentation rate in the Pacific core used by Suganuma et al. (2010), and although it agrees with the ice-core age proposed by Dreyfus et al. (2008) there are uncertainties in the age models proposed for the EPICA Dome C ice core (Channell et al., 2010). Ménabréaz et al. (2014) examined the ${ }^{10}$ Be flux in West Equatorial Pacific core MD05-2930 and obtained a significant peak in ${ }^{10} \mathrm{Be}$ production at $\sim 773 \mathrm{Ma}$ linked with the Matuyama-Brunhes reversal.

Radiometric ages of the Matuyama-Brunhes boundary have yielded unresolved discrepancies with these marine records (Channell et al., 2010). Singer et al. (2005) considered the boundary to be recorded only within "transitional" lavas on Maui and an uppermost lava on La Palma (Singer et al., 2005). The Maui "transitional" lavas were ${ }^{40} \mathrm{Ar} /{ }^{39} \mathrm{Ar}$-dated at 775.6 $\pm 1.9 \mathrm{ka}$ (Coe et al., 2004; Singer et al., 2005), and although a subsequent recalibration by Renne et al. $(2010,2011)$ gave a significantly older age, a new recalibration using exceptionally low, stable, blanks has brought these Maui lavas in accord with the astrochronological age (Singer, 2014). The ${ }^{40} \mathrm{Ar} /{ }^{39} \mathrm{Ar}$ dates of putative boundary-age lavas on Tahiti by Mochizuki et al. (2011) was questioned by Singer (2014).

To summarize, the most reliable age of the Matuyama-Brunhes boundary based on astronomical calibration to the marine isotope record is $\sim 773 \mathrm{ka}$ (Channell et al., 2004, 2010; Singer, 2014) or 772 ka (Valet et al., 2014), or 770 ka (Suganuma et al., 2015), although the traditional age of 780 or $781 \mathrm{ka}$ continues to be cited in the literature (e.g. Hilgen et al., 2012, Jin et al., 2012; Bidegain et al., 2013; Parés et al., 2013). The onset of the polarity transition postdates MIS 19.3, its midpoint occurs in the upper MIS 19, and its duration and onset are variable with latitude, and perhaps longitude, by several thousand years. ${ }^{10} \mathrm{Be}$ is a useful if imprecise proxy for the true boundary position in marine sediments as well as in ice cores.

However, these generalizations are not entirely unchallenged. A lacustrine sequence at Sulmona in central Italy, with the high depositional rate of $20 \mathrm{~cm} / \mathrm{kyr}$ tightly constrained by numerous ${ }^{40} \mathrm{Ar} /{ }^{39} \mathrm{Ar}$-dated tephras, yields a reversal duration of less than 100 years for the Matuyama-Brunhes polarity reversal, which is an order of magnitude less than that found in deep-sea deposits (Sagnottoi et al., 2014). The polarity reversal age is dated at $786.1 \pm 1.5 \mathrm{ka}$ (Sagnottoi et al., 2014) and difficult to reconcile not only with the much younger North Atlantic ages based on astrochronology, but even with ${ }^{40} \mathrm{Ar} /{ }^{39} \mathrm{Ar}$ dates based on lavas. However, while the ${ }^{40} \mathrm{Ar} /{ }^{39} \mathrm{Ar}$ absolute dates can be questioned owing to the assumptions made with this method, the acknowledged high precision of ${ }^{40} \mathrm{Ar} /{ }^{39} \mathrm{Ar}$ dating should still yield a reliable duration for the Matuyama-Brunhes boundary transition. Support for a rapid reversal is provided by a shallow-marine core from Osaka Bay, southwest Japan with exceptionally high sedimentation rates of around $63 \mathrm{~cm} / \mathrm{kyr}$ (Kitaba et al., 2013). Here, the boundary has a duration of less than 300 years (Hyodo et al., 2006, fig. 8), although it occurs within a longer-duration transitional zone 
of reversals (Hyodo and Kitaba, 2015; see below), and its age of $777.6 \mathrm{ka}$ based on orbitally tuned climate proxies and a ${ }^{10} \mathrm{Be}$ record (Hyodo et al., 2006; Kitaba et al., 2013; Hyodo and Kitaba, 2015) is again older than North Atlantic ages.

The nature of the transition is also open to question. Although the MatuyamaBrunhes is usually recorded as an abrupt single reversal, some studies of highsedimentation-rate sections have discerned multiple rapid polarity swings both in marine and loess-paleosol records (Yang et al., 2010 and references therein; Zhao et al., 2014; Hyodo and Kitaba, 2015 and references therein); although the fidelity of some Chinese loess-paleosol records may have been affected by complications relating to remanence acquisition and retention (Wang et al., 2014). The shallow-marine record from Osaka Bay, Japan reveals two normal events, of 800 and 200 years duration respectively, during a 784.9-777.6 ka (7.3 kyr) interval immediately prior to the main Matuyama-Brunhes boundary, and two brief reverse polarity events immediately afterwards (Hyodo et al., 2006; Kitaba et al., 2013; Hyodo and Kitaba, 2015 and references therein). This results in a polarity transition lasting $10.1 \mathrm{kyr}$. It is argued that these brief (mostly a few hundred years) excursions are only captured when sedimentation rates are very high (Hyodo and Kitaba, 2015).

With respect to the timing of the reversal, the Valle di Manche section in the Crotone Basin, southern Italy is one of few records in the Mediterranean that preserves a $\delta^{18} \mathrm{O}$-dated record of the Matuyama-Brunhes boundary. Here the boundary occurs below the lightest isotopic values of MIS 19 in spite of high sedimentation rates of $13 \mathrm{~cm} / \mathrm{kyr}$ (Capraro et al., 2005; L. Capraro, pers. commun. 2014). The same appears to be true for the Petrogallo section also in the Crotone Basin, southern Italy (Capraro et al., 2011). In piston core KC01B from the southern Calabrian Ridge, Ionian Sea, the MatuyamaBrunhes boundary occurs near the MIS 21/20 boundary (Rossignol-Strick et al., 1998, fig. 1a; based on Globigerinoides ruber) and is dated at $827 \mathrm{ka}$ based on astronomical tuning of the color reflectance (Lourens, 2004, tab. 3). At ODP Site 964, drilled just $1 \mathrm{~km}$ northeast of Piston core KC01B, a similar age of 814 ka was recorded (Lourens, 2004, tab. 3, based also on color reflectance). These observations contrast with piston core LC07 taken west of the Sicily Strait where a rock-magnetic proxy for climate variation places the Matuyama-Brunhes boundary in the upper part of MIS 19 (Dinarès-Turell et al., 2002), although the low sedimentation rate of $2.2 \mathrm{~cm} / \mathrm{kyr}$ hinders detailed assessment. These Mediterranean records require further consideration.

\subsubsection{Jaramillo Subchron}

The Jaramillo Subchron has been studied less intensively in marine sediments than the Matuyama-Brunhes reversal, and the EPICA Dome ice core does not extend to the Jaramillo Subchron. As with the Matuyama-Brunhes boundary, age reliability and precision are a function of several factors but particularly the resolution and quality of both the oxygen isotopic and geomagnetic records, which are themselves dependent partly on sedimentation rates. Estimated ages based on comparison with astronomically

tuned benthic $\delta^{18} \mathrm{O}$ records are listed in Table 2. Estimates range between 1072 and 1060 ka for the base of the Jaramillo, and between 991 and 987 ka for the top.

Shackleton et al. (1990) were first to provide reliable astrochronological ages for the Jaramillo Subchron boundaries, based on eastern equatorial Pacific ODP Site 677, but 
as with the Matuyama-Brunhes boundary, the chronology from ODP Site 677 was transferred to DSDP sites 552 and 607 in the North Atlantic for which the paleomagnetic record had been resolved. This gave a base at $1070 \mathrm{ka}$ (mid-MIS 31) and a top at $990 \mathrm{Ka}$ (mid-MIS 27). Horng et al. (2002) refined these ages to $1072 \pm 2 \mathrm{ka}$ (MIS 31) and 988 \pm 3 ka (MIS 27) respectively based on astronomical tuning of Philippine Sea core MD972143, ages that were subsequently used by Lourens et al. (2005a) and Hilgen et al. (2012) in spite of the low $(1.5 \mathrm{~cm} / \mathrm{kyr})$ sedimentation rates across the subchron in core MD972143.

Ages of $1070 \mathrm{ka}$ (mid-MIS 31) for the base of the Jaramillo and 988 (MIS 28) for the top are accepted in the present paper, as they are based on central North Atlantic IODP U1308 which has high sedimentation rates $(7 \mathrm{~cm} / \mathrm{kyr})$ across the subchron (Channell et al., 2008). These ages are similar to those derived by Shackleton et al. (1990). A change in MIS taxonomy introduced by Lisiecki and Raymo (2005) accounts for the difference in MIS placement of the upper boundary (mid-MIS 27 vs. MIS 28). Earlier authors including Ruddiman et al. (1989) and Shackleton et al. (1990) had labeled MIS 27 as a double peak whereas Lisiecki and Raymo (2005) labeled only the higher of these as MIS 27, assigning the lower peak to MIS 28 which then becomes a double trough with intervening peak. This change in the MIS 28/27 boundary was likely inadvertent (L. Lisiecki pers. comm. 2014) but is followed here for continuity.

\subsection{Chinese loess-paleosol stratigraphy}

Owing to their orbitally-forced and often uninterrupted stratigraphy, Chinese paleosol-loess sequences are important for continental correlations with Europe, and enable crucial correlations to be made with the marine realm (Dodonov, 2005). They are also exceptionally useful for understanding the development of monsoon climate. However, paleosol-loess sequences are subject to displaced magnetic remanence resulting from chemical weathering and secondary overprinting (chemical remanent magnetization). Recognizing the true positions of the Matuyama-Brunhes palaeomagnetic boundary and the boundaries of the Jaramillo Subchron in these sequences is therefore essential to their utilization.

\subsubsection{Matuyama-Brunhes boundary}

The Matuyama-Brunhes boundary is often recorded in loess unit L8, a glacial, and therefore inconsistent with placement in MIS 19, an interglacial. Aided by a microtectite horizon identified as occurring below the Matuyama-Brunhes boundary in Australia, and assuming a boundary correlation with the earlier part of MIS 19, Zhou and Shackleton (1999) proposed a deep lock-in depth ranging from a few tens of centimeters to more than $3 \mathrm{~m}$. Accordingly they equated paleosol S7 with MIS 19 and loess L8 with MIS 20. This correlation was followed by Ding et al. (2002), Dodonov (2005), Head and Gibbard (2005), Sun et al. (2006), Pillans and Gibbard (2012), and Zhao et al. (2014).

However, Wang et al. (2005) found the Matuyama-Brunhes boundary at the top of S8, and Q. Liu et al. (2008) noted that generally in Chinese loess sequences the boundary is detected in the middle or lower L8. Indeed, Wang et al. (2010) recorded it at the bottom of L8. Because the Matuyama-Brunhes boundary is now known to correlate 
near to the MIS 19/18 transition, equating paleosol S7 with MIS 19 (Zhou and Shackleton, 1999) was considered unjustifiable.

Additionally, the deep lock-in proposed by Zhou and Shackleton (1999) has been thought unlikely because mixing (physical and biotic) in these sediments is generally confined to the upper sediment layers, and the high-frequency paleomagnetic signal sometimes preserved is inconsistent with deep mixing. However, Spassov et al. (2003) attributed deep displacement while preserving some high-frequency signatures to a later pedogenic chemical remanent magnetization, although the magnetic carrier seems to be magnetite (rather than maghemite) which is detrital rather than of newly-formed pedogenic origin.

Finally, the Chinese microtectites correlated with those from Australia (which occur 18 kyr below the Matuyama-Brunhes boundary; Valet et al., 2014) are chemically different, have a different origin, and have since been considered to occur above the true boundary position (Q. Liu et al., 2008).

Recognition of the precursor event to the Matuyama-Brunhes boundary in the Chinese loess deposits by Jin et al. (2012), occurring about 21 kyr earlier and also within paleosol S8, confirms the global distribution of this anomaly and was taken to support the correlation of S8 with MIS 19. Jin et al. (2012) argued that with the Matuyama-Brunhes boundary positioned late in MIS 19, and the precursor event also within MIS 19, their presence both within S8 confirmed equivalence with MIS 19, without need to invoke deep lock-in.

Chemical remanent magnetization may nonetheless be dominant in some Chinese paleosols (Liu and Zhang 2013), for which reason quartz grain size is a better measure of paleosol-loess pedostratigraphy than magnetic susceptibility owing to its resilience to diagenesis. Zhao et al. (2014) reassessed and astronomically re-tuned the loess-paleosol records from four sequences in the central Chinese Loess Plateau using grain-size variation. They agreed that the Matuyama-Brunhes boundary occurs in the S8-L8 transition (as previously noted), but based on the tuning of the grain-size curve and consideration of sedimentation rates considered correlation of S8 to MIS 21 more parsimonious than to MIS 19. Paleosol S7 then equates to MIS 19. This gives a boundary age of 808-826 ka for the Matuyama-Brunhes boundary, based on substantial lock-in depth (Zhao et al., 2014) as Zhou and Shackleton (1999) had originally predicted.

Clearly more research is needed to resolve equivalency with the marine isotope record. The problematic interval is between S6 and L9 (Zhao et al., 2014, fig. 5).

\subsubsection{Jaramillo Subchron and latest Matuyama Chron}

For the Jingbian section, located in the northernmost part of the Chinese Loess Plateau, Ding et al. $(2002,2005)$ recorded the upper boundary of the Jaramillo Subchron in L10 and the lower boundary at the top of L12, whereas for the southeastern margin of the Loess Plateau, Wang et al. (2005) reported the upper and lower boundaries at the top of soil S10 and top of loess L13, respectively. More recent studies confirm an upper boundary in soil S10 (Jin and Liu, 2011 and references therein; Liu and Zhang, 2013). However, the placement of the lower boundary is unresolved, occurring at the top of L12 (Ding et al. (2002, 2005), bottom of L12 (Wang et al., 2010), or top of L13 (Wang et al., 2005; Liu et al., 2010; Liu and Zhang, 2013). 
Using a combination of grain size and environmental magnetism parameters, Jin and Liu (2011) refined the Chinese loess timescale for the interval between the Jaramillo Subchron and the Matuyama-Brunhes boundary. Loess L9 was reinterpreted to correspond to MIS 24-20, and not 24-22 as previously accepted. In this scheme, MIS 21 represents an extended and moderate interglacial corresponding to part of the middle of loess L9 whose upper and lower limits correspond to glacial MIS 24 and 20.

Accordingly, the top of the Jaramillo Subchron occurs in S10 which equates to MIS 28 (Jin and Liu, 2011, using the MIS taxonomy of Lisiecki and Raymo, 2005). Equating L9 with MIS 24-20 would then explain why Wu and Wu (2011) in their study of terrestrial molluscs recorded three, not two, cold intervals in L9.

The lower boundary of the Jaramillo is accepted as occurring in mid-MIS 31 (see above), so should coincide with a paleosol rather than a loess unit. The Jaramillo should represent two or three paleosols (MIS 29, MIS 31, and possibly the interglacial peak within MIS 28). Taking the upper boundary placement in S10 as reliable, the correct position of the lower boundary should then be in S11 or S12. Its observation at the base of L12 or top of L13 presumably represents downward displacement by magnetic overprinting. Indeed, chemical remanent magnetism is the main mode of magnetic acquisition in paleosols and such pedogenic processes can also affect the underlying loess (Liu and Zhang, 2013).

\section{Early-Middle Pleistocene transition in the marine realm}

Marine archives represent an essential and continuous record of oceanic changes across the EMPT both at the global and regional scale, and at timescales that examine highfrequency (sub-Milankovic) fluctuations, orbital (Milankovic) forcing, and secular trends. Comparisons between the major ocean basins have revealed both similarities and differences, the reasons for which are not always clear. An important challenge has been to understand the role of oceans in responding to the growth of large ice sheets during the EMPT, and perhaps amplifying their effects, and indeed in contributing to ice sheet growth such as by supplying moisture to high northern latitudes and in sequestering $\mathrm{CO}_{2}$ from the atmosphere.

A general long-term cooling trend in SST, observed through the EMPT in both lower and higher latitudes, results primarily from increased cooling during glacial stages, as already mentioned, and usually begins or intensifies at about $1.2 \mathrm{Ma}$ (McClymont et al., 2013). A trend towards increased global ice volume also starts around this time, but predates the first major expansion of continental ice sheets at about 0.9 Ma (MIS 24-22). Quasi-100 ka periodicity in SST and $\delta^{18} \mathrm{O}$ records emerges at $1.2 \mathrm{Ma}$, and becomes dominant at 0.9 Ma. Intensified glacial stage cooling is associated with changes in the abyssal ocean ventilation, and atmospheric circulation, suggesting that important changes during the EMPT were driven by evolving glacial climate dynamics and boundary conditions causing altered climate sensitivity to orbital forcing (McClymont et al., 2013).

There are regional exceptions to the trends noted above, including the West Pacific Warm Pool where SSTs remained stable, and the northwestern Pacific where gradual secular warming has been observed (see below). Each oceanic region gives a different response, and selected regions are discussed below. The characteristics of individual marine isotope stages are summarized in Section 11. 


\subsection{North Atlantic region}

Many studies of the EMPT have focused on the North Atlantic Ocean, as discussed above (see Section 4). Alkenone records of high-latitude ODP Sites 982 and 983 show a declining SST trend from $~ 1.1-1.2 \mathrm{Ma}$, with Site 983 also showing pronounced cooling at $0.9 \mathrm{Ma}$ (MIS 22-20), in keeping with estimates of increased global ice volume (Clark et al., 2006; McClymont et al., 2013). From the subpolar North Atlantic IODP Site U1314, an increase in the magnitude and duration of IRD events after MIS 25 coincides with the timing of increased ice-rafting along the NorwegianGreenland margins and Barents Sea after 900 ka (Hernández-Almeida et al. (2012, 2013 and references therein) and signals an expansion of northern ice sheets from this time onwards. Prior to this time, the Arctic Front evidently had a relatively steady position south of Site U1314, limiting the flow of warmer waters into the Norwegian-GreenlandIceland seas. Interglacial conditions similar to those of today did not occur at Site U1314 until MIS 25. From this time onwards, oscillations in the position of the Arctic Front allowed greater northward export of heat and moisture during interglacials, with MIS 21 and 19 signaling a significant northward retreat of the Arctic Front, and MIS 22 seeing the most extreme cooling of surface waters at Site U1314 (Hernández-Almeida et al., 2013). The intensification of interglacials at this time may therefore provide the moisture supply necessary for expanding ice sheets during succeeding glacials of the EMPT (Ruddiman and McIntyre 1981; Raymo and Nisancioglu 2003; Hernández-Almeida et al., 2013).

Within the IRD belt of the North Atlantic, a major event occurs in MIS 16 where the first Heinrich event is recorded (Hodell et al., 2008). This is expressed by the occurrence of IRD rich in detrital carbonate sourced from the Hudson Strait, and is thought to represent the first time the Laurentide Ice Sheet had reached sufficient thickness to result in instability in the Hudson Strait region. This event significantly cooccurs with an increase to dominance in $\sim 100$-kyr power in the benthic $\delta^{18} \mathrm{O}$ record, suggesting that the duration of the glaciation (and hence thickness of the ice sheet) exceeded a critical threshold during the EMPT to trigger the instability and hence ice rafting (Hodell et al., 2008).

The mid-Brunhes Event at $420 \mathrm{ka}$, widely recognized as a stepwise increase in interglacial temperatures from MIS 11 onwards, is anomalously expressed in the North Atlantic. A synthesis of numerous boreholes in the North Atlantic for which sea-surface temperature has been estimated (Candy and McClymont, 2013) reveals no evidence for the mid-Brunhes Event within the latitudes $40^{\circ}-56^{\circ} \mathrm{N}$, but north of $56^{\circ} \mathrm{N}$ it becomes increasingly expressed. It appears therefore that the expression of the mid-Brunhes Event in the North Atlantic is controlled by the position of the Arctic Front, which suppresses interglacial temperatures between MIS 19 and MIS 13 only at sites north of $56^{\circ} \mathrm{N}$ (Candy and McClymont, 2013).

\subsection{Pacific}

In the northwest Pacific ODP Site 882 developing from $~ 1.2 \mathrm{Ma}$, a secular expansion of subarctic watermasses lowered sea-surface temperatures during both 
glacials and interglacials, and reaching a maximum at about 1.0 Ma. Indeed, this early cooling trend, occurring simultaneously also in the northern North Atlantic, has provided an explanation (moisture starvation) for the delay in establishment of the first major ice sheets of the EMPT at around $900 \mathrm{ka}$ (McClymont et al., 2008). From about 9.0 Ma to $0.5 \mathrm{Ma}$ at Site 882, there occurred a secular retreat of subarctic watermasses that was more gradual than observed for the North Atlantic, reflecting a somewhat anomalous long-term warming trend through the post-9.0 Ma EMPT (McClymont et al., 2008, 2013).

\subsection{South China Sea and West Pacific Warm Pool}

Sea-surface temperatures have remained remarkably stable at the core of the West Pacific Warm Pool for at least 1.6 Ma. Even here sea-surface temperatures dropped by several degrees from $29-30^{\circ} \mathrm{C}$ in MIS 25 to $\sim 26^{\circ} \mathrm{C}$ in MIS 22 (de Garidel-Thoron et al., 2005; Medina-Elizalde and Lea, 2005; Wara et al., 2005; Li et al., 2008; McClymont et al., 2013). These stable temperatures account for the West Pacific Warm Pool's role as a refugium for thermophilic marine species that elsewhere disappeared during Pleistocene cooling (Mertens et al., 2014). However, the size of the Warm Pool shrank from about $900 \mathrm{ka}$, with marginal areas such as the South China Sea showing evidence of a dramatic drop in SST at about $900 \mathrm{ka}$, with winter SST declining from $24-25^{\circ} \mathrm{C}$ to $17-18^{\circ} \mathrm{C}$ in the northern and from $26-27^{\circ} \mathrm{C}$ to $23-24^{\circ} \mathrm{C}$ in the southern South China Sea (Li et al., 2008). This change at $900 \mathrm{ka}$, while reflecting a global cooling event, also signals the regional strengthening of winter monsoon influence.

Today, the southeast Asia monsoon system heavily influences surface circulation of the South China Sea, with winter monsoons from the north and northeast bringing cold and saline surface waters southward into the South China Sea. This results in a large $\left(\sim 6^{\circ} \mathrm{C}\right) \mathrm{SST}$ gradient between the northern (cooler) and southern (warmer) South China Sea during winter. During summer, the prevailing southwest monsoon carries warm equatorial Indian Ocean water into the South China Sea. The summer SST across the South China Sea is a fairly uniform $28-29.75^{\circ} \mathrm{C}$ ( $\mathrm{Li}$ et al., 2008). Assessing the evolution of this system through the EMPT is made possible using a N-S transect of cores across South China Sea for which there are multiproxy data. In particular, foraminiferal transfer functions based on the northernmost site, ODP Site 1144, reveal a sharp and severe decline in winter SSTs from 28 to $17^{\circ} \mathrm{C}$ at $900 \mathrm{ka}$ across the MIS 23/22 boundary (Zheng et al., 2005). Summer SSTs in contrast fluctuated by only a few degrees Celsius. This contrast between winter and summer SSTs persisted throughout the EMPT and reflects the strengthening of the winter monsoon from 900 ka onwards (Zheng et al., 2005 and references therein; Li et al., 2008). In general it has been shown that winter monsoons prevailed during glacials and reached maximum strength toward the end of the EMPT, whereas summer monsoons were stronger during interglacials (Li et al., 2008 and references therein). High-resolution stable isotopes (multispecies) and foraminiferal $\mathrm{Mg} / \mathrm{Ca}$ analyses were used by Jin and Jian (2013) to further explore the early part of the EMPT (MIS 30-20) at the northern ODP Site 1144. The N-S temperature gradient in the South China Sea was found to increase, and confirmed a strengthened winter monsoon and weakened summer monsoon during the glacial stages, and vice versa during interglacials. They also discovered precessional and semi-precessional cycles in the time 
series of the proxies analysed, providing evidence that changes associated with the EMPT are partly driven by tropical forcing, and not only by ice-sheet growth in the higher latitudes. Indeed Short et al. (1991) noted that maximum thermal forcing of the monsoon is in central Asia, this being the centre of a large land-mass, and a high-latitude signal in a low-latitude record can therefore be expected. Jin and Jian (2013) also found that during the mid-Pleistocene terminations, SST warming in the South China Sea was synchronous with northern ice sheet retreat. Indeed Li et al. (2008) had speculated that low-latitude processes such as monsoons and heat storage in the western Pacific may have had an important role in the development of the EMPT. Nonetheless, a study of ODP Site 1143 in the southern South China Sea by Ao et al. (2011) using a proxy based on the ratio of hematite to goethite reveals a less straightforward relationship between monsoons and glacial/interglacial cyclicity for low-latitude southeast Asia. In particular, no change is observed across the EMPT, and the relationship between strong summer monsoons and interglacials, noted for the northern South China Sea, does not always hold at ODP Site 1143. It appears that in low-latitude southeast Asia, the monsoon record is linked to insolation rather than high-latitude processes (Ao et al., 2011). A muted expression of the EMPT at other low-latitude sites (e.g. the Arabian Sea, subtropical West Africa, and the eastern Mediterranean - all driven by climate fluctuations in low-latitude Africa) similarly points to the EMPT as a primarily mid- to high-latitude phenomenon (Ao et al., 2011, fig. 8).

\subsection{Indian Ocean}

The Agulhas Current is the largest western boundary current in the world, bringing warm saline surface waters from the Indian Ocean southwest and then westward around South Africa before looping back to the Indian Ocean. Some of this water, known as Agulhas leakage, feeds directly into the South Atlantic where it can influence Atlantic meridional overturning circulation (AMOC) and hence global climate. Indeed, of the 17 glacial terminations over the last $1200 \mathrm{kyr}$, each coincided with an enhanced input of Agulhas water to the southeast Atlantic (Peeters et al., 2004; Caley et al., 2012). Over the past $1350 \mathrm{kyr}$, Agulhas leakage strengthened during three phases beginning at $1200 \mathrm{ka}$, $880 \mathrm{ka}$, and $425 \mathrm{ka}$ (Caley et al., 2012, fig. 3), with maximum strength reached during glacial maxima and hence potentially facilitating a resumption of interglacial conditions. Agulhas leakage seems to have been controlled by latitudinal variations in the position of the subtropical front south of Africa in the Southern Ocean. Thus Agulhas leakage may have acted as an important internal regulator of global ice volume, and appears to be related both to the early stages of the EMPT and to the Mid-Brunhes event owing to enhanced leakage during the interglacial peak of MIS 11 (Bard and Rickaby 2009; Caley et al., 2012).

\section{High-frequency variability in the marine realm}

While the shift from 41-kyr (obliquity) to dominance of quasi-100 kyr cycles represents a defining feature of the EMPT, high-frequency variability remains an important feature of the climate system, and seems to have become more pronounced 
through and beyond the EMPT, probably owing in part to the instability of large ice sheets. This increasing complexity within climate cycles likey explains why no formal labeling of subdivisions of marine isotope stages exists before MIS 28 (1.0 Ma) (Railsback et al., 2015).

Based on a high-resolution analysis of ODP Site 1058 in the subtropical northwestern Atlantic, Weirauch et al. (2008) found high-frequency fluctuations throughout the EMPT and during interglacials as well as glacials, pointing to the influence of precessional forcing at low-latitudes. They also noted increasing in amplitude from MIS 22, which implies that feedback mechanisms associated with the growth of large polar ice sheets act as amplifiers. Among these might have been an increase in the strength of pole-to-equator winds during times of ice sheet expansion, leading to more vigorous ocean surface currents in general and enhancing the prospects of northward advection of tropical waters to high latitudes (Weirauch et al., 2008; Ferretti et al., 2010).

Ferretti et al. (2005) noted for subtropical western Atlantic ODP Site 1063 that highest amplitude fluctuations, up to a few millennia in duration, were mainly associated with interglacials, especially after the intensification of glaciation at $\sim 900 \mathrm{ka}$. Similarly, Ferretti et al. (2010) noted high-frequency variability in the benthic as well as planktonic $\delta^{18} \mathrm{O}$ record of IODP Site U1313 in the central North Atlantic during MIS 23-20, and that MIS 21 could be divided into four interstadial peaks traceable across N. Atlantic. These authors suggested that cooling events in the surface waters were coupled with the meridional overturning circulation, with similar suborbital reorganizations having already been documented at the Gardar Drift ODP Site 983 (Kleiven et al. 2003). Interestingly, spectral analysis through the studied interval showed significant power at periods of 10.7 kyr and $6 \mathrm{kyr}$, close to the second and forth harmonics of precession (Berger et al., 2006). This, along with an excellent match between the foraminiferal $\delta^{18} \mathrm{O}$ records and insolation variations at the equator in March and September, suggested the influence of low-latitude precession through advection via tropical convective processes to the high latitudes (Ferretti et al., 2010). This process can be explained by the twice-yearly passage of the sun across the equator during each precession cycle, which generates a signal corresponding to nearly half (10-12-kyr) of the precession period at the equator (Short et al., 1991). Indeed 23-kyr cyclicity and its harmonics are well known to be strong up to $40^{\circ} \mathrm{N}$, with power attenuating northward (Ruddiman and McIntyre, 1981; Ruddiman and McIntyre, 1984; Hernández-Almeida et al., 2012).

However, high-frequency variability during the EMPT is not restricted to the interglacials. From the northwestern subtropical Atlantic Site 1058, Billups et al. (2006) found highest amplitude $\delta^{18} \mathrm{O}$ variations (4-6 kyr period) to occur during glacial MIS 12, with smaller amplitude variations occurring in the less severe MIS 14. They attributed these variations to climatic instability caused by extensive continental glaciation that characterizes MIS 12. Glacial-stage instability was noted by Grützner and Higgins (2010) for northern North Atlantic IODP Site U1314 over the past $1.1 \mathrm{myr}$, where millennial-scale variability was found to be expressed by high amplitude variations during ice sheet growth (typically benthic $\delta^{18} \mathrm{O}$ values between 4.15 and 4.65 per mil), and lower variance during peak glacial and interglacial phases. Alonso-Garcia et al. (2011) noted millennial-scale waning events during ice sheet growth at Site U1314 for the interval 800-400 ka. The first two events for each glacial stage examined was 
characterized by interglacial temperatures that rose abruptly by $6-10^{\circ} \mathrm{C}$ in about $3 \mathrm{kyr}$. These events are also found in Antarctic temperature and $\mathrm{CO}_{2}$ records and imply close interhemispheric coupling; while comparison of sea-surface proxies with the benthic $\delta^{18} \mathrm{O}$ record (representing Antarctic temperature) at Site U1314 reveals a seesaw mechanism comparable to that observed during the Last Glaciation (Alonso-Garcia et al., 2011). Both Grützner and Higgins (2010) and Alonso-Garcia et al. (2011) noted a global icevolume threshold for millennial-scale variability at Site 1314 for at least the last 1.1 myr. Hernández-Almeida et al. (2012) examined the earlier part of the EMPT at subpolar North Atlantic IODP Site U1314 over the interval 1069-779 ka (MIS 31-19). They found significant power at half-precessional (10 kyr) frequency in IRD, SST and planktonic $\delta^{18} \mathrm{O}$ time series, which they attributed to equatorial insolation forcing advected northwards via atmospheric or oceanic tropical convective process. As with the study of Alonso-Garcia et al. (2011), they found IRD associated with ice-sheet growth during times of maximum cooling prior to a warming event. Importantly, the halfprecessional frequency in IRD implies that high-latitude ice-sheet dynamics are influenced by tropical processes (Hernández-Almeida et al., 2012).

Records of MIS 19 from the EPICA Dome C ice core and ODP Site 983 located on the Gardar Drift (North Atlantic) have been compared in detail. Several small peaks in the Site 983 record and ice core proxies characterize the latter part of MIS 19. Analysis of these small peaks has revealed a bipolar seesaw mechanism caused by ice sheet growth and subsequent instability that began close to the MIS 19c-b boundary (Tzedakis et al., 2012, and Section 11, under MIS 19).

\section{Sedimentological evidence from the Chinese Loess Plateau}

Loess-paleosol sequences particularly from the Chinese Loess Plateau provide critical information about paleoenvironmental evolution through the EMPT in central and northern Asia, and the development of the East Asian monsoon system. These sequences are also important for continental correlations with Europe and enable crucial correlations to be made with the marine realm (Dodonov, 2005; Sun et al., 2006), despite uncertainties described above (Section 5.2).

Magnetic susceptibility and grain size are the primary means of interpreting loess-paleosol records in China. During glacials, the more intense winter monsoons cause an increase in both grain size and the quantity of wind-blown sediment, resulting in loess deposition. Magnetic susceptibility is a feature of both loess and paleosols. Its origin in loess is apparently largely wind-borne (higher coercivity), and its origin in paleosol most likely results from in-situ chemical processes (lower coercivity). During interglacials, the summer monsoon prevails, dust levels are reduced, and warm, wet conditions facilitate soil formation (Maher et al., 2009; Song et al., 2014 and references therein). Of the several well-studied sections across the Chinese Loess Plateau, Chaona in the central Chinese Loess Plateau is discussed below in detail.

An astronomically tuned loess-paleosol record from Chaona was analysed by Han et al. (2012) using magnetic susceptibility and grain-size as indicators for summer and winter monsoon intensity, respectively. Results show dominant 41-kyr obliquity forcing between 2.6 Ma and 0.9 Ma, with strengthening of the $100 \mathrm{kyr}$ signal at 1.2-1.1 Ma, 
which becomes strong at $0.9 \mathrm{Ma}$, and increases strongly after 0.64 Ma. Both magnetic susceptibility and grain-size increase persistently from 0.9 Ma and also register a stepwise increase at 0.64-0.52 Ma, implying that both East Asian summer and winter monsoons became enhanced at these times. Other loess-paleosol records across the Chinese Loess Plateau show a similar pattern of enhanced summer or winter monsoons at around 1.3-1.0 Ma and 0.55-0.45 Ma, and climatic evidence from other proxies including pollen and mammal remains across the Chinese Loess Plateau indicate a longterm increase in winter monsoon dominance and drying (Han et al., 2012 and references therein). This mirrors a strinkage of the West Pacific Warm Pool and declining tempertures in the South China Sea at about $900 \mathrm{ka}$, attributable to a strengthening of winter monsoon influence (see Section 6.2).

An untuned loess-paleosol record also from Chaona, using paleomagnetic boundaries (but see Section 5) and variable sedimentation rate based on grain size for the age model, was subjected to time series analysis (Song et al., 2014). Results confirmed power in the $\sim 400,100$, and 40-kyr frequency bands, as previous studies had done, and show the influence of both orbital forcing and ice volume. However, although $\sim 100 \mathrm{kyr}$ periodicity began to dominate at $\sim 1.2-1.3 \mathrm{Ma}$ as expected, it disappeared at $\sim 0.9 \mathrm{Ma}$, only to reappear and dominate after 0.6 Ma. Song et al. (2014) suggested that this hiatus was caused by rapid uplift of the Himalaya-Tibetan Plateau above a critical threshold, beginning with the deposition of the pronounced loess L15 ( 0.9 Ma) and close in age to the dessication of a series of lakes across northern China at $\sim 1.1 \mathrm{Ma}$. Han et al. (2012) had arrived at a similar conclusion from their tuned record of the same sequence. This rise in elevation is speculated to have interfered with atmospheric circulation, strengthening the intensity of the Siberian High and hence the winter monsoon which is responsible for loess deposition (Song et al., 2014 and references therein).

Comparable results have been obtained from other sections across the Chinese Loess Plateau including, for example, Lingtai in the south. Here, a magnetostratigraphically constrained and orbital tuned record reveals a major shift at 1.25 Ma marked by a stepwise strengthening of both the glacial (winter) monsoon and interglacial (summer precipitation) monsoon, with the uplift of the Himalaya-Tibetan Plateau and Northern Hemisphere ice sheet development both controlling long-term trends in the record (Sun et al., 2010). Recognised across the Chinese Loess Plateau, three marker horizons have special significance. Loess L15 at 1.25 Ma represents a remarkable coarsening event (Sun et al., 2010) and can be correlated to MIS 38. A particularly coarse L9 is also widely recognized and can be assigned to MIS 24-20 (Jin and Liu, 2011; see Section 5.2.2. for discussion). A third marker is the paleosol S5a at about 0.5 Ma represents an enhanced summer monsoon and can be correlated to MIS 13 .

\section{Glacial, fluvial and coastal history}

A key characteristic of Quaternary climates is the repeated glaciation of what are today temperate regions. The increasing intensity and duration of glaciation through the EMPT interval remains a critical element in the operation of the Earth's climate system. Head and Gibbard (2005) summarised evidence accumulated in the INQUA project "Extent and Chronology of Quaternary Glaciations" (Ehlers and Gibbard 2003, 2004a, b, c; 
Ehlers et al., 2011) that demonstrated a strong consistency in the pattern and extent of glaciation with other lines of evidence. A recent compilation confirms that glaciation had already occurred in the high latitudes of both the Northern and Southern Hemispheres during the late Neogene, in particular at intervals during the late Pliocene Piacenzian Stage (De Schepper et al. 2014). The Early Pleistocene (2.6 to $0.7 \mathrm{Ma}$ ) continued this pattern, including relatively few intervals that were sufficiently cold and long to allow the development of substantial ice sheets beyond mountain or high-latitude settings, such as Antarctica or northernmost North America.

The "glacial" Pleistocene effectively began with extensive glaciation of lowland areas, particularly around the North Atlantic region, and the intensification of global cold period (glacial) climates, in general. This coincides with the main part of the EMPT $(1.2-0.8 \mathrm{Ma})$ and the onset to dominance of $\sim 100 \mathrm{kyr}$ cycles in which the cold periods were of sufficiently long duration to allow the development of continental-scale ice sheets.

Till sheets of the major glaciations during the "glacial Pleistocene" are found throughout Europe. In northern Europe, till sheets characterise large areas of the lowlands and are also found on the floors of the adjacent seas (Gibbard and Clark, 2011; Karabanov and Matveyev, 2011; Lunkka et al., 2011; Raukas et al., 2011; Rose et al., 2011). Recent investigations have demonstrated the extent to which the North Sea floor was sculpted by repeated glaciation (Graham et al., 2011). Further south, in central and southern Europe, glacial diamicton is restricted to the mountains and piedmonts (Calvet et al., 2011; Giraudi, 2011; Nývlt et al., 2011; Urdea et al., 2011; van Husen, 2011; Woodward and Hughes, 2011). In northern Europe, widespread lowland glaciation began in the early Middle Pleistocene shortly after the Brunhes-Matuyama palaeomagnetic reversal (0.73 Ma) in the Donian (Narevian, Sanian, MIS 16) Stage during the "Cromerian Complex" Stage. More limited glaciation may have occurred in the circumBaltic region during the latest Early Pleistocene (MIS 22 and 20). The evidence for these Early Pleistocene glaciations is restricted to Latvia (Zelčs et al., 2011), Poland (Marks, 2011), and possibly Lithuania (Guobyte and Satkūnas, 2011), although pre-Cromerian glaciation in this area could have extended into central Jylland, Denmark (HoumarkNielsen, 2011). Although Early Pleistocene glaciation has been demonstrated from icerafting in the northern North Sea (Ottesen et al. 2014), early Middle Pleistocene glaciation has not yet been recorded from the North Atlantic and offshore Norway (where the earliest Middle Pleistocene glaciation occurred $~ 0.5 \mathrm{Ma}$, possibly in MIS 12; Sejrup et al. 1995), it is certainly present in Denmark, the Baltic region, and European Russia. In the Italian Dolomites, glaciation became established in MIS 22 (Muttoni et al. 2003). Comparable evidence is also found north of the Alps in Switzerland and southern Germany (Fiebig et al., 2011). Further west, the oldest glaciation identified in the Pyrenees is of late Cromerian age (MIS 16 or 14) (Calvet, 2004). In North America, widespread lowland glaciation is again first recorded during MIS 22 or 20 (Barendregt and Duk-Rodkin, 2011; Duk-Rodkin and Barendregt, 2011). Subsequently, major ice sheets repeatedly extended over large regions of the continent during the Middle Pleistocene pre-Illinoian events beginning in MIS 16. According to Chinese investigations, glaciation of Tibet and Tianshu is not recorded before the Middle Pleistocene, of which the MIS 12 glaciation was the most extensive. Two discrete Pleistocene glaciations, correlated to MIS 18 16 and MIS 12, have been identified on the 
Qinghai-Tibetan Plateau and the bordering mountains. Of these, the first, Kunlun Glaciation (MIS 18 16) was the most extensive (Zhou et al., 2011). The apparent delay in glaciation of the Himalayan chain has been explained as reflecting late uplift of high Asia.

As in the Northern Hemisphere, circum-Atlantic region glaciation increased in intensity from 800 ka to today throughout the South American Andes. In the northern Andes there is evidence of glacial deposition from the early Pleistocene in Colombia (e.g. Helmens, 2011). In the southern Andes, the Late Pleistocene saw glaciation that was less extensive than during the Early Pleistocene events (Coronato and Rabassa, 2011; Martínez et al., 2011; Harrison and Glasser, 2011). In Australasia, the glacial record continues in MIS 12, following a 1 million year hiatus. However, the earliest Pleistocene ice advances in Tasmania may have begun about 1 million years ago, although they may be older (Colhoun and Barrows, 2011). Glaciations in Africa were restricted to the East African mountains including Mount Kilimanjaro, Mount Kenya and the High Atlas, where the major glacial events appear to be broadly synchronous beginning in MIS 12 .

The repeated records for the occurrence of Middle Pleistocene glaciations during MIS 16 and MIS 12 throughout the world is striking, whereas the absence of evidence for glaciations during MIS 18, and to a lesser extent MIS 14, implies that later glaciations were more extensive and therefore probably destroyed evidence for these events. However, it is also possible that some of these glacial deposits have been inadequately differentiated owing to the limitations of current dating techniques. Lack of precision for dating terrestrial Middle Pleistocene sequences leaves some uncertainty until better dating techniques become available.

It therefore appears from direct evidence that until $\sim 1.2 \mathrm{Ma}$ the cold periods (glacials) were not regularly cold and long enough to allow ice-sheet development on a continental scale, outside mountain or polar regions, and that the most extensive glaciations in the Quaternary ( 5-6 intervals) began in the last $900 \mathrm{kyr}$ (ca. MIS 22 to present) in the Northern Hemisphere. In contrast, Southern Hemispheric glaciation is a much longer-established phenomenon with substantial glaciation already a regular occurrence in the Tertiary. The striking development of ice sheets through the Quaternary clearly emphasises that world-wide glaciation is in effect a Northern Hemispheric phenomenon (Ehlers et al., 2011).

Head and Gibbard (2005) have noted that river systems also apparently responded significantly to the increased intensity of climatic deterioration and duration of climatic events during the EMPT. Throughout Europe, the preserved fluvial sequences predominantly comprise coarse sediments of cold-climate origin. Comparison of modern, deeply-incised river valleys with the shallow valleys predominant through the Neogene strongly suggests that alternating incision and deposition are direct consequences of rapid climatic change. Indeed, as Gibbard (1988) and Gibbard and Lewin $(2003,2009)$ have suggested, the increased frequency of downcutting and aggradation represented from the late Early Pleistocene onwards in the region is a result of the occurrence of cold climates and the consequent supply of abundant fresh materials by periglacial processes. These increased incision and depositional terrace sequence cycles in river systems began during the interval 1.2-0.8 Ma (Gibbard and Lewin 2009) in all the major European drainage systems. It is apparent that the impact of the climatic changes on the drainage systems has been profound, although the effects of additional 
climatically controlled parameters, including precipitation, seasonality, and groundwater hydrology, are generally poorly understood. Finally, it should be stressed that the observed relatively short-term deposition/incision patterns have been superimposed on long-term climatic and geological trends over the past few million years.

In a manner comparable to the fluvial terrace sequences, coastal raised-beach terraces recording sea-level changes through the period again show similar patterns. As is well known, glacioeustatically and isostatically controlled sea-level changes characterise the later Cenozoic. Many coasts worldwide exhibit sequences of Quaternary and late Cenozoic shorelines that were shaped by a combination of sea-level oscillations and tectonics. Marine terraces occur in many coastal regions of the world, except downwarping areas. According to Pedoja et al. (2014), these stairways are considered to result from uplift at tectonic plate margins, based on a global synthesis of sea-level highstands, beginning in the Middle Pleistocene MIS 11. Indeed, the geomorphological expression of fossil shorelines appears to match the amplitude and frequency of MiddleLate Pleistocene glacial cyclicity ( $100 \mathrm{kyr}$, from MIS 11 to present). By contrast, the earlier Pleistocene strandlines, associated with 40-kyr climatic cyclicity, readily merge into rasas - or coastal plane-like surfaces that were repeatedly occupied through the interval. According to Pedoja et al. (2014), although many coasts worldwide feature sequences of Quaternary shorelines resulting from a combination of sea-level oscillations and tectonics, Middle-Late Pleistocene strandlines are altitudinally separated owing to high-amplitude eustatic oscillations that follow the EMPT. Earlier sea-level oscillations were more frequent and of smaller amplitude, resulting in the reoccupation of ancient palaeocoasts (e.g. terraces) and hence the development of compound morphologies to form rasas.

\section{Early-Middle Pleistocene transition in the terrestrial biota}

The large and small mammal record, including that of hominins, shows a significant response to climatic and environmental change across the mid-Pleistocene transition, with the famous 'end-Villafranchian event' in Europe representing a major faunal turnover (Azzaroli 1983; Azzaroli et al. 1988). The event is marked mostly by the arrival in Europe of fauna of Asian origin, but also representatives (mostly carnivores) from Africa including the extant spotted hyaena Crocuta crocuta at around 0.9-0.8 Ma. The transition to a modern fauna was protracted, however, with for example the arrival in Europe of Panthera leo (lion), Panthera pardus (leopard), and Bos primigenius (large bovine) from Africa all occurring at around 600-500 ka (Martínez-Navarro, 2010; van der Made, 2013).

The challenges in determining patterns within the faunal record, in addition to issues of taxonomy, relate to the fragmentary and often imprecisely dated nature of these continental records. Consequently, it is usually not possible to assign faunal events definitively to individual marine isotope stages, except near paleomagnetic boundaries. In contrast, pollen records have produced detailed and relatively continuous if localized reconstructions of vegetation (and hence climate) across the EMPT especially in Europe (e.g. Suc and Popescu, 2005). 


\subsection{Terrestrial vegetation}

On a global scale, the vegetational response as determined from pollen records largely reflects fluctuations at the scale of individual climate cycles, although with a strong regional influence. Europe and particularly the Mediterranean region serve well to illustrate the vegetational response across the EMPT. Suc and Popescu (2005) in their review of 16 pollen records, perhaps surprisingly found no strong perturbations of the Mediterranean flora and vegetation between 1.2 and 0.7 Ma. Moreover, no new tree genera appeared from 1.5 Ma onwards in southern Europe, in stark contrast to the many new large mammal arrivals during this time. The EMPT instead saw a progressive loss of floristic diversity in this region during the EMPT (Magri and Polombo, 2013).

In comparing trends in large mammal faunas and vegetation across the EMPT, Magri and Palombo (2013) found important discrepancies. During the late Early Pleistocene, for example, large mammal faunas reflect a savanna-type vegetation over southern Europe, whereas pollen records show a dominance of forest environments. Moerover, diversity trends, turnover indices, and other metrics suggest that changes in the faunal structure are not related directly to changes in the vegetation cover and composition (Magri and Palombo (2013). More research is clearly needed to illuminate these apparent discrepancies. In this respect, it is worth noting that local conditions may have a profound influence on vegetational develpoment. For example, at Montalbano Jonico in southern Italy, wooded steppes to steppes characterize glacial phases of MIS 21-18, when cold and dry conditions prevailed (Bertini et al., 2015). In contrast, Valle di Manche, just $140 \mathrm{~km}$ to the south, was presumably closer to upland areas as a raindemanding conifer forest was established during the glacial intervals of MIS 20 and 18, with arid conditions occurring during the deglaciations (Capraro et al., 2005).

Several long and continuous terrestrial pollen records in Europe have improved our understanding of the EMPT. Tenaghi Philippon in NE Greece has an astronomically tuned record that reveals long-term trends in vegetation dynamics over the past 1.35 myr (Tzedakis et al., 2006). Glacial maxima are indicated by contractions in tree populations, with MIS 22 being particularly severe. Other notable glacial maxima in descending order of severity are MIS 12,16, 6, 2, 10 and 8, with MIS 16 characterised by a particularly sustained contraction. Following the mid-Brunhes event, there was no change in the magnitude of interglacial tree population expansion, in agreement with ice core and marine records. The extreme conditions of MIS 22 and 16 seem to explain the disappearance of Tertiary relict taxa from the area. After MIS 16, Quercus and Carpinus become the dominant interglacial forest taxa (Tzedakis et al., 2006).

\subsection{Large non-hominin mammals}

Europe, and Italy in particular, provides a valuable record of faunal change across the EMPT. Owing to its north-south orientation, Italy has served as a refuge for warmadapted mammals, with the Alpine mountain chain at its northern limit acting as an ecological filter (Palombo et al., 2005).

An extirpation phase in Italy began at about 1.4 Ma (the Farneta faunal unit; late Villafranchian Mammal Age) with the last apearances of many typical Villafranchian 
taxa, but was accompanied by the significant first appearances of Praemegaceros obscurus (megalocerine deer) and Stephanorhinus cf. hundsheimensis (a rhinocerotid) (Martínez-Navarro, 2010). This extirpation phase culminated around 1.2-1.0 Ma as evidenced by the Pirro Nord and Colle Curti faunal units (Palombo and Valli, 2005), although the Pirro Nord faunal unit is marked also by the first appearances of Equus altidens (mid-sized horse), Praemegaceros verticornis (large deer), Lycaon lycaonoides (wild dog), and the first occurrence in Europe of Theropithecus sp. (large African gelada baboon). The first evidence of hominins in Western Europe is also associated with the Pirro Nord faunal unit, where paleolithic artifacts have been found. The African species Hippopotamus antiquus has its first occurrence in this faunal unit, although recorded in Spain rather than Italy (Martínez-Navarro, 2010).

The extinction phase was followed by, and indeed overlapped with, the arrival in Italy of large ungulates from eastern and central Europe. The Colle Curti faunal unit, assigned to the Jaramillo Subchron, represents the beginning of the most important faunal change of the Pleistocene (the transition from late Villafranchian to Galerian mammal ages) and is characterized by the dominant occurrence of Hippopotamus, P. verticornis, and Bison subgen. Bison. The stratigraphic ranges of these and other taxa are shown in Rook and Martínez-Navarro (2010, fig. 2). However, the faunal renewal was progressive, and accompanied by a pronounced increase in regionalization during the EMPT (Magri and Palombo, 2013). The dispersal of Hippopotamus (Martínez-Navarro, 2010), and particularly Bison (van der Made, 2013), at around 1.2 Ma may be significant to the dispersal of Homo in southern Europe at about this time, as these animals could have been prey for Homo and thus part of the same fauna. Bison appears to have originated in Asia, with the implication that Homo may therefore have dispersed into Western Europe from or through the open environments of the Asian steppe during or shortly after a particularly cold climate cycle (van der Made, 2013). It may be significant that the earliest lithic artefacts in Italy, from Pirro Nord (1.6-1.3 Ma), are associated with the earliest occurrence of many taxa in Italy including Bison degiulii (Arzarello et al., 2012), and it is particularly notable that lithic artefacts from Orce in Spain (1.2-1.3 Ma) co-occur with fossil bones mainly of hippopotamus and elephant that have cut marks (Lozano-Fernández et al., 2014).

The large mammal record from Italy reflects a shift from open and arid conditions in the late Early Pleistocene to a wetter and substantially cooler climate in the early Middle Pleistocene (Palombo et al., 2005). These wetter conditions in the early Middle Pleistocene seem to have supported a larger proportion of large herbivore species relative to the number of carnivores present. Similar patterns are reflected elsewhere in Europe, with open landscapes dominating eastern, southeastern and southwestern Europe during 1.8-1.2 Ma, and more variabile habitats occurring during 1.2-0.9 Ma. Progressively cooler climates oscillating between intense cold and warm periods characterize the 0.9 0.4 Ma interval, and led to the alternation of very different landscapes across most of Europe (Kahlke et al., 2011). Large mammal records also infer that hominins initially colonized Northwestern and Central Europe during interglacials of the late Early to early Middle Pleistocene, when these regions experienced periods of low seasonality and substantial habitat diversity (Kahlke et al., 2011).

Some modern lineages, such as Cervus elaphus (red deer) and Sus scrofa (wild boar), were present in the late Villafranchian fauna (Magri and Palombo, 2013; van der 
Made, 2013). However, by about $600 \mathrm{ka}$, the faunal renewal marking the early Middle Pleistocene had come to a close, with taxa characteristic of the late Early Pleistocene (Villafranchian) having been mostly replaced by modern taxa (Palombo et al., 2005). France was a migration route from Central Europe to Italy. As with Italy, the French record shows an extinction event followed by a dispersal event, although both events apparently occur later in France, and the Middle Pleistocene dispersal event may have been more gradual (Palombo and Valli, 2005; Head and Gibbard, 2005). The transition was evidently complex and possibly diachronous, in which an extinction phase partially overlapped the following dispersal event. Faunal reorganization seems to relate to a climatic transition, as reflected in the vegetation that changed from 'warm' steppedeciduous forest alternations during the Early Pleistocene, to 'cold' steppe-warmtemperate deciduous forest after about 1 Ma (Suc et al. 1995; Bertini 2003; Palombo and Valli, 2005), with a prevalence of faunal taxa that inhabited open landscape in the early Middle Pleistocene. The statistical analyses of French and Italian faunas by Palombo and Valli (2005) also show that the 'end-Villafranchian event' of earlier authors was a mammal reorganization event more profound than occurred at either the GelasianCalabrian or Middle-Late Pliocene boundaries.

The transition from Villafranchian to Galerian Mammal Ages, beginning at around 1.0 Ma in the Northwest Mediterranean (Spain, France and Italy), represents an increase in large herbivores and megaherbivores that arrived mostly from Asia but also from Africa in coincidence with the onset of high intensity glacial cycles (Rodríguez et al. 2004; Martínez-Navarro, 2010). The migration of Crocuta crocuta (spotted hyaena), which today preys on large ungulates, offers insights into the process. This species originated in Africa, migrated to Asia by 2.2 Ma (Qiu et al, 2004; Lewis and Werdelin, 2010), and had arrived in the Levant by 1.4-1.2 Ma ('Ubeidiya site, Israel; MartínezNavarro et al., 2009). Its earliest record in Europe is from Atapuerca, Spain (García and Arsuaga, 2001), dating to about $0.9-0.8 \mathrm{Ma}$, just below the M-B boundary. The earliest record of Crocuta crocuta in Italy is the Ponte Galeria 2 faunal assemblage, assigned to MIS 18 and therefore dated to about $750 \mathrm{Ma}$ (Sardella and Petrucci, 2012). This assemblage also records the first appearance in Italy of the Asian migrants Mammuthus trogontheri, Hemibos galerianus, and Megaloceros savini. Significantly, the appearance of Crocuta crocuta in Europe coincides with the disappearance of the specialized carcusscavenger Pachycrocuta brevirostris (giant hyaena). Changes to the carnivore guild including the disappearance of several large hunting carnavores probably reduced the abundance of partially consumed carcusses upon which $P$. brevirostris depended. The more adaptable Crocuta crocuta, with its cursorial hunting as well as scavenging behaviour, enabled it to survive the new ecological conditions of the early Middle Pleistocene (Sardella and Petrucci, 2012). The concomitant extinction of Pachycrocuta brevirostris and arrival of Crocuta crocuta has been called the "Crocuta crocuta event" and represents the beginning of modern faunas in Europe (Martínez-Navarro, 2010).

In western Siberia, there occurs a shift somewhat comparable to that seen in Europe, at $\sim 0.86 \mathrm{Ma}$ (=early part of MIS 21 ), where the fauna became dominated by the large mammals Mammuthus trogontherii, Bison ex gr. priscus, and Equus mosbachensis, reflecting the development of open landscapes (Foronova 2005). Indeed, the steppe mammoth Mammuthus trogontherii had spread into the Asian Arctic at $1.2 \mathrm{Ma}$ (Kahlke, 2014), and first appears just before the Brunhes-Matuyama boundary (MIS 21-early MIS 
19) across Eurasia (Foronova 2005; Van Kolfschoten and Markova, 2005). From 800 ka onwards, Mammuthus trogontherii became the dominant mammoth species across the Palaearctic region, at about the same time that the steppe-adapted saiga antelope appeared in high latitudes (Kahlke, 2014). Mammoths were the most successful cold-adapted large mammals ever to have lived, and underwent an important faunal turnover during the pronounced glacial of MIS $12(\sim 460 \mathrm{ka})$ that led to the formation of the earliest panEurasian Mammoth Fauna (Kahlke, 2014).

In assessing whether the large mammals of the African continent underwent a turnover perhaps similar to the 'end-Villafranchian event' in Europe at about $0.9 \mathrm{Ma}$ (above), and to an event in Indonesia occurring between $0.8 \mathrm{Ma}$ and $0.7 \mathrm{Ma}$ (van den Bergh et al. 2001), O'Regan et al. (2005) statistically examined the large mammal record in Africa and the Levant for the interval 1.0-0.5 Ma. The African large mammal faunas seem to have been relatively stable throughout this interval, and while several new species, including the modern hippopotamus, reedbuck and black wildebeest, seem to appear at about $0.7 \mathrm{Ma}$, they are not seen as part of a significant turnover. The continent of Africa is presently separated into Palaearctic (Levant and north Africa, but also including Europe and much of Asia) and African (Sub-Saharan Africa) zoogeographical regions, a separation that appears to originate before the mid-Pleistocene transition (O'Regan et al., 2005).

Recent proposed changes to the mammal-age terminology require some clarification. The Epivillafranchian Mammal Age has been proposed by Bellucci et al. (2015) as a formal biochron to represent the Villafranchian-Galerian transition (1.2-0.9 Ma). It comprises the Colle Curti and superjacent Slivia Italian faunal units, the latter occurring just below the Matuyama-Brunhes boundary. Above this, the Ponte Galeria faunal unit is assigned by Bellucci et al. (2015) to the lowest faunal unit of the Galerian mammal age.

\subsection{Hominins}

The EMPT represents a critical phase in the evolution and dispersal of hominins. Hominins had migrated out of Africa soon after the evolution of Homo erectus, a hominin of modern-like body pattern and increased brain size. Homo erectus itself is thought to range from 1.9 to at least $0.3 \mathrm{Ma}$ and has an East African-Eurasian distribution (Maslin et al., 2014). By $\sim 1.8 \mathrm{Ma}$, hominins were present as far west as Dmanisi in Georgia (Lordkipanidze et al., 2005, 2007, 2013; Ferring et al., 2011), this being the earliest verifiable fossil occurrence of Homo outside of Africa, with sparse records early across the lower latitudes of central and eastern Asia and southeast Asia being placed around 1.7-1.6 Ma (O'Regan et al., 2011). Hominin teeth and artefacts from 'Ubeidiya in Israel at $\sim 1.5 \mathrm{Ma}$ (Belmaker et al., 2002) mark the westward dispersal of hominins by this time. By about $1 \mathrm{Ma}$, hominins had penetrated into higher northern latitudes including those of China and Europe (Dennell, 2003).

The earliest evidence for hominin occupation in Europe is reviewed by Bermúdez-de Castro et al. (2013). Represening a very early occupation of eastern Europe, the lowest levels of the Kozarnika Cave sequence in Bulgaria are biostratigraphically dated to about 1.6-1.4 Ma and contains a Mode 1 ( Oldowan) lithic industry. Associated cut-marked mammal bones indicate butchering, but some also show the earliest known 
evidence of skinning, and one bone with groups of parallel cuts suggests symbolism. Significantly, the lithic industry in the lowest levels did not change substantially until 500 ka (Sirakov et al., 2010). From southern France is a record of pebble-culture-type Mode 1 lithic artefacts from the Hérault Valley, constrained by a 1.57 Ma overlying basalt layer (Crochet et al., 2009).

The Italian site of Pirro Nord, fissure 13, contains Mode 1 lithic artefacts (Arzarello et al., 2009, 2012), and has been assigned to the 1.3-1.6 Ma Allophaiomys ruffoi small-mammal biozone (López-García et al., 2015). Along with the Hérault Valley site, it records one of the earliest hominin occupations in southwestern Europe.

The first direct fossil evidence of hominin occupation in Europe is based on an isolated tooth from level D of the Barranco León site in the Guadix-Baza Basin, Orce in southeastern Spain (Toro-Moyano et al., 2013). This level has been dated as 1.26 \pm 0.13 Ma using Mimomys savini small-mammal biochronology (Lozano-Fernández et al., 2014). Abundant Mode 1 lithic artefacts are reported both at Barranco León level D and at the slightly younger Fuente Nueva 3 site (1.20 \pm 0.12 Ma using M. savini biochronology; Lozano-Fernández et al., 2014) also in the Guadix-Baza Basin. An absence of such artefacts from earlier levels at Orce suggests that early hominin dispersal across southern Europe was sparse. Evidence from small mammal remains at the Orce sites indicates a warm and humid climate, suggesting a climatic control of hominins into Europe at this time (Agustí et al., 2009, 2010).

Important evidence of early hominin occupation in Europe also comes from the Sierre de Atapuerca cave complex near Burgos in northern Spain. Here, a mandible belonging to the genus Homo has been found along with Mode 1 lithic artefacts and some cut-marked herbivore bones including a bovid at the Sima del Elefante site from the Trinchera Elefante 9c (TE9c) level (Carbonell et al., 2008). This level was dated to $\sim 1.2-$ 1.1 Ma based on a combination of paleomagnetism (pre-Jaramillo Subchron), cosmogenic nuclides, and biostratigraphy (Carbonell et al., 2008). The TE9c level is similar in age to the Barranco León D level at Orce, but the absence of Mimomys savini from the TE9c level prevents their relative ages from being precisely determined (Lozano-Fernández et al., 2014). Nonetheless, the TE9c level at Atapuerca, the Barranco León D level at Orce, Pirro Nord, and 'Ubeidiya site, all correlate to the Allophaiomys lavocati small mammal biozone, which predates the Jaramillo Subchron with a range of 1.5-1.2 Ma. The small mammal assemblages of this biozone reflect relatively warm and wet climatic conditions (Cuenca-Bescós et al., 2013).

The Vallparadís site, within the city of Terrassa, north-eastern Spain, is close to the upper limit of the Jaramillo Subchron (between 1 and $0.9 \mathrm{Myr}$ ) and has yielded a Mode 1 lithic industry and cut-marked and fractured bones (Garcia et al., 2014). This site reveals a continuity of hominin occupation in Spain from the Sima del Elefante site $(\sim 1.2-1.1 \mathrm{Ma})$ to the Gran Dolina sublevel TD6.2 (>936 ka), both at Atapuerca.

The Gran Dolina sublevel TD6.2 at Atapuerca, between the top of the Jaramillo Subchron and the Matuyama-Brunhes boundary, contains numerous Homo antecessor fossils, Mode 1 lithic artifacts, and cut-marked and fractured herbivore bones (Bermúdez de Castro et al., 1997, 2008, 2012; Garcia et al., 2014). Homo antecessor is thought to represent a distinct European lineage, and may be closer to Asian than African hominins (Bermúdez de Castro et al., 2008, 2012). It is not possible to determine whether the Sima del Elefante mandible belongs to Homo antecessor (Bermúdez de Castro et al., 2013). 
Paleomagnetic studies suggest an age slightly greater than $936 \mathrm{ka}$, immediately preceeding the Kamikatsura/Santa Rosa paleomagnetic event, and possibly equivalent to MIS 25 (Bermúdez de Castro et al., 2012, Parés et al., 2013). A wet and temperate climate is indicated for level TD6 (Bermúdez de Castro et al., 2013).

Evidence that hominins had already moved into higher latitudes of Europe by this time comes from the Loire basin of central France. Here, at Pont-de-Lavaud, Lunery, and Saint-Hilaire-la-Gravelle, Mode 1 lithic artefacts are dated to around 1.1 Ma ( MIS 31) based on ESR and the reconstruction of a warm and wet climate. The sites suggest occupation during the beginning and end of cold periods (Despriée et al., 2011). At Untermassfeld in central Germany, a Mode 1 lithic industry associated with cut-marked bone has been dated to around 1.05 Ma (Garcia et al., 2013; Landeck and Garcia, 2015), demonstrating that hominins had spread as far north as as $50^{\circ} \mathrm{N}$ by this time. Monte Poggiolo in northern Italy $\left(44^{\circ} \mathrm{N}\right)$ is dated to $1.1-0.9 \mathrm{Ma}$, and associated with a cold and arid steppic environment (Milliken, 1999) that contradicts any notion that hominins were restricted to intergalacial intervals.

Early hominin incursions into northern Europe indicate a fairly rapid adjustment to cooler winters. Hominin footprints from Happisburgh in eastern England were probably made by Homo antecessor and date between 1.0 and $0.73 \mathrm{Ma}$ (i.e. Chron C1r1r). They represent activity on an estuarine mudflat during a cooler climate characteristic of the beginning or end of an interglacial or during an interstadial (Ashton et al., 2014). At the nearby Happisburgh site 3, flint artefacts provide further evidence of hominin activity during this time, and represent the shore of a former estuary. With summer temperatures between 16 and $18^{\circ} \mathrm{C}$, winter temperatures between 0 and $-3^{\circ} \mathrm{C}$, and conifer dominated woodland, conditions were similar to those in southern Scandinavia today near the transition between temperate and boreal vegetational zones (Parfitt et al., 2010). The site dates between 1.0 and $0.73 \mathrm{Ma}$ (i.e. Chron C1r1r), and appears to correlate with warm stage MIS 25 or 21 (Parfitt et al., 2010).

Later evidence of occupation at higher latitudes include Pakefield, also in eastern England (Cohen et al. 2012), and dated to between about 750-680 ka (MIS 19 or 17) where a provisionally assigned Mode 1 assemblage of artefacts has been found (Parfitt et al., 2005). Despriée et al. (2011, fig. 10) illustrate the wide distribution of Mode 1 lithic industries across Europe during the early Pleistocene.

Mode 1 lithic artefacts occur across Europe between 1.6 and 0.6 Ma. At about 1.0 Ma, retouched artefacts became incorporated into the assemblages (Garcia et al. 2013). This happens both in the Orce sites and Vallparadís, both in Spain, and in the northern European sites of Untermassfeld, Pakefield and Happisburgh, suggesting a continuity of cultures across Europe, and that a novel technology and presumably social innovations brought from Asia Minor (retouched artefacts are recorded in 'Ubeidiya, Israel at $\sim 1.5$ Ma) spread rather quickly (Garcia et al. 2013). Mode 2 ( Acheulian) tools appeared at about 700-600 ka and are characterized, inter alia, by the presence of hand axes as exemplified by Boxgrove and Happisburgh Site 1 in England which are both assigned to MIS 13 (Preece and Parfitt, 2012). In the Loire basin, central France, hand axes first appear about 700-600 ka based on ESR dating (Despriée et al., 2011). In Atapuerca in northern Spain, hand axes do not occur until the Galería GII and GIIIa stratigraphic units dated from $\sim 500 \mathrm{ka}$ (Rodríquez et al., 2011; Ollé et al., 2013). This technology presumably was introduced from southwest Asia where it was already in extistence in 
'Ubeidiya, Israel at 1.5 Ma (Garcia et al. 2013). Despriée et al. (2011, fig. 10) illustrate the extensive distribution of Mode 2 lithic industries across Europe during the Middle Pleistocene.

At Atapuerca, Spain, a reduced-diversity Mode 1 technology is associated with a Homo sp. from the Sima del Elefante TE9c level, and Mode 1 technology was certainly possessed by Homo antecessor described from Gran Dolina sublevel TD6.2. After 300 kyr without evidence of hominin occupation at Atapuerca, hominin remains referred to Homo heidelbergensis have been recorded at the Galería site dating to $\sim 500 \mathrm{ka}$ and at the Sima de los Huesos site dating to $\sim 430 \mathrm{ka}$ (Arsuaga et al., 2014), both sites having yielded Mode 2 technology (Ollé et al., 2013). A single hand-axe found with at least 28 individuals at the Sima de los Huesos site, an apparent mortuary, suggests that it is an offering of some kind (Carbonell et al., 2006). The rich human fossil assemblage at Sima de los Huesos reveals a constellation of shared traits with Neanderthals, confirming that these specimens belong to the Neandethal lineage, and implying that the earliest common ancestor of modern humans/Neanderthals predates $\sim 430 \mathrm{ka}$ (Arsuaga et al., 2014). As such, these specimens are not in fact assignable to Homo heidelbergensis in the strict sense. Mitochondrial DNA from a Sima de los Huesos specimen surprisingly shows a closer relationship to the Denisovans, a Late Pleistocene eastern Eurasian sister group to Neanderthals, than to Neanderthals themselves (Meyer et al., 2014), reflecting either the shortcomings of mitochondrial DNA for phylogenetic reconstruction or the complex nature of hominin dispersal and gene flow during the Middle Pleistcene.

Homo heidelbergensis appears to have evolved around $600 \mathrm{ka}$, and was probably not a direct descendant of Homo antecessor. There are significant taxonomic problems associated with Homo heidelbergensis, even when excluding the Sima de los Huesos specimens (Stringer, 2012). This is largely because the type specimen, first described from Mauer, Germany in 1908, is an isolated mandible. The type stratum has since been dated to $609 \pm 40 \mathrm{ka}$ and therefore equivalent to MIS 15 (Wagner et al., 2010). It is assumed, however, that many of the early Middle Pleistocene Mode 2 lithic assemblages including hand axes were made by Homo heidelbergensis. A tibia and isolated teeth found along with Mode 2 lithic artifacts at Boxgrove in southern England and dated to $\sim 500 \mathrm{ka}$ (MIS 13) are possibly assignable to Homo heidelbergensis (Hillson et al., 2010; Preece and Parfitt, 2012; Stringer, 2012). A platform preparation technique used at Boxgrove that allowed bifacial thinning of tools gave rise to a new level of complexity analagous to that achievable by modern expert knappers. The technique required patient learning and practice and implies important cognitive and social advances (Stout et al., 2014). Nevertheless, the control of fire appears not to have been acquired at this time, or at least used habitually, as firm evidence of anthropogenic fire in Europe does not appear until around MIS 11-9 (Roebroeks and Villa, 2011), such as at site 13-I, Schöningen, Germany which is correlated to the Holsteinian interglacial (MIS 11; Van Kolfschoten, 2014). The famous wooden spears at site 13-II of Schöningen are now believed to date to $\sim 310$ ka (Haidle and Pawlik, 2010). It is not known what hominin occupied the Schöningen site. Homo heidelbergensis seems to have had a wide geographical range, with possible records in Africa and Eurasia at around $600 \mathrm{ka}$. Hence, while an African origin is usually assumed for this species, an Asian origin cannot be excluded (Stringer, 2012). 
Notwithstanding the long evolutionary roots of Homo neanderthalensis, Neanderthal-derived features are evident in Europe only from MIS 11 onwards (Stringer, 2012). Nonetheless, Homo heidelbergensis may have persisted in Europe beyond this time. The incomplete hominin cranium described as Homo cepranensis (from Cepraro, near Rome, Italy) in 1994 was initially considered to be an early inhabitant of Europe and dated to 900-800 ka (Manzi et al. 2001). More recent studies indicate a much younger age: either $\sim 450 \mathrm{ka}$ (Muttoni et al, 2009), or $353 \pm 4 \mathrm{k}$ based on ${ }^{40} \mathrm{Ar} /{ }^{39} \mathrm{Ar}$ dating and therefore assignable to MIS 10 (Nomade et al., 2011). The lack of Neanderthal traits and unique combination of archaic and derived characteristics do not allow easy attribution, but best fit with the morphological plexus known as Homo heidelbergensis (Mounier et al., 2011).

The arrival of hominins in Europe, perhaps in several phases, prior to the EMPT is a significant advance but must be viewed in the context of other mammal migrations from Africa and Asia. Hominins during the latest Early Pleistocene and early Middle Pleistocene had increased their geographical range and adaptability, as witnessed by the distribution of lithic artifacts and their manufacture, and the fossil evidence reflects increased encephalisation (Rightmire, 2012). This therefore represents a critical interval in human evolution.

\subsection{Small mammals}

Rodents, in particular the arvicolids (voles and lemmings), are among the most stratigraphically important mammal groups during the EMPT owing to their wide dispersal and rapid evolution. They show a clear pattern of evolution from the Jaramillo Subchron to the beginning of the Brunhes Chron that can be traced between eastern and western Europe (Van Kolfschoten and Markova, 2005; Markova, 2005). It is particularly illustrated by evolution in the Allophaiomys-Microtus lineage, with evolution within the genus Allophaiomys occurring before the Jaramillo Subchron, and Microtus subgenus Terricola and Microtus subgenus Stenocranius occurring after it. The lowest occurrence of Microtus ex gr. oeconomus just below the M-B boundary in Eurasia may be a useful guide to the Early-Middle Pleistocene boundary. It seems to be associated with the arrival of the steppe mammoth Mammuthus trogontherii (Van Kolfschoten and Markova, 2005; Markova, 2005). A change in the small mammal fauna in southern Siberia at the the Early-Middle Pleistocene transition has been attributed to a sharp transition from dry steppe (arid) to semi-desert and desert (extremely arid) conditions (Alexeeva and Erbajeva (2005). A morphometric study of European sites by Maul et al. (2014) has revealed several trends among various arvicolid lineages. For example, the water vole (Mimomys-Arvicola) lineage shows increasing hypsodonty leading to rootless molars at $\sim 600 \mathrm{ka}$. Changes in this lineage appear to reflect a shift to a fossorial (burrowing) lifestyle. In general, the measured traits across all lineages reveal a complex pattern of both stasis and changes occurring at gradual, episodic and variable rates; suggesting that these trends can only be used for biostratigraphy in a very general sense (Maul et al., 2014).

The mid-Pleistocene evolution of widely dispersed rodent species appears to have been more or less simultaneous across Eurasia (Van Kolfschoten and Markova, 2005). The vole record has indeed been indispensible in biostratigraphically constraining 
hominin records across this area. Biostratigraphy through the EMPT using arvicolids is discussed by Preece and Parfitt (2012) in the context of England, and Agustí et al. (2015) for SE Spain, both studies showing the genus Arvicola as appearing for the first time at about 700-600 ka, just above the M-B boundary. The lowest occurrence of this genus is therefore a reliable guide for the lower Midde Pleistocene.

\section{Discrete events during the Early-Middle Pleistocene transition}

Notable events are listed from 1.4 Ma ( MIS 45) to MIS 11 (424-374 ka). Most mammalian (including human) evolutionary and dispersal events are not included because too few data are available to constrain them at the resolution of marine isotope stages, but they are shown on Figure 2. The ages of MIS boundaries are taken from http://www.lorraine-lisiecki.com/LR04_MISboundaries.txt.

\subsection{Ma ( MIS 45)}

Spectral analysis of the LR04 benthic stack reveals a substantial change in the climate dynamics at 1.4 Ma (Lisiecki and Raymo, 2007), and low-frequency power (2-3 bundled obliquity cycles) has been detected in low-latitude SST records at this time (Liu et al., 2008).

\section{MIS 38 ( 1.25 Ma)}

The dust and iron flux in the Southern Ocean rose dramatically $\sim 1.25 \mathrm{Ma}$. The iron flux may have fertilized the ocean and increased productivity, causing a drawdown of $\mathrm{CO}_{2}$ and accelerating cooling. Extensive diatom mats in the Southern Ocean seem to support this scenario (Martínez-Garcia et al., 2011). Also at 1.25 Ma begins a long-term increase in average global ice-volume (Clark et al., 2006). Within the Chinese loess records, loess $\mathrm{L}_{15}$ is particularly coarse-grained, and indicates from this time onwards a major intensification of the East Asian winter monsoon during glacials (Heslop et al., 2002; Ding et al., 2005; but correlated to MIS 36). It appears to correlate with MIS 38 at 1.25 Ma (Sun et al., 2006), the timing of which matches the Southern Ocean dust flux. From around 1.25 Ma onwards, the East Asian summer monsoon during interglacials appears also to have strengthened (Sun et al., 2010).

\section{MIS 37 ( 1.23 Ma)}

A pronounced interglacial in the LR04 stack, MIS 37 is characterized by strongly elevated bottom-water temperatures in the southwestern South Pacific (Elderfield et al., 2012).

\section{MIS 36 ( 1.20 Ma)}

MIS 36 is not an exceptional glacial stage based on its amplitude, although its duration is a little longer than earlier glacial stages. In fact, low-frequency variability in the benthic $\delta^{18} \mathrm{O}$ record first becomes evident at $\sim 1.2 \mathrm{Ma}$ (Mudelsee and Stattegger, 1997; Head et al., 2008). In the southeastern South Atlantic, glacial-interglacial contrasts in regional conveyor circulation strengthened after 1.20 Ma, presumably in harmony with changes in global ice volume, and the onset of $\sim 100-\mathrm{kyr}$ cycles is also detected at this time 
(Diekmann and Kuhn 2002). A weak enhancement of Agulhas leakage occurs at the termination of MIS 36 (Termination 17, Caley et al., 2012). A long-term cooling trend in North Atlantic bottom-waters starting at 1.2 Ma is documented by Sosdian and Rosenthal (2009). Indeed, long-term SST cooling begins or intensifies at around 1.2 Ma for most globally distributed records (McClymont et al., 2013). In general, this should be regarded as a time of accelerated cooling, as cooling trends having been recorded as early as 1.8 Ma (reviewed in McClymont et al., 2013). Sediment architecture off Greece shows a sealevel lowstand during MIS 36 that is more pronounced than intervening lowstands (Anastasakis and Piper, 2013). Direct evidence of Northern Hemisphere glaciation suggests that cold periods (glacials) were not regularly cold and long enough to allow icesheet development on a continental scale, outside mountain or polar regions.

\section{MIS 35 ( 1.16 Ma)}

MIS 35 appears to represent two obliquity cycles owing to its anomalous thickness (Shackleton et al., 1990; Huybers, 2007 as MIS 36), and Mudelsee and Stattegger (1997) speculated that this event was a precursor to the $\sim 100 \mathrm{kyr}$ climate state. Although a warm interval of unusual length, the climate in Auckland, New Zealand was cooler than today based on the expansion of Nothofagus forests (Byrami et al., 2005).

\section{MIS 34 ( 1.12 Ma)}

From MIS 34 (until 0.9 Ma), alkenone evidence from northern North Atlantic ODP Site 983 and northwestern Pacific ODP Site 882 indicates a secular expansion of polar waters spanning both glacial and interglacial stages (McClymont et al. 2008).

Cooling of high northern latitude surface waters may have delayed ice sheet growth through moisture starvation during this early stage of the EMPT (McClymont et al. 2008). In the southeastern South Atlantic pronounced northward shifts of the polar front during glacial periods started at MIS 34, accompanied by reduced SSTs and an expansion of Antarctic sea ice (Diekmann and Kuhn 2002). Cooling is also expressed by a long-term expansion of Nothofagus forests in New Zealand through MIS 34 and continuing for successive later cool stages. It probably represents increased temperature extremes between warm and cool stages, and reduced humidity and increased seasonality during cool stages (Byrami et al., 2005). Sediment architecture off Greece shows a sealevel lowstand during MIS 34 that is more pronounced than intervening lowstands (Anastasakis and Piper, 2013).

\section{MIS 32 (1.10 Ma)}

In Pacific Ocean sediment records prior to $1.10 \mathrm{Ma}$ (MIS 32), carbonate abundance is higher in interglacials and lower in glacials, as with Atlantic Ocean records. From 1.10 Ma onwards, this pattern reverses in the Pacific Ocean, i.e. becomes antiphased with the Atlantic (Sexton and Barker, 2012). This switch in the Pacific is explained by enhanced carbonate preservation during glacials and reduced preservation in interglacials, due to a change in deep-water ventilation. It seems that the Pacific sector of the Southern Ocean increased deep-water ventilation during glacials (preserving carbonate), whereas a weakening of well-ventilated North Atlantic Deep Water during interglacials caused increased carbonate dissolution (Sexton and Barker, 2012). The increased alkalinity of the global deep ocean during glacials may have caused an atmospheric $\mathrm{CO}_{2}$ drawdown 
that has been hypothesized to explain increasingly severe glacial cycles later in the Pleistocene (Sexton and Barker, 2012). The Atlantic sector of the southern Ocean was characterized by more dynamic and productive surface waters during MIS 32-25 (Marino et al., 2009).

\section{MIS 31 ( 1.07 Ma)}

MIS 31 was characterized by exceptionally high levels of high-latitude insolation, featuring two southern hemisphere maxima bracketing a northern hemisphere maximum (Scherer et al. 2008). It is therefore a major Early Pleistocene interglacial (a "superinterglacial" event according to DeConto et al., 2012), with an estimated eustatic rise of $20 \mathrm{~m}$ (Raymo et al., 2006). Warming led to a modeled WAIS collapse (DeConto et al., 2007; Pollard and DeConto, 2009; DeConto et al., 2012) for which there is support from the sedimentary record (Scherer et al. 2008; Naish et al., 2009). Southern Ocean and Antarctic continental margin records indicate reduced sea-ice and enhanced carbonate production during MIS 31, with SSTs around $3-5^{\circ} \mathrm{C}$ higher than today in the western Ross Sea (Scherer et al. 2008). Nannofossils from the South Atlantic sector of the Southern Ocean show warming and imply a major southward shift of the Polar Front associated with MIS 31 (Flores and Sierro, 2007; Maiorano et al., 2009). Moreover, nannofossils found in the extreme southern high latitude Western Ross Sea of Antarctica imply that the warming extended around the Antarctic Continent, and perhaps caused a temporary dissipation of the Polar Front (Villa et al., 2012). A pollen record from New Zealand also registers distinctly warm conditions (Byrami et al., 2005), and bottom-water temperatures were exceptionally warm in the southwestern South Pacific (Elderfield et al. 2012). Unusual warmth is also documented for the northern North Atlantic (McClymont et al., 2008), although in the Nordic Seas MIS 31 sea surface temperatures were not very different from today's and fully interglacial conditions lasted only for about 1-2 kyr (Helmke et al., 2003).

MIS 30 ( 1.05 Ma). A protracted glacial stage spanning most of the lower half of the Jaramillo Subchron, MIS 30 represents a marked increase occurs in the contrast between glacial-interglacial stages in the tropical African vegetation (Dupont et al. 2001).

Sediment architecture off Greece shows a sea-level lowstand during MIS 30 that is more pronounced than intervening lowstands (Anastasakis and Piper, 2013).

\section{MIS 28 ( 1.00 Ma)}

A significant decline among "extinction group" deep-sea benthic foraminifera starting in MIS 28 was recorded in the SW Pacific Ocean core MD 97-2114 by Mancin et al. (2013).

\section{MIS 26 ( 0.96 Ma)}

Particulate proxies for dust and hence aridity, documented in a core off Mauritanian margin, eastern tropical Atlantic, show conspicuous increases during MIS 26, 24, and 22 (Malaize et al., 2012). These timings agree with evidence for enhanced aridity over the African continent, and benthic $\delta^{13} \mathrm{C}$ minima occurring during the same glacial periods indeed suggest a global rise in aridity during the EMPT. Aridity will have led to an expansion of $\mathrm{C}_{4}$ vegetation in Northwest Africa, resulting from a shift in the intertropical convergence zone, as part of a wider pattern of aridity. In general, global aridity and 
stronger winds will have increased the export of $\delta^{13} \mathrm{C}$-depleted carbon into the ocean. Raymo et al. (1997, see also Shackleton, 1977) speculated that the decrease in mean ocean $\delta^{13} \mathrm{C}(\sim 0.3 \mathrm{ppt})$ during a $1.0-0.9 \mathrm{Ma}$ interval, followed by a return to pre-1.0 Ma values by $400 \mathrm{ka}$ might be the result of global aridity. Support for this explanation (but see Elderfield et al., 2012) comes from a strengthening of the Asian winter monsoon with continuing weak summer monsoons, leading to enhanced wind strength and aridity over Asia (Malaize et al., 2012). Sediment architecture off Greece shows a sea-level lowstand during MIS 26 that is more pronounced than intervening lowstands (Anastasakis and Piper, 2013).

\section{MIS 25 ( 0.95 Ma)}

The typical configuration of the $\sim 100$-kyr glacial cycles begins at MIS 25, with higher glacial-interglacial contrasts occuring from here onwards (Wright and Flower, 2002; McClymont et al., 2008; Hernandez-Almeida et al., 2012). Higher temperatures are recorded in MIS 25 than previously, at least back to MIS 31, perhaps allowing more moisture to be transported to the arctic, thereby facilitating the buildup of larger ice sheets (Hernandez-Almeida et al., 2012).

\section{MIS 24-22 (936-866 ka)}

Interrupted by the weak interglacial MIS 23, this interval, the so-called "900 ka event" of Clarke et al. (2006), is the first long-duration glaciation of the Pleistocene and represents a progression to the heaviest $\delta^{18} \mathrm{O}$ values yet seen during the EMPT. McClymont et al. (2013) in their global review of Pleistocene temperature variability found anomalously cool SSTs in nearly every record during the MIS 24-22 interval, an exception being the West Pacific Warm Pool. The interval represents two obliquity-driven climate cycles, with glacial phases at MIS 24 and MIS 22, and the deglaciation of MIS 23 seems to reflect a prominent maximum in obliquity (Hernández-Almeida et al., 2012). The amplitude of millennial-scale fluctuations in climate increases from MIS 22 onwards, suggesting a link with ice-sheet growth (Weirauch et al., 2008).

Elderfield et al. (2012) considered this event to represent an abrupt reorganization of the climate system, based on their foraminiferal stable isotope and $\mathrm{Mg} / \mathrm{Ca}$ study of ODP Site 1123 in the southwest Pacific. A major perturbation of the Deep Western Boundary Current, which sees the passage of $40 \%$ of the deep water in the world's ocean, has already been identified at a nearby site during MIS 22 and implies important fluctuation in Antarctic Bottom Water production (Venuti et al., 2007). The strength of the MIS 22 glacial seems to have been exacerbated by a low insolation peak at $75^{\circ} \mathrm{S}$ during MIS 23, which suggests an abrupt increase in Antarctic ice volume at this time (Elderfield et al., 2012).

According to Elderfield et al. (2012), a sudden increase in continental ice volume during MIS 22 resulted in an abrupt eustatic fall of $120 \mathrm{~m}$ below present sea level, the lowest for millions of years prior to MIS 22. Earlier lowstands had been around $70 \mathrm{~m}$ (Elderfield et al., 2012). This is a more abrupt shift than previously estimated (Bintanja et al., 2005), has strong support based on independent molluscan evidence from Japan (Kitamura and Kawagoe, 2006) and evidence from seismic stratigraphy off Greece (Anastasakis and Piper, 2013). 
Benthic $\delta^{13} \mathrm{C}$ reached its most depleted levels in 5 million years in both the Pacific and Atlantic during MIS 22 (Raymo et al., 1990; Ferretti et al., 2005; Elderfield et al., 2012). This peak might be caused by the 120 -m sea-level lowstand exposing continental shelves worldwide and accelerating the transport of organic carbon into the oceans, although on a broader time scale, depleted benthic $\delta^{13} \mathrm{C}$ seems to be linked to changes in deep-ocean circulation, either by a decrease in export of NADW or increase in Southern Ocean deep-water production (Elderfield et al., 2012). Indeed, from the western subtropical Atlantic, Ferretti et al. (2005) recorded $\delta^{13} \mathrm{C}$ levels showing almost pure AABW during MIS 22 and 24.

Based on the production of laminated diatom mats in the South Atlantic, Kemp et al. (2010) found that the position of the Antarctic Polar Front had undergone a sustained northward shift starting in MIS 22 that did not return until the termination of MIS 12. Indeed, Schmieder et al. (2000) documented an extreme minimum in carbonate accumulation during MIS 24 in the South Atlantic, which they interpreted as an abrupt reduction in deep-water circulation. Similarly, Marino et al. (2009) reported a nannofossil-barren interval during MIS 24 in the Atlantic sector of the Southern Ocean (ODP Site 1090). They interpreted this as resulting from dissolution by corrosive, bottom-flowing, northward-penetrating Circumpolar Deep Water (CPDW) along with a stagnation of South Atlantic Deep Water circulation during MIS 24 and reduced or suppressed production of North Atlantic Deep Water. During the MIS 23-22 transition, nannofossil assemblage fluctuations reflect strong instability and major changes in oceanic circulation at this time (Marino et al., 2009). Meanwhile, in the southwest Pacific, increased carbonate dissolution and increased sortable silt fraction during MIS 22 attest to vigorous, southern-sourced deep-water ventilation at this time (Crundwell et al., 2008 and references therein). A strong enhancement of Agulhas leakage into the southeastern Atlantic occurs at the termination of MIS 22 (Termination 10, Caley et al., 2012).

Both at North Atlantic DSDP Site 607 and Eastern Mediterranean ODP Site 967 nannofossil assemblages from MIS 22 through to the MIS 22-21 transition record minimum diversity and reflect unstable surface waters (Marino et al., 2008). Similarly, at eastern North Atlantic Site 980/981, the most important nannofossil assemblage changes occur during MIS 22, with MIS 24 representing the first severe cooling of surface waters in the Eastern North Atlantic (Marino et al., 2011). As a presumed response to these changes, Reticulofenestra asanoi has a global and synchronous highest common occurence in MIS 23 (Raffi 2002; Reale and Monechi, 2005; Marino et al., 2011), although this species does not present a clear relationship with glacial-interglacial cycles (Marino et al., 2011). Further north, the nearly barren intervals in foraminifera during MIS 24-22 in the central Arctic Ocean (Cronin et al., 2008) testify to the severity of the glaciation at this time.

At the Gardar Drift in the northern North Atlantic, the highest IRD events occur at glacial terminations 24/23, 22/21 and 20/19 (Hernández-Almeida et al., 2012), with intensification of glacial conditions during MIS 22 and 20 (Hernández-Almeida et al., 2013).

A sustained northward shift of the Antarctic Polar Front starting in MIS 22 will have displaced northwards the mid-latitude westerlies, even during interglacials, thereby preventing full ventilation of the deep ocean and causing a pooling of respired $\mathrm{CO}_{2}$ 
(Toggweiler et al., 2006; Kemp et al., 2010). This postulated northward shift of the midlatitude westerlies may also be related to important changes to the African monsoon system and aridification of North Africa (Kemp et al., 2010). Notwithstanding the cautionary remarks of Larrasoaña et al. (2008), multiproxy evidence including dust flux records from the eastern Mediterranean have been interpreted to show intensified northeast African aridity from $~ 950$ ka (MIS 25) onwards, with further intensification coinciding with a lack of sapropels in the eastern Mediterranean from 930-690 ka (MIS 24-17) (Larrasoaña et al. (2003; Almogi-Labin, 2011).

Evidence for savannah expansion in southern Africa beginning at MIS 24 and 22 provides further support for aridification at this time, and is linked to a reduction in seasurface temperatures and an increase in trade-wind strength (Schefuß et al., 2003, 2005). Eolian dust records from marine cores in the eastern equatorial Atlantic and Arabian Sea have been reported to show increasing African aridity at broadly this time (deMenocal, 2004). However, a re-examination of dust flux records from the eastern Mediterranean Sea, Arabian Sea, off subtropical West Africa, and from East African lakes by Trauth et al. (2009) reveals a more complex pattern affected by different monsoon systems and dust transport paths. They conclude that eccentricity minima lead to weakened monsoon dynamics and aridity in the East African lakes region and Saharo-Arabian desert belt, and that eccentricity maxima lead to alternating strongest and weakest monsoons at precessional cyclicities. Desert and "green Sahara" conditions then alternate at precessional frequencies. Eccentricity maxima at 100- and 400-kyr cycles are independent of the growth of ice sheets during the EMPT and exert an immportant effect on African climate via monsoon dynamics. An eccentricity maximum at around $1 \mathrm{Ma}$ will have provided sharply contrasting alternations of wet and arid conditions, following precessional cycles, that might have stimulated human evolution in east Africa (Trauth et al., 2009).

In the South China Sea, winter monsoons increased at around $900 \mathrm{ka}$, accompanied by a severe drop in SST with temperatures declining from $24-25^{\circ} \mathrm{C}$ to $17-$ $18^{\circ} \mathrm{C}$ in the north and from $26-27^{\circ} \mathrm{C}$ to $23-24^{\circ} \mathrm{C}$ in the south (Li et al., 2008). This represents the first significant decrease in the region for the Quaternary, and implies a contraction of the western Pacific warm pool during this and subsequent glacials.

Thicker and sandier loess deposits representing loess L9 in northern Eurasia are indicative of severe palaeoclimatic conditions and significant increase in winter monsoon activity (Heslop et al. 2002; Dodonov, 2005). On the Chinese Loess Plateau, L9 appears to correlate with MIS 24-20 rather than MIS 24-22 as previously assumed (Jin and Liu, 2011). In the Italian Alps, valley glaciers reached their earliest Pleistocene maximum southward expansion during MIS 22 (Muttoni et al., 2003; Muttoni et al., 2007), while elsewhere on land significant advances occurred (see above).

A significant decline among "extinction group" deep-sea benthic foraminifera at intermediate-water sites during MIS 24-22 has been recorded in the North Atlantic, South Atlantic, SW Pacific Ocean and elsewhere, and coincides with major glaciation (Hayward et al., 2007; Mancin et al., 2013).

On land, the earliest glaciation in northern Europe is represented by limited glaciation in the circum-Baltic region possibly occurring during MIS 22 and 20. Glaciation became established during MIS 22 in the Italian Dolomites and Alpine areas. In North America, widespread lowland glaciation during the EMPT is again first recorded 
during MIS 22 or 20. The paucity of Northern Hemisphere records prior to MIS 22 indicates that world-wide glaciation is effectively a Northern Hemispheric phenomenon.

\section{MIS 21 (866-814 ka)}

Ruddiman et al. (1986) had treated MIS 21 as a single obliquity cycle, Hilgen (1991) assigned it to two obliquity cycles, and Shackleton et al. (1990) and Bassinot et al. (1994) considered it to involve three precession peaks. Its seven presently assigned substages (MIS 21.7-21.7 of Ferretti et al., 2010; MIS 21a-g of Railsback et al., 2015) show additional complexity, with interstadials MIS 21a, c, e, and g being correlated across North Atlantic region (Ferretti et al., 2010). A detailed study of central North Atlantic IODP Site U1313 by Ferretti et al. (2010) for the interval MIS 23-20 seems to reveal the harmonics of precession. This implies the advection of low-latitude precession variations to high northern latitudes, with meridional overturning possibly also involved (Ferretti et al., 2010).

At eastern North Atlantic Site 980/981, high carbonate content, nannofossil assemblages indicative of warm surface waters, and lack of IRD all indicate elevated temperatures for MIS 21 (Marino et al., 2011). Similarly, in the temperate southwest Pacific abrupt warming is recorded in foraminiferal assemblages during MIS 21 (Crundwell et al., 2008).

The MIS 22-21 transition represents a distinctive loess-palaeosol boundary in northern Eurasia that Dodonov (2005) proposed as representing the Early-Middle Pleistocene Subseries boundary. As noted in Head and Gibbard (2005), the MIS 22-21 transition coincides with the base of the following units: the 'Cromerian Complex' Stage of Northwestern Europe, the Tiraspolian mammal Stage of Russia (Dodonov, 2005), the Petropavlovian (Sub)stage of the Russian Plain, and the Neopleistocene Subseries of the Russian Plain (Zhamoida 2004; Gibbard and van Kolfschoten 2004).

\section{MIS 20 (814-790 ka)}

During MIS 20, summer insolation values at $65^{\circ} \mathrm{N}$ were relatively high for a glacial cycle, owing to low precession and eccentricity forcing. Even so, MIS 20 represents a severe if short-lived glacial event. A marginally heavier isotopic maximum is recorded for MIS 20 than for the preceding MIS 22 in the LR04 stack (Lisiecki and Raymo, 2005). This is mirrored by a global sea level fall of about $120 \mathrm{~m}$ below present sea level, which is similar to that for MIS 22 (Elderfield et al., 2012). Independent stratigraphic evidence off Greece supports a severe eustatic drop during MIS 20 that was even lower than the drop in MIS 16 (Anastasakis and Piper, 2013). MIS 20 also conceivably relates to erosion following the major sequence boundary Io 1 identified from seismic stratigraphy and dated at $860 \mathrm{ka}$ (the peak of MIS 21), although the age control is not published (Hardenbol et al, 1998; Snedden and Liu (2010).

At ODP Site 983 just south of Iceland, McClymont et al. (2008) recorded a drop of about $6^{\circ} \mathrm{C}$ in alkenone-based SSTs and simultaneous abrupt increase in a geochemical proxy for Arctic-sourced waters during MIS 20. At the Gardar Drift in the northern North Atlantic, the highest IRD events occur at glacial terminations 24/23, 22/21 and 20/19 (Hernández-Almeida et al., 2012), with an intensification of glacial conditions during MIS 22 and 20 (Hernández-Almeida et al., 2013).

Eastern Mediterranean ODP Site 967 shows significantly increased dust flux 
during 930-690 ka and especially during MIS 20, which coincident with extremely weak precession forcing, suppression of sapropel formation in the Mediterranean during the interval 930-690 ka, and reduced lake levels in east Africa, all imply a weak African monsoon intensity leading to extreme aridity across the northern Sahara Desert at this time (Almogi-Labin, 2011). The most severe and pronounced aridity occurred in northeast Africa during 900-700 ka, whereas the Levant had a more moderate climate (Almogi-Labin, 2011).

A significant decline among "extinction group" deep-sea benthic foraminifera starting in late MIS 21-20 is recorded in the SW Pacific Ocean and elsewhere (Hayward et al., 2007; Mancin et al., 2013).

\section{MIS 19 (790-761 ka)}

Serving as the primary guide to the Early-Middle Pleistocene boundary (Head et al., 2008), the Matuyama-Brunhes Chron boundary appears to lie in the upper part of MIS 19 at around $773 \mathrm{ka}$ (see above). The MIS 20-19 transition is characterised by rapidly lightening of isotopic values (Termination IX), and represents a lowstand-highstand eustatic rise from minus $120 \mathrm{~m}$ to plus $20 \mathrm{~m}$ above present sea level (Elderfield et al., 2012, fig. 4a).

Candy and McClymont (2013, fig. 2) showed a steep gradient in SST of $4.0^{\circ} \mathrm{C}$ during the peak of MIS 19 between $40^{\circ}$ and $57^{\circ} \mathrm{N}$ in the North Atlantic, compared to just $2.1^{\circ} \mathrm{C}$ for the peak of MIS 11. The difference is caused by a southward expansion of polar waters during the interglacials MIS 19-13 compared with those of MIS 11-5.

MIS 19 has been suggested as the closest analogue of the present interglacial in terms of its astronomical and paleoclimatic signatures (Tzedakis et al., 2009; 2012; Tzedakis, 2010). This relates to the lowered amplitude of the $400 \mathrm{kyr}$ eccentricity cycle during MIS 1 and MIS 19, and the consequent suppression of precessional forcing. The phasing between precession and obliquity are very similar between the two stages (obliquity maximum close to the precession minimum), but obliquity increases more rapidly (and hence to a greater amplitude) during the beginning of MIS 1 than for MIS 19, and the LR04 record shows lighter peak values for MIS 1 (Tzedakis, 2010, figs. 6, 7). Also the deglaciation associated with the beginning of MIS 1 is interrupted by the Younger Dryas whereas there is usually no such interruption documented in climate records of the beginning of MIS 19.

Although the early half of MIS 19 (i.e. MIS 19c) shows a single broad peak in the LR04 stack, the EPICA Dome C Antarctic ice core record shows an early peak in $\delta \mathrm{D}$ values. Significantly, three later peaks in atmospheric $\mathrm{CH}_{4}, \delta \mathrm{D}$ values and $\mathrm{CO}_{2}$, beginning at the MIS $19 \mathrm{c}-\mathrm{b}$ boundary, match but are out of phase with peaks in ice-rafted debris and planktonic $\delta^{18} \mathrm{O}$ in North Atlantic ODP Site 983 in the Gardar Drift. In addition, the planktonic $\delta^{18} \mathrm{O}$ and benthic $\delta^{18} \mathrm{O}$ signals at Site 983 are out of phase, with the benthic signal leading. These features all suggest a bipolar seesaw mechanism caused by ice sheet growth and subsequent instability. The onset of this variability, both in the EPICA Dome C ice core and ODP Site 983, is dated at 774.5-772.5 ka and coincides stratigraphically with the Matuyama-Brunhes boundary. Assuming, based on the last glacial inception, that sea-level started falling about $3 \mathrm{kyr}$ before the onset of significant bipolar seesaw variability, then the full interglacial conditions of MIS 19 ended near the summer insolation minimum at $777 \mathrm{ka}$ (Tzedakis et al., 2012). 
From their study of a high-sedimentation-rate $(63 \mathrm{~cm} / \mathrm{kyr})$ core from Osaka Bay, southwest Japan, Kitaba et al. (2013) and Hyodo and Kitaba (2015) recorded in detail the paleovegetational, paleoclimatic, and paleodepth evolution of MIS 19. Hyodo and Kitaba (2015) recorded a 4000 -year time lag of the thermal maximum, as indicated by the relative abundance of Quercus subgen. Cyclobalanopsis pollen, relative to the sea level maximum as inferred from diatom assemblages. They attributed this delay in temperature to increased cloud cover induced by cosmic ray flux, itself resulting from suppressed magnetic field intensity associated with rapid reversals prior to the main Matuyama-Brunhes boundary.

Detailed changes through MIS 19 have also been documented for Montalbano Jonico, a candidate GSSP succession in southern Italy (Marino et al., 2015, Bertini et al., 2015, and Aiello et al., 2015). Here, conditions during MIS 19.3 were similar the present day, whereas drier and possibly cooler conditions are registered for MIS 19.2, along with a lowering of sea level (Marino et al., 2015). In contrast with Osaka Bay, the maximum flooding surface and the thermal maximum are synchronous. With respect to the analogy between MIS 19 and MIS 1, it may be noted that judging from the duration of abundant Quercus in the Montalbano Jonico succession (Marino et al., 2015), the length of full interglacial conditions during MIS 19 was between about 14 and $20 \mathrm{kyr}$ (the uncertainty relating to sample spacing). Both at Montalbano Jonico, and at the other Italian GSSP candidate succession, the Valle di Manche (Capraro et al., 2005; Capraro et al., 2015), the development of mesothermic forest closely follows the overall structure of MIS 19.

In describing the paleoenvironmental evolution of Osaka Bay during MIS 19, Hyodo and Kitaba (2015) emphasized the importance of correctly calibrating the lowstand of MIS 19.2 to the astronomical time scale. This obviously holds for all events in MIS 19 including the age of the Matuyama-Brunhes boundary. A markedly bimodal peak in MIS 19 was first noted by Bassinot et al. (1994) in their study of a core in the tropical Indian Ocean. They labelled the two peaks and intervening trough, from oldest to youngest, as MIS 19.3, 19.2, and 19.1. Although these labels (or their substage counterparts, MIS 19c, b, a) are widely applied, the strongly bimodal peak of Bassinot et al. (1994), which probably represents two precession peaks, is seldom seen. More typically, a single broad peak (MIS 19c) is present, with perhaps one or several small peaks (MIS 19a) occurring near the MIS 19/18 boundary (Railsback et al., 2015) and which seem to represent bipolar seesaw variability (see Tzedakis et al., 2012, above). Hence, these small peaks representing MIS 19a may not be genetically or temporally related to MIS 19.1 described by Bassinot et al. (1994) from the Indian Ocean.

\section{MIS 18 (761-712 ka)}

This represents a two glacial phases, MIS 18e and 18a, separated by a weak interglacial during MIS 18d-b (Railsback et al., 2015).

\section{MIS 17 (712-676 ka)}

Interglacial MIS 17, like MIS 11, has a protracted deglaciation and interglacial values persisting over two insolation peaks. An obliquity maximum and precession minimum being nearly opposite in phase may account for the extended duration of this interglacial (Tzedakis et al., 2012). Nannofossil assemblage data from the Atlantic sector of the 
Southern Ocean (ODP Site 1090) reflect especially warm surface waters and a southward displacement of the subtropical front during MIS 17 (Marino et al., 2009).

\section{MIS 16 (676-621 ka)}

This particularly pronounced glacial cycle, registering the heaviest isotopic values yet seen for the EMPT on the LR04 stack (Lisiecki and Raymo, 2005) and at southwest Pacific ODP Site 1123 (Elderfield et al., 2012), is notable for containing the first Heinrich event in the North Atlantic (Hodell et al., 2008). Heinrich layers are carbonate-rich IRD layers sourced from the Hudson Strait area of eastern Arctic Canada, and also occur frequently in later glacial stages. Hodell et al. (2008) speculated that ice thickness and duration exceeded a critical threshold causing Laurentide Ice Sheet instability in the Hudson Strait region. They noted that MIS 16 set a new pattern for glaciations that were colder and supported larger ice sheets than previously (see above). They noted that iceberg discharge is linked to a weakening of thermohaline circulation in the North Atlantic at this time and throughout the Pleistocene. In fact, widespread lowland glaciation in northern Europe did not begin until MIS 16, and the oldest glaciation identified in the Pyrenees equates with MIS 16 or 14. In North America, widespread lowland glaciation saw major advances beginning in MIS 16.

Pollen records at Tenaghi Philippon in Greece show particularly severe conditions during the glacial maximum of MIS 16, as reflected by a prolonged suppression of the tree population and a long-term change in the forest composition thereafter (Tzedakis et al., 2006).

\section{MIS 15 (621-563 ka)}

As with MIS 17, nannofossil assemblage data from the Atlantic sector of the Southern Ocean (ODP Site 1090) seem to reflect warm surface waters and a southward displacement of the subtropical front at this time (Marino et al., 2009).

\section{MIS 14 (560-530 ka)}

This glacial stage marks the last global extinction event of "extinction group" deep-sea benthic foraminifera (Mancin et al., 2013).

\section{MIS 13 (533-478 ka)}

MIS 13 is associated with an exceptionally strong summer monsoon throughout the Northern Hemisphere (marked by paleosol S5a on the Chinese Loess Plateau), although methane levels as determined from Antarctic ice core records, which are associated with expansion of tropical wetlands, are not particularly high for this interval (Ziegler et al., 2010). Ziegler et al. (2010) noted anomalously high productivity in the Arabian Sea during MIS 13 and proposed that this was related to the onset of intensive Atlantic meridional overturning circulation at the end of the EMPT, rather than an upwelling event associated with a strong summer monsoon.

\section{MIS 12 (478-424 ka)}

MIS 12 is one of the most extreme glacials of the Pleistocene. Together with MIS 16 in the LR04 stack (Lisiecki and Raymo, 2005), and with MIS 22 and 16 at southwestern Pacific ODP Site 1123 (Elderfield et al., 2012), it registers the heaviest oxygen isotopic 
values of any glacial during the EMPT. It also shows unusually large amplitude, highfrequency climate variability (Weirauch et al., 2008 and references therein).

A southwestern Pacific site under the flow of the Deep Western Boundary Current, which sees the passage of $40 \%$ of the world's deep water, registers a major perturbation at MIS 12, implying an important fluctuation in Antarctic Bottom Water production (Venuti et al., 2007). Similarly, a major climatic deterioration is recorded in foraminiferal assemblages during MIS 12 in the temperate southwest Pacific (Crundwell et al., 2008). A strong enhancement of Agulhas leakage into the southeastern Atlantic occurs at the termination of MIS 12 (Termination 5, Caley et al., 2012). In the northern hemisphere, an interval largely barren of foraminifera is documented in the central Arctic Ocean (Cronin et al., 2008). Glaciation of Tibet and Tianshu is not recorded until the Middle Pleistocene, of which the MIS 12 glaciation was the most extensive. In Africa, glaciations were restricted to the East African mountains and the High Atlas, where the major glacial events apparently begin in MIS 12.

Pollen records at Tenaghi Philippon in Greece show MIS 12 as being a particularly severe glacial stage (Tzedakis et al., 2006). Mammoths underwent an important faunal turnover during MIS 12 that led to the formation of the earliest panEurasian Mammoth Fauna (Kahlke, 2014).

\section{MIS 11 (424-374 ka)}

Discussed in detail in Droxler et al. (2003), MIS 11 is one of the longest and warmest interglacials of the past $400 \mathrm{ka}$ (Weirauch et al., 2008), registering among the lightest isotopic values of any interglacial during the Quaternary (Lisiecki and Raymo, 2005). Antarctic ice core records show interglacial levels of atmospheric $\mathrm{CO}_{2}$ and $\delta \mathrm{D}$ all increasing from MIS 11 onwards (Tzedakis et al., 2009), and benthic isotopic values all show greater amplitude of variation beginning with MIS 11 (Lisiecki and Raymo, 2005). Interglacial temperatures in particular increase from MIS 11 onwards, as illustrated particularly in the bottom-water temperatures of the southwest Pacific (Elderfield et al., 2012), although this feature is less obvious when SST records are viewed in the full context of the Pleistocene and may not be observed everywhere (McClymont et al., 2013). It has been supposed that these long-term changes cannot be explained solely by the influence of insolation, and that the climate system therefore had evolved a new response to orbital forcing (McClymont et al., 2013 and references therein). Alternatively, modeling experiments have suggested that there is indeed an insolation impact at $430 \mathrm{ka}$, although interglacials have responded individually to insolation changes (Yin, 2013).

Some astronomical parallels with MIS 1 and MIS 19 relate to weak eccentricityprecession forcing during MIS 11, and similarities with MIS 17 in that both have interglacial values spanning two insolation peaks, and obliquity maxima and precession minima being nearly opposite in phase (Tzedakis et al., 2012). MIS 11 marks a shift of exceptionally high amplitude from the very low isotopic values of MIS 12, although deglaciation was rather protracted. MIS 11 marks the end of what is known as the "midBrunhes event", although Cronin et al. (2008) considered it an extended interval between $\sim 600 \mathrm{ka}$ and $200 \mathrm{ka}$ of global carbonate dissolution that peaked in MIS 11 (Cronin et al., 2008). A strong enhancement of Agulhas leakage into the southeastern Atlantic occurs at the peak of MIS 11, this phenomenon usually coinciding with glacial terminations and 
allowing speculation that the unusually intense interglacial peak of MIS 11 and successive interglacials result from an invigorated AMOC owing to enhanced Agulhas leakage (Cayley et al., 2012).

\section{Conclusions}

The Early-Middle Pleistocene transition (EMPT, previously known as the MidPleistocene Transition or Mid-Pleistocene Revolution) sees a progressive increase in the amplitude of climate oscillations, and a shift towards a quasi-100 kyr frequency that begins at about 1.2 Ma. It is accompanied by additional features reflecting an increasingly non-linear response to orbital forcing, including strong asymmetry in global ice volume cycles and a stepped decrease in the relative durations of interglacials, that begins at $\sim 1.4 \mathrm{Ma}$. This is here taken to mark the beginning of the EMPT. It is considered to terminate at $\sim 420 \mathrm{ka}$ (MIS 12-11 transition), after which Earth's climate experienced much higher-amplitude interglacials than earlier in the EMPT. The EarlyMiddle Pleistocene boundary will be placed at its approximate mid-point, within MIS 19.

Although obliquity forcing is confirmed for the early early Pleistocene, uncertainty exists whether the following quasi-100 kyr cycles represent bundles of 4-5 precession cycles, or 2-3 obliquity cycles. The latter, modifying an existing mode, is simpler to invoke. The precise timing of deglaciations may nonetheless have been influenced by precession cycles, and indirectly by eccentricity as it modulates precession.

However, the orbital parameters are themselves unable to explain the switch in climate state. Some form of amplification or threshold response seems responsible, and a number of mechanisms have been proposed, as follows: (1) secular global cooling trend, (2) long-term decline in atmospheric $\mathrm{CO}_{2}$, (3) progressive regolith erosion, (4) mountain range uplift disrupting long-wave atmospheric flow, (5) accelerated silicate weathering associated with mountain range uplift, (6) uplift of the Greenland-Scotland submarine ridge, (7) dissociation of gas hydrates and release of methane on the continental shelf, (8) expansion of the East Antarctic Ice Sheet, (9) expansion of the West Antarctic Ice Sheet, (10) stochastic processes such as natural oscillatory properties within the Pleistocene climate system, and a phase-space model for Pleistocene ice volume. No one mechanism is predominantly favoured, but we note that in addition to any primary trigger or crossed threshold, multiple feedback mechanisms are likely at work, including ice-sheet growth, deep-water temperature, surface water currents, atmospheric circulation, iron fertilization of the oceans, and interhemispheric teleconnections.

The upper and lower boundaries of the Jaramillo Subchron (within the Jaramillo Chron) and the Jaramillo-Brunhes Chron boundary provide crucial time control when orbitally-tuned records are unavailable or difficult to interpret. A critical appraisal of the literature shows that the commonly cited age of $780 \mathrm{ka}$ for the Jaramillo-Brunhes Chron boundary is too old, and an age of $\sim 773 \mathrm{ka}$ based on a variety of methods is more reliable. This places the Jaramillo-Brunhes boundary in the upper part of MIS 19, above the peak lightest values. The lower and upper boundaries of the Jaramillo Subchron, at 1070 and 988 ka respectively, are rather more consistently represented in the literature.

Chemical remanent magnetization has downwardly displaced paleomagnetic boundaries in many loess-paleosol sequences of the Chinese Loess Plateau, complicating 
efforts to equate these sequences with the marine isotope record. Soil S10 is now considered to correspond to MIS 28, Loess L9 to MIS 24-20, and paleosol S7 to MIS 19.

A characteristic of the EMPT, observed in both lower and higher latitudes, is a long-term cooling trend in SST, and results primarily from increased cooling during glacial stages. It usually begins or intensifies at about 1.2 Ma (MIS 36), coincident with a trend towards increased global ice volume, but predating the first major expansion of continental ice sheets at about $0.9 \mathrm{Ma}$. Quasi-100 ka periodicity in SST and $\delta^{18} \mathrm{O}$ records emerges at 1.2 Ma, and becomes dominant at 0.9 Ma. Individual oceans nonetheless responded differently to the EMPT, the West Pacific Warm Pool for example having stable SSTs throughout, although reducing in size from about $900 \mathrm{ka}$. Early cooling in the northwest Pacific lowered sea-surface temperatures during both glacials and interglacials, and this may have delayed the establishment of the first major ice sheets of the EMPT at around $900 \mathrm{ka}$ (MIS 24-22) through moisture starvation. SST data from the South China Sea show a strengthening of the winter monsoon during glacials also from $900 \mathrm{ka}$, although global evidence from marine records points to the EMPT as being primarily a mid- to high-latitude phenomenon.

The Agulhas Current is the largest western boundary current in the world, and has periodically transferred warm saline surface waters from the Indian Ocean directly into the South Atlantic where it can influence AMOC and hence global climate. This Agulhas leakage has been associated with 17 glacial terminations over the last $1200 \mathrm{kyr}$, and may have influenced the early stages of the EMPT, the intensification of glaciation at $880 \mathrm{ka}$, and the Mid-Brunhes event through enhanced leakage during the interglacial peak of MIS 11 .

Marine records also reveal high-frequency climate variability, which seems to have become more pronounced through and beyond the EMPT, probably reflecting in part the instability of large ice sheets. It occurs during both glacial and interglacial phases, and has been attributed to the influence of precessional forcing (including the harmonics of precession) at low-latitudes, amplification by large polar ice sheets, and bipolar seesaw effects. Interestingly, half-precessional frequency in IRD at a subpolar North Atlantic site implies that high-latitude ice-sheet dynamics are influenced by tropical processes.

Terrestrial sequences are rarely as continuous as those of the deep oceans, but the loess-paleosol deposits from the Chinese Loess Plateau provide an uninterrupted climate record well beyond the EMPT. Dominance of 41-kyr obliquity forcing until $0.9 \mathrm{Ma}$, and strengthening of $\sim 100 \mathrm{kyr}$ cyclicity at $1.2-1.1 \mathrm{Ma}, 0.9 \mathrm{Ma}$, and from $0.64 \mathrm{Ma}$, have been registered and are comparable with the marine record, although the disappearance of $\sim 100$ kyr cyclicity at between $\sim 0.9$ Ma and 0.6 Ma has been attributed to rapid uplift of the Himalaya-Tibetan Plateau above a critical threshold. Enhanced summer (interglacial) and winter (glacial) monsoons are typically registered at steps around 1.3-1.0 Ma and 0.55-0.45 Ma, and climatic evidence across the Chinese Loess Plateau indicates a longterm increase in winter monsoon dominance and drying during this time. The uplift of the Himalaya-Tibetan Plateau and Northern Hemisphere ice sheet development seem to have both controlled long-term trends.

Direct evidence of glaciation is an invaluable climatic proxy. In northern Europe, limited glaciation possibly occurred during MIS 22 and 20, and glaciation became established during MIS 22 in the Italian Dolomites and Alpine areas. However, 
widespread lowland glaciation in northern Europe did not begin until MIS 16. In North America, widespread lowland glaciation is again first recorded during MIS 22 or 20, with subsequent major advances beginning in MIS 16. Glaciation of Tibet and Tianshu is not recorded before the Middle Pleistocene, of which the MIS 12 glaciation was the most extensive. Late uplift of high Asia may explain the apparent delay in glaciation of the Himalayan chain. The repeated records of glaciations during MIS 16 and MIS 12 throughout the world is striking, as is the paucity of Northern Hemisphere records before $900 \mathrm{ka}$ and especially before $\sim 1.2 \mathrm{Ma}$. Until $\sim 1.2 \mathrm{Ma}$ the cold periods (glacials) were apparently not regularly cold and long enough to allow ice-sheet development on a continental scale, outside mountain or polar regions. World-wide glaciation is therefore effectively a Northern Hemispheric phenomenon.

Plant records through the EMPT reveal the effects of increasingly severe glacial stages, especially in Europe where a progressive loss of floristic diversity is recorded. A long pollen record in Greece records particularly severe glaciations during MIS 22, 16, and 12, marked by the contraction of interglacial tree populations and disappearance of Tertiary relict taxa from the area.

The 'end-Villafranchian event' and its transition to the Galerian mammal age represent a major faunal turnover in Europe during the EMPT. It represents an extirpation phase in Italy that began at $\sim 1.4 \mathrm{Ma}$ and culminated $\sim 1.2-1.0 \mathrm{Ma}$, but is marked also by the arrival of large mammals from Asia (e.g., Bison) and Africa (e.g. Hippopotamus), with the genus Homo also being among these dispersals in Europe. Faunal reorganization seems to relate to a climatic transition, with a prevalence of faunal taxa that inhabited open landscape in the early Middle Pleistocene. A comparable shift is seen in western Siberia where the fauna became dominated by the large mammals Mammuthus trogontherii (the steppe mammoth), Bison ex gr. priscus, and Equus mosbachensis, reflecting the development of open landscapes. From 800 ka onwards, Mammuthus trogontherii became the dominant mammoth species across the Palaearctic region, and the pronounced glacial of MIS 12 saw the formation of the earliest panEurasian Mammoth Fauna at $460 \mathrm{ka}$.

The evolution and dispersal of small mammals across the EMPT in Europe and Asia reflects similar trends, and a change in the small mammal fauna in southern Siberia has been attributed to a sharp transition from dry steppe to semi-desert and desert conditions as also seen in the loess-paleosol records.

The genus Homo had already migrated into south-western Europe by around 1.6 Ma, had moved into central France by around 1.1 Ma, and into eastern England by 1.0 $0.73 \mathrm{Ma}$. Signaling advances in cognition and adaptability, retouched artifacts appear in Europe by $\sim 1.0 \mathrm{Ma}$, and Mode 2 artifacts in Europe $~ 700-600$ at around the earliest appearance of Homo heidelbergensis. By around $\sim 500 \mathrm{ka}$, bifacial thinning of tools represents a further technological advance, with the increased social complexities this implied, although firm evidence of human-controlled fire surprisingly does not occur until $\sim 400 \mathrm{ka}$.

In summary, the Early-Middle Pleistocene transition (EMPT), previously known as the Mid-Pleistocene Transition or Mid-Pleistocene Revolution and here taken to represent the interval spanning 1.4-0.4 Ma, represents a fundamental climate shift both in the marine and terrestrial realms, with changes in Earth's climate stage occurring just before the progressive development of quasi-100 kyr cyclicity. An integration of marine 
and terrestrial signals reveals particularly severe cooling events during MIS 38, 36, 24-22 (the "900 ka event"), 16, and 12. Especially pronounced interglacials occur during MIS 31 (a "super-intergalcial"), 25, 21, and MIS 11. Cooling during the EMPT was essentially effected by the increasing duration and severity of cold climate cycles, although it was their severity rather than their duration or the shift to quasi-100 kyr cyclicity that modified the global biota, particularly from $~ 900 \mathrm{ka}$ onwards, by creating a series of environmental filters. This resulted in extinctions, dispersals, and adaptations among the terrestrial fauna, with the constriction and isolation of populations during glaciations stimulating evolution.

The present synthesis has examined the responses to these environmental pressures among the microfossil and geochemical signals in the marine realm, and the terrestrial biota and physical processes on land including glacial deposits and loess sequences. The correspondence between marine and terrestrial responses is striking. However, the marine realm reflects a global climate evolution across the EMPT, whereas for the terrestrial realm this is largely a Northern Hemisphere phenomenon owing to the profound influence of expanding Northern Hemisphere ice sheets. Yet, while the physical and biotic responses to the EMPT are being revealed with ever increasing detail and clarity, the root causes of this critical climate transition remain elusive.

\section{Acknowledgements}

We are grateful to the organisers of the ESF Earthtime-EU Scientific Meeting at Burgos in 2013 for a timely opportunity to exchange ideas about the Early-Middle Pleistocene transition. Mathieu Duval is especially thanked for his patience in waiting for this contribution. MJH acknowledges support from a Natural Sciences and Engineering Research Council of Canada Discovery Grant.

\section{References}

Agustí, J., Blain, H.-A., Cuenca-Bescós, G., Bailon, S., 2009. Climate forcing of first hominid dispersal in Western Europe. Journal of Human Evolution 57, 815-821.

Agustí, J., Blain, H.-A., Furió, M., De Marfá, R., Santos-Cubedo, A., 2010. The early Pleistocene small vertebrate succession from the Orce region (Guadix-Baza Basin, SE Spain) and its bearing on the first human occupation of Europe. Quaternary International 223-224, 162-169.

Agustí, J., Lozano-Fernández, I., Oms, O., Piñero, P., Furió, M., Blain, H.-A., LópezGarcía, J.M., Martínez-Navarro, B., 2015. Early to Middle Pleistocene rodent biostratigraphy of the Guadix-Baza Basin (SE Spain). Quaternary International (in press)

Aiello, G., Barra, D., Parisi, R., 2015. Lower-Middle Pleistocene ostracod assemblages from the Montalbano Jonico section (Basilicata, Southern Italy). Quaternary International (in press). 
Alexeeva, N.V., Erbajeva, M.A. 2005. Fossil mammals and the Pliocene-Pleistocene boundary and Early-Middle Pleistocene transition in the Western Transbaikalia. Quaternary International 131, 109-115.

Almogi-Labin, A., 2011. The paleoclimate of the Eastern Mediterranean during the transition from early to mid Pleistocene (900 to $700 \mathrm{ka}$ ) based on marine and non-marine records: An integrated overview. Journal of Human Evolution 60, 428-436.

Alonso-Garcia, M., Sierro, F.J., Kucera, M., Flores, J.A., Cacho, I., Andersen, N., 2011. Ocean circulation, ice sheet growth and interhemispheric coupling of millennial climate variability during the mid-Pleistocene (ca 800-400 ka). Quaternary Science Reviews 30, 3234-3247.

Anastasakis, G., Piper, D.J.W., 2013. The changing architecture of sea-level lowstand deposits across the Mid-Pleistocene Transition: South Evoikos Gulf, Greece. Quaternary Science Reviews 73, 103-114.

Ao, H., Dekkers, M.J., Qin, L., Xiao, G., 2011. An updated astronomical timescale for the Plio-Pleistocene deposits from South China Sea and new insights into Asian monsoon evolution. Quaternary Science Reviews 30 (2011) 1560-1575.

Arsuaga, J.L., Martínez, I., Arnold, L.J., Aranburu, A., Gracia-Téllez, A., Sharp, W.D., Quam, R.M., Falguères, C., Pantoja-Pérez, A., Bischoff, J., Poza-Rey, E., Parés, J.M., Carretero, J.M., Demuro, M., Lorenzo, C., Sala, N., Martinón-Torres, M., García, N., Alcázar de Velasco, A., Cuenca-Bescós, G., Gómez-Olivencia, A., Moreno, D., Pablos, A., Shen, C.-C., Rodríguez, L., Ortega, A.I., García, R., Bonmatí, A., Bermúdez de Castro, J.M., Carbonell, E., 2014. Neandertal roots: Cranial and chronological evidence from Sima de los Huesos. Science 344, 1358-1363.

Arzarello, M., Marcolini, F., Pavia, G., Pavia, M., Petronio, C., Petrucci, M., Rook, L., Sardella, R., 2009. L'industrie lithique du site Pléistocène inférieur de Pirro Nord (Apricena, Italie du sud): une occupation humaine entre 1,3 et 1,7 Ma. L'Anthropologie $113,47-58$.

Arzarello, M., Pavia, G., Peretto, C., Petronio, C., Sardella, R., 2012. Evidence of an Early Pleistocene hominin presence at Pirro Nord (Apricena, Foggia, southern Italy): P13 site. Quaternary International 267, 56-61.

Ashkenazy, Y., Tziperman, E., 2004. Are the $41 \mathrm{kyr}$ glacial oscillations a linear response to Milankovitch forcing? Quaternary Science Reviews, 23: 1879-1890.

Ashton, N., Lewis, S.G., De Groote, I., Duffy, S.M., Bates, M., Bates, R., Hoare, P., Lewis, M., Parfitt, S.A., Peglar, S., Williams, C., Stringer, C., 2014. Hominin footprints from Early Pleistocene deposits at Happisburgh, UK. PLoS ONE 9(2): e88329.

doi:10.1371/journal.pone.0088329 
Azzaroli, A. 1983. Quaternary mammals and the 'end Villafranchian' dispersal event - a turning point in the history of Eurasia. Palaeogeography, Palaeoclimatology, Palaeoecology, 44, 117-139.

Azzaroli, A., De Giuli, C., Ficcarelli, G., Torre, D. 1988. Late Pliocene to Early MidPleistocene mammals in Eurasia: Faunal succession and dispersal events.

Palaeogeography, Palaeoclimatology, Palaeoecology, 66, 77-100.

Bard, E., Rickaby, R.E.M., 2009. Migration of the subtropical front as a modulator of glacial climate. Nature, 460, 380-384.

Barendregt, R.W., Duk-Rodkin, A., 2011. Chronology and extent of late Cenozoic ice sheets in North America: A magnetostratigraphical assessment. Chapter 32. In: Ehlers, J., Gibbard, P.L., Hughes, P.D. (Eds.), Quaternary Glaciations - Extent and Chronology - A Closer Look. Developments in Quaternary Sciences, Elsevier, vol. 15, pp. 419-426.

Bassinot, F.C., Labeyrie, L.D., Vincent, E., Quidelleur, X., Shackleton, N.J., Lancelot, Y., 1994. The astronomical theory of climate and the age of the Brunhes-Matuyama magnetic reversal. Earth and Planetary Science Letters 126, 91-108.

Bellucci, L., Sardella, R., Rook, L., 2015. Large mammal biochronology framework in Europe at Jaramillo: The Epivillafranchian as a formal biochron. Quaternary International (in press).

Belmaker, M., Tchernov, E., Condemi, S., Bar-Yosef, O., 2002. New evidence for hominid presence in the Lower Pleistocene of the Southern Levant. Journal of Human Evolution 43, 43-56.

Berger, A., Loutre, M.F., 1994. Precession, eccentricity, obliquity, insolation and paleoclimates, In: Duplessy, J.-C., and Spyridakis, M.-T. (eds.), Long-Term Climatic Variations. NATO ASI Series, vol. I22, p. 107-151. Springer-Verlag, Berlin, Heidelberg.

Berger, A., Li, X.S., Loutre, M.F., 1999. Modeling northern hemisphere ice volume over the last 3 Ma. Quaternary Science Reviews 18, 1-11.

Berger, A., Loutre, M.F., Mélice, J.L., 2006. Equatorial insolation: from precession harmonics to eccentricity frequencies. Climate of the Past, 2, 131-136.

Berger, W.H., Jansen, E., 1994. Mid-Pleistocene climate shift - the Nansen Connection. In: The Polar Oceans and Their Role in Shaping the Global Environment. Geophysical Monograph 84, p. 295-311.

Berger, W.H., Bickert, T., Jansen, E., Wefer, G., Yasuda, M., 1994. The central mystery of the Quaternary ice age: a view from the South Pacific. Oceanus 36(4), 53-56. 
Bermúdez de Castro, J.M., Arsuaga, J.L., Carbonell, E., Rosas, A., Martínez, I., Mosquera, M., 1997. A hominid from the lower Pleistocene of Atapuerca, Spain: possible ancestor to Neandertals and modern humans. Science 276, 1392-1395.

Bermúdez de Castro, J.M., Pérez-González, A., Martinón-Torres, M., Gómez-Robles, A., Rosell, J., Prado, L., Sarmiento, S., Carbonell, E., 2008. A new early Pleistocene hominin mandible from Atapuerca-TD6, Spain. Journal of Human Evolution 55, 729-735.

Bermúdez de Castro, J.M., Carretero, J.M., García-González, R., Rodríguez-García, L., Martinón-Torres, M., Rosell, J., Blasco, R., Martín-Francés, L., Modesto, M., Carbonell, E., 2012. Early Pleistocene human humeri from the Gran Dolina-TD6 site (Sierra de Atapuerca, Spain). American Journal of Physical Anthropology 147, 604-617.

Bermúdez de Castro, J.M., Martinón-Torres, M., Blasco, R., Rosell, J., Carbonell, E., 2013. Continuity or discontinuity in the European Early Pleistocene human settlement: the Atapuerca evidence. Quaternary Science Reviews 76, 53-65.

Berner, R. A., Lasaga A. C., Garrels, R. M., 1983. The carbonate-silicate geochemical cycle and its effect on atmospheric carbon dioxide over the past 100 million years. Am. J. Sci. 283, 641-683.

Bertini, A. 2003. Early to Middle Pleistocene changes of the Italian flora and vegetation in the light of a chronostratigraphic framework. Il Quaternario, 16, 19-36.

Bertini, A., Toti, F., Marino, M., Ciaranfi, N., 2015. Vegetation and climate across the Early-Middle Pleistocene transition at Montalbano Jonico, southern Italy. Quaternary International (in press).

Bidegain, J. C., Jurado, S., Chaparro, M. A. E., Gómez Samus, M., Zicarelli, S., Parodi, A. V., 2013. Magnetostratigraphy and environmental magnetism in a Pleistocene sedimentary sequence, Marcos Paz, Argentina. Environ. Earth Sci., 69: 749-763.

Billups, K., Lindley, C., Fisler, J., Martin, P., 2006. Mid Pleistocene climate instability in the subtropical northwestern Atlantic. Global and Planetary Change 54, 251-262.

Bintanja, R., van de Wal1, R.S.W., Oerlemans, J., 2005. Modelled atmospheric temperatures and global sea levels over the past million years. Nature, 437, 125-128.

Bock, M., Schmitt, J., Möller, L., Spahni, R., Blunier, T., and Fischer, H., 2010. Hydrogen isotopes preclude marine hydrate $\mathrm{CH}_{4}$ emissions at the onset of DansgaardOeschger events. Science, 328, 1686-1689.

Boudreau, B.P., 1994. Is burial velocity a master parameter for bioturbation? Geochim. Cosmochim. Acta 58, 1243-1249. 
Boudreau, B.P., 1998. Mean mixed depth of sediments: the wherefore and the why. Limnol. Oceanogr. 43, 524-526.

Butzer, K.W., and Isaac, G.L. (Editors), 1975. After the Australopithecines. Mouton, The Hague, 911 pp.

Byrami, M. L., Newnham, R. M., Alloway, B. V., Pillans, B., Ogden, J., Westgate, J., Mildenhall, D. C., 2005. A late Early Pleistocene tephrochronological and pollen record from Auckland, New Zealand. In: Head, M.J. and Gibbard, P.L. (eds.), Early-Middle Pleistocene transitions: the land-ocean evidence. Geological Society of London, Special Publication 247, p. 183-208.

Caley, T., Giraudeau, J., Malaizé, B., Rossignol, L., Pierre, C., 2012. Agulhas leakage as a key process in the modes of Quaternary climate changes. PNAS, 109 (18), 6835-6839.

Calvet, M., 2004: The Quaternary glaciations of the Pyrenees. In: Ehlers, J. and Gibbard, P. L. (editors): Quaternary Glaciations - Extent and Chronology. Part I, Europe.

Developments in Quaternary Science 2, 119-128. Amsterdam, Elsevier.

Calvet, M., Delmas, M., Gunnell, Y., Braucher, R., Bourlès, D., 2011. Recent advances in research on Quaternary glaciations in the Pyrenees. Chapter 11. In: Ehlers, J., Gibbard, P.L., Hughes, P.D. (Eds.), Quaternary Glaciations - Extent and Chronology - A Closer Look. Developments in Quaternary Sciences, Elsevier, vol. 15, pp. 127-139.

Candy, I., McClymont, E.L., 2013. Interglacial intensity in the North Atlantic over the last 800000 years: investigating the complexity of the mid-Brunhes Event. Journal of Quaternary Science, 28(4), 343-348.

Capraro, L., Asioli, A., Backman, J., Bertoldi, R., Channell, J.E.T., Massari, F., Rio, D., 2005. Climatic patterns revealed by pollen and oxygen isotope records across the Matuyama-Brunhes Boundary in the central Mediterranean (southern Italy). In: M.J. Head and P.L. Gibbard (Editors), Early-Middle Pleistocene transitions: the land-ocean evidence. Geological Society of London, Special Publication 247, pp. 159-182.

Capraro, L., Massari, F., Rio, D., Fornaciari, E., Backman, J., Channell, J.E.T., Macrì, P., Prosser, G., Speranza, F., 2011, Chronology of the Lower-Middle Pleistocene succession of the south-western part of the Crotone Basin (Calabria, Southern Italy). Quaternary Science Reviews 30, 1185-1200.

Capraro, L., Macrì, P., Scarponi, D., Rio, D., Fornaciari, E., 2015. The Lower to Middle Pleistocene Valle di Manche section (Calabria, Southern Italy): state of the art and current advances. Quaternary International (in press).

Carbonell, E., Mosquera, M., 2006. The emergence of a symbolic behaviour: the sepulchral pit of Sima de los huesos, Sierra de Atapuerca, Burgos, Spain. Comptes Rendus Palevol 5 (1-2), 155-160. 
Carbonell, E., Bermúdez de Castro, J.M., Parés, J.M., Pérez-González, A., Ollé, A., Mosquera, M., Cuenca-Bescós, G., García, N., Granger, D.E., Huguet, R., van der Made, J., Martinón-Torres, M., Rodríguez, X.P., Rosas, A., Sala, R., Stock, G.M., Vallverdú, J., Vergés, J.M., Allué, E., Benito, A., Burjachs, F., Cáceres, I., Canals, A., Díez, J.C., Lozano, M., Mateos, A., Navazo, M., Ródríguez, J., Rosell, J., Arsuaga, J.L., 2008. The first hominin of Europe. Nature 452, 465-469.

Clark, P.U., Pollard, D., 1998, Origin of the middle Pleistocene transition by ice sheet erosion of regolith. Paleoceanography, 13 (1), 1-9.

Clark, P.U., Archer, D., Pollard, D., Blum, J.D., Riale, J.A., Brovkin, V., Mix, A.C., Pisias, N.G., Roy, M., 2006. The middle Pleistocene transition: characteristics, mechanisms, and implications for long-term changes in atmospheric $\mathrm{pCO}_{2}$. Quaternary Science Reviews 25, 3150-3184.

Clement, B.R., 2004. Dependence of the duration of geomagnetic polarity reversals on site latitude. Nature, 428, 637-640.

Channell, J.E.T. and Kleiven, H.F., 2000. Geomagnetic palaeointensities and astrochronological ages for the Matuyama-Brunhes boundary and the boundaries of the Jaramillo Subchron: palaeomagnetic and oxygen isotope records from ODP Site 983. Philosophical TransActions of the Royal SocIety, London A, 358, 1027-1047.

Channell, J.E.T., Mazaud, A., Sullivan, P., Turner, S., Raymo, M.E., 2002. Geomagnetic excursions and paleointensities in the Matuyama Chron at Ocean Drilling Program Sites 983 and 984 (Iceland Basin). Journal of Geophysical Research, 107, NO. B6, 101029/2001JB000491, 2002.

Channell, J. E. T., Raymo, M.E., 2003, Paleomagnetic record at ODP Site 980 (Feni Drift, Rockall) for the past 1.2 Myrs, Geochemistry Geophysics Geosystems, 4(4), 1033, doi:10.1029/2002GC000440.

Channell, J.E.T., Curtis, J.H., Flower, B.P., 2004. The Matuyama-Brunhes boundary interval (500-900 ka) in North Atlantic drift sediments. Geophysical Journal International, 158: 489-505.

Channell, J. E. T., D. A. Hodell, C. Xuan, A. Mazaud, and J. S. Stoner (2008), Age calibrated relative paleointensity for the last 1.5 Myr at IODP Site U1308 (North Atlantic), Earth Planet. Sci. Lett., 274, 59-71, doi:10.1016/j.eps1.2008. 07.005.

Channell, J. E. T., D. A. Hodell, B. S. Singer, and C. Xuan, 2010, Reconciling astrochronological and ${ }^{40} \mathrm{Ar} /{ }^{39} \mathrm{Ar}$ ages for the Matuyama-Brunhes boundary and late Matuyama Chron. Geochemistry Geophysics Geosystems, 11, Q0AA12, doi:10.1029/2010GC003203. 
Ciaranfi, N., Lirer, F., Lirer, L., Lourens, L.J., Maiorano, P., Marino, M., Petrosino, P., Sprovieri, M., Stefanelli, S., Brilli, M., Girone, A., Joannin, S., Pelosi, N., Vallefuoco, M., 2010. Integrated stratigraphy and astronomical tuning of the Lower-Middle Pleistocene Montalbano Jonico land section (southern Italy). Quaternary International 210, 109-120.

Clark, P.U., Pollard, D., 1998. Origin of the Middle Pleistocene transition by ice sheet erosion of regolith. Paleoceanography 13, 1-9.

Clark, P. U., Archer, D., Pollard, D., Blum, J. D., Rial, J. A., Brovkin, V., Mix, A. C., Pisias, N. G., and Roy, M., 2006. The middle Pleistocene transition: characteristics, mechanisms, and implications for long-term changes in atmospheric $p \mathrm{CO}_{2}$, Quaternary Science Reviews, 25, 3150-3184, doi:10.1016/j.quascirev.2006.07.008.

Coe, R.S., Singer, B.S., Pringle, M.S., Zhao, X., 2004. Matuyama-Brunhes reversal and Kamikatsura event on Maui: paleomagnetic directions, ${ }^{40} \mathrm{Ar} /{ }^{39} \mathrm{Ar}$ ages and implications. Earth and Planetary Science Letters 222, 667-684.

Cohen, K.M., Gibbard, P.L., 2011. Global chronostratigraphical correlation table for the last 2.7 million years, v. 2011. ICS Subcommission on Quaternary Stratigraphy. URL: http://quaternary.stratigraphy.org/correlation/POSTERSTRAT_v2011.pdf.20110222162627

Cohen, K. M., MacDonald, K., Joordens, J. C. A., Roebroeks, W., and Gibbard, P. L. 2012. 'Earliest occupation of north-west Europe: a coastal perspective'. Quaternary International 271, 70-83.

Colhoun, E.A., Barrows, T.T., 2011. The glaciation of Australia. Chapter 74. In: Ehlers, J., Gibbard, P.L., Hughes, P.D. (Eds.), Quaternary Glaciations - Extent and Chronology A Closer Look. Developments in Quaternary Sciences, Elsevier, vol. 15, pp. 1037-1045.

Coronato, A., Rabassa, J., 2011. Pleistocene glaciations in southern Patagonia and Tierra del Fuego. Chapter 51. In: Ehlers, J., Gibbard, P.L., Hughes, P.D. (Eds.), Quaternary Glaciations - Extent and Chronology - A Closer Look. Developments in Quaternary Sciences, Elsevier, vol. 15, pp. 715-727.

Crochet, J.Y., Welcomme, J.L., Ivorra, J., Ruffet, G., Boulbes, N., Capdevila, R., Claude, J., Firmat, C., Métais, J., Michaux, J., Pickford, M., 2009. Une nouvelle faune de vertébrés continentaux, associée á des artefacts dans le Pléistocéne inférieur de l'Hérault (Sud de la France), vers 1,57 Ma. Comptes Rendus Palevol 8, 725-736.

Cronin, T. M., Smith, S. A., Eynaud, F., O'Regan, M., and King, J., 2008. Quaternary paleoceanography of the central Arctic based on Integrated Ocean Drilling Program Arctic Coring Expedition 302 foraminiferal assemblages, Paleoceanography, 23, PA1S18, doi:10.1029/2007PA001484. 
Crundwell, M., Scott, G., Naish, T., Carter, L., 2008. Glacial-interglacial ocean climate variability from planktonic foraminifera during the Mid-Pleistocene transition in the temperate Southwest Pacific, ODP Site 1123. Palaeogeography, Palaeoclimatology, Palaeoecology 260 (2008) 202-229.

Cuenca-Bescós, G., Rofes, J., López-García, J. M., Blain, H.-A., Rabal-Garcés, R., Sauqué, V., Arsuaga, J. L., Bermúdez de Castro, J. M., and Carbonell, E., 2013. The small mammals of Sima del Elefante (Atapuerca, Spain) and the first entrance of Homo in Western Europe. Quaternary International 295, 28-35.

DeConto, R.M., Pollard, D., Harwood, D., 2007. Sea ice feedback and Cenozoic evolution of Antarctic climate and ice sheets. Paleoceanography 22, PA3214. doi.org/10.1029/2006PA001350.

DeConto, R.M., Pollard, D., Kowalewski, D., 2012. Modeling Antarctic ice sheet and climate variations during Marine Isotope Stage 31. Global and Planetary Change 96-97, 181-188.

de Garidel-Thoron, T., Rosenthal, Y., Bassinot, F., Beaufort, L., 2005. Stable sea surface temperatures in the western Pacific warm pool over the past 1.75 million years. Nature 433, 293-297.

deMenocal, P.B., 2004. African climate change and faunal evolution during the PliocenePleistocene. Earth and Planetary Science Letters 220, 3-24.

De Schepper, S., Gibbard, P.L., Salzmann, U., Ehlers, J., 2014. A global synthesis of the marine and terrestrial evidence for glaciation during the Pliocene Epoch. Earth-Science Reviews 135, 83-102.

Dennell, R., 2003. Dispersal and colonisation, long and short chronologies: how continuous is the Early Pleistocene record for hominids outside East Africa? Journal of Human Evolution 45, 421-440.

Denton, G.H., 2000. Does an asymmetric thermohaline-ice-sheet oscillator drive 100 000-yr glacial cycles? Journal of Quaternary Science, 15: 301-318.

Despriée, J., Voinchet, P., Tissoux, H., Bahain, J.-J., Falguères, C., Courcimault, G., Dépont, J., Moncel, M.-H., Robin, S., Arzarello, M., Sala, R., Marquer, L., Messager, E., Puaud, S., Abdessadok, S., 2011. Lower and Middle Pleistocene human settlements recorded in fluvial deposits of the middle Loire River Basin, Centre Region, France. Quaternary Science Reviews 30, 1474-1485.

Diekmann, B., Kuhn, G. 2002. Sedimentary record of the mid-Pleistocene climate transition in the southeastern South Atlantic (ODP Site 1090). Palaeogeography, Palaeoclimatology, Palaeoecology, 182, 241-258. 
Dinarès-Turell, J., Sagnotti, L., Roberts, A.P. 2002. Relative geomagnetic paleointensity from the Jaramillo Subchron to the Matuyama/Brunhes boundary as recorded in a Mediterranean piston core. Earth and Planetary Science Letters 194, 327-341.

Ding, Z. L., Derbyshire, E., Yang, S. L., Yu, Z. W., Xiong, S. F., and Liu, T. S., 2002. Stacked 2.6-Ma grain size record from the Chinese loess based on five sections and correlation with the deep-sea $\delta^{18}$ O record. Paleoceanography, 17, no. 3, DOI: 1033. 10.1029/2001pa000725.

Ding, Z.L., Derbyshire, E., Yang, S.L., Sun, J.M. and Liu, T.S. 2005 Stepwise expansion of desert environment across northern China in the past 3.5 Ma and implications for monsoon evolution. Earth and Planetary Science Letters, 237, 45-55.

Dodonov, A.E., 2005. The stratigraphic transition and suggested boundary between the Early and Middle Pleistocene in the loess record of northern Eurasia. In: M.J. Head and P.L. Gibbard (Editors), Early-Middle Pleistocene transitions: the land-ocean evidence: Geological Society of London, Special Publication 247, pp. 209-219.

Dreyfus, G.B., Raisbeck, G.M., Parrenin, F., Jouzel, J., Guyodo, Y., Nomade, S., Mazaud, A., 2008. An ice core perspective on the age of the Matuyama-Brunhes boundary. Earth and Planetary Science Letters 274, 151-156.

Droxler, A.W., Poore, R.Z., Burckle, L.H., 2003. Earth's Climate and Orbital Eccentricity: The Marine Isotope Stage 11 Question. American Geophysical Union, Geophysical Monograph Series, Volume 137.

Duk-Rodkin, A., Barendregt, R.W., 2011. Stratigraphical record of glacials/interglacials in Northwest Canada. Chapter 49. In: Ehlers, J., Gibbard, P.L., Hughes, P.D. (Eds.), Quaternary Glaciations - Extent and Chronology - A Closer Look. Developments in Quaternary Sciences, Elsevier, vol. 15, pp. 661-698.

Dupont, L. M., Donner, B., Schneider, R. \& Wefer, G. 2001. Mid-Pleistocene environmental change in tropical Africa began as early as 1.05 Ma. Geology, 29, 195198.

Ehlers, J., Gibbard, P.L., 2003. Extent and chronology of glaciations. Quaternary Science Reviews 22, 1561-1568.

Ehlers, J., Gibbard, P.L. (Eds.) 2004a. Quaternary Glaciations - Extent and Chronology, Part I: Europe. Developments in Quaternary Science, Vol. 2a. Amsterdam, Elsevier.

Ehlers, J., Gibbard, P.L. (Eds.) 2004b. Quaternary Glaciations - Extent and Chronology, Part II: North America. Developments in Quaternary Science, Vol. 2b. Amsterdam, Elsevier. 
Ehlers, J. and Gibbard, P.L. (Eds.) 2004c. Quaternary Glaciations - Extent and Chronology, Part III: South America, Asia, Africa, Australasia, Antarctica. Developments in Quaternary Science, Vol. 2c. Amsterdam, Elsevier.

Ehlers, J., Gibbard, P.L., Hughes, P.D. (Eds.), 2011. Quaternary Glaciations - Extent and Chronology - A Closer Look. Developments in Quaternary Sciences, Elsevier, vol. 15, $1108 \mathrm{pp}$.

Elderfield, H., Ferretti, P., Greaves, M., Crowhurst, S., McCave, I. N., Hodell, D., Piotrowski, A. M. 2012. Evolution of Ocean Temperature and Ice Volume Through the Mid-Pleistocene Climate Transition. Science, 337, 704-709.

Ferretti, P., N. J. Shackleton, D. Rio, and M. A. Hall (2005), Early-Middle Pleistocene deep circulation in the western subtropical Atlantic: southern hemisphere modulation of the North Atlantic Ocean, in Early-Middle Pleistocene Transitions: The Land-Ocean Evidence, edited by M. J. Head and P. L. Gibbard, Geol. Soc. Spec. Publ., 247, 131-145.

Ferretti, P., Crowhurst, S.J., Hall, M.A., Cacho, I., 2010. North Atlantic millennial-scale climate variability 910 to $790 \mathrm{ka}$ and the role of the equatorial insolation forcing. Earth and Planetary Science Letters 293, 28-41.

Ferring, R., Oms, O., Agustí, J., Berna, F., Nioradze, M., Shelia, T., Tappen, M., Vekua, A., Zhvanida, D., Lordkipanidze, D., 2011. Earliest human occupations at Dmanisi (Georgian Caucasus) dated to 1.85-1.78 Ma. Proceedings of the National Academy of Sciences 108, 10432-10436.

Fiebig, M., Ellwanger, D., Doppler, G., 2011. Pleistocene Glaciations of Southern Germany. In: Ehlers, J., Gibbard, P. L. and Hughes, P. D. (editors): Quaternary Glaciations - Extent and Chronology - A Closer Look. Developments in Quaternary Science 15, 163-173.

Flores, J.A., Sierro, F.J., 2007. Pronounced mid-Pleistocene southward shift of the Polar Front in the Atlantic sector of the Southern Ocean. Deep-Sea Research II, 54 (21-22), 2432-2442.

Foronova, I. V. 2005. Large mammal faunas from southwestern Siberia of the PlioPleistocene boundary and Lower/Middle Pleistocene transition. Quaternary International, 131, 95-99.

García, N., Arsuaga, J.L., 2001. Les carnivores (Mammalia) des sites du Pleistocène ancient et moyen d'Atapuerca (Espagne). L'Anthropologie 105, 83-93.

Garcia, J., Landeck, G., Martínez, K., Carbonell, E., 2013. Hominin dispersals from the Jaramillo subchron in central and south-western Europe: Untermassfeld (Germany) and Vallparadís (Spain). Quaternary International 316, 73-93. 
Garcia, J., Martínez, K., Cuenca-Bescós, G., Carbonell, E., 2014. Human occupation of Iberia prior to the Jaramillo magnetochron (>1.07 Myr). Quaternary Science Reviews 98, 84-99.

Gibbard, P.L., 1988. The history of the great north-west European rivers during the past three million years. Philosophical Transactions of the Royal Society of London B318, 559-602.

Gibbard, P.L., Clark, C.D., 2011. Pleistocene glaciation limits in Great Britain. Chapter 7. In: Ehlers, J., Gibbard, P.L., Hughes, P.D. (Eds.), Quaternary Glaciations - Extent and Chronology - A Closer Look. Developments in Quaternary Sciences, Elsevier, vol. 15, pp. $75-93$.

Gibbard, P.L., Head, M.J., 2010. The newly-ratified definition of the Quaternary System/Period and redefinition of the Pleistocene Series/Epoch, and comparison of proposals advanced prior to formal ratification. Episodes, 33: 152-158.

Gibbard, P.L., Lewin, J., 2003. The history of the major rivers of southern Britain during the Tertiary. Journal of the Geological Society 160, 829-845.

Gibbard, P.L., Lewin, J., 2009. River incision and terrace formation in the late Cenozoic of Europe. Tectonophysics 474, 41-55.

Gibbard, P. L. and van Kolfschoten, T. 2004. The Pleistocene and Holocene epochs. In: Gradstein, F. M., Ogg, J. G. \& Smith, A. G. (eds.), A Geologic Time Scale. Cambridge University Press, Cambridge UK, p. 441-452.

Gibbard, P.L., Head, M.J., Walker, M.J.C. and The Subcommission on Quaternary Stratigraphy, 2010. Formal ratification of the Quaternary System/Period and the Pleistocene Series/Epoch with a base at 2.58 Ma. Journal of Quaternary Science, 25(2): 96-102.

Giraudi, C., 2011. Middle Pleistocene to Holocene glaciations in the Italian Apennines. Chapter 17. In: Ehlers, J., Gibbard, P.L., Hughes, P.D. (Eds.), Quaternary Glaciations Extent and Chronology - A Closer Look. Developments in Quaternary Sciences, Elsevier, vol. 15, pp. 211-219.

Graham, A.G.C., Stoker, M.S., Lonergan, L., Bradwell, T., Stewart, M.A., 2011. The Pleistocene glaciations of the North Sea Basin. Chapter 21. In: Ehlers, J., Gibbard, P.L., Hughes, P.D. (Eds.), Quaternary Glaciations - Extent and Chronology - A Closer Look. Developments in Quaternary Sciences, Elsevier, vol. 15, pp. 261-278.

Grützner, J., and S. M. Higgins (2010), Threshold behavior of millennial scale variability in deep water hydrography inferred from a $1.1 \mathrm{Ma}$ long record of sediment provenance at the southern Gardar Drift, Paleoceanography, 25, PA4204, doi:10.1029/2009PA001873. 
Guobyte, R., Satkūnas, J., 2011. Pleistocene glaciations in Lithuania. Chapter 19. In: Ehlers, J., Gibbard, P.L., Hughes, P.D. (Eds.), Quaternary Glaciations - Extent and Chronology - A Closer Look. Developments in Quaternary Sciences, Elsevier, vol. 15, pp. 231-246.

Haidle, M.N., Pawlik, A.F., 2010. The earliest settlement of Germany: Is there anything out there? Quaternary International 223-224, 143-153.

Hayward, B. W., Kawagata, S., Grenfell, H. R., Sabaa, A. T., and O’Neill, T., 2007. Last global extinction in the deep sea during the mid-Pleistocene climate transition.

Paleoceanography, 22, PA3103, doi:10.1029/2007PA001424.

Han, W., Fang, X, Berger, A., 2012. Tibet forcing of mid-Pleistocene synchronous enhancement of East Asian winter and summer monsoons revealed by Chinese loess record. Quaternary Research 78 (2012) 174-184.

Hardenbol, J., J. Thierry, M.B. Farley, T. Jacquin, P.C. de Graciansky, and P. Vail, 1998, Mesozoic and Cenozoic sequence chronostratigraphic framework of European basins, in P.C. Graciansky, et al. (eds) Mesozoic and Cenozoic Sequence Stratigraphy of European Basins: SEPM Special Publication 60, p. 3-13, charts 1-8.

Harrison, S., Glasser, N.F., 2011. The Pleistocene glaciations of Chile. Chapter 54. In: Ehlers, J., Gibbard, P.L., Hughes, P.D. (Eds.), Quaternary Glaciations - Extent and Chronology - A Closer Look. Developments in Quaternary Sciences, Elsevier, vol. 15, pp. 739-756.

Head, M.J., Gibbard, P.L., 2005. Early-Middle Pleistocene transitions: an overview and recommendation for the defining boundary. In: Head, M.J. and Gibbard, P.L. (Eds.), Early-Middle Pleistocene transitions: the land-ocean evidence. Geological Society of London, Special Publication 247, p. 1-18.

Head, M.J., Pillans, B., and Farquhar, S., 2008. The Early-Middle Pleistocene Transition: characterization and proposed guide for the defining boundary. Episodes 31(2): 255-259.

Helmens, K.F., 2011. Quaternary glaciations of Colombia. Chapter 58. In: Ehlers, J., Gibbard, P.L., Hughes, P.D. (Eds.), Quaternary Glaciations - Extent and Chronology - A Closer Look. Developments in Quaternary Sciences, Elsevier, vol. 15, pp. 815-834.

Helmke, J.P., Bauch, H.A., Erlenkeuser, H., 2003. Development of glacial and interglacial conditions in the Nordic seas between 1.5 and 0.35 Ma. Quaternary Science Reviews 22, 1717-1728.

Herbert, T.D., Peterson, L.C., Lawrence, K.T., Liu, Z., 2010. Tropical ocean temperatures over the past 3.5 million years. Science 328, 1530-1534, DOI: $10.1126 /$ science. 1185435 . 
Hernández-Almeida, I., Sierro, F. J., Cacho, I., and Flores, J. A., 2012. Impact of suborbital climate changes in the North Atlantic on ice sheet dynamics at the MidPleistocene Transition. Paleoceanography 27, PA3214, doi:10.1029/2011PA002209.

Hernández-Almeida, I., Sierro, F. J., Flores, J.-A., Cacho, I., Filippelli, G. M. 2013. Palaeoceanographic changes in the North Atlantic during the Mid-Pleistocene Transition (MIS 31-19) as inferred from planktonic foraminiferal and calcium carbonate records. Boreas 42, 140-159. 10.1111/j.1502-3885.2012.00283.x.

Heslop, D., Dekkers, M.J., Langereis, C.G., 2002. Timing and structure of the midPleistocene transition: records from the loess deposits of northern China. Palaeogeography, Palaeoclimatology, Palaeoecology 185, 133-143.

Hilgen, F.J., 1991. Astronomical calibration of Gauss to Matuyama sapropels in the Mediterranean and implication for the Geomagnetic Polarity Time Scale, Earth and Planetary Science Letters 104, 226-244.

Hilgen, F.J., Lourens, L.J., and Van Dam, J.A., 2012. The Neogene Period. In: Gradstein, F.M., Ogg, J.G., Schmitz, M., and Ogg, G., eds., The Geologic Time Scale 2012, vol. 2, Elsevier, Amsterdam, p. 923-978.

Hillson, S.W. Parfitt, S.A. Bello, S.M. Roberts, M.B. Stringer, C.B., 2010. Two hominin incisor teeth from the middle Pleistocene site of Boxgrove, Sussex, England. Journal of Human Evolution 59, 493-503.

Hodell, D. A., Channell, J. E. T., Curtis, J. H., Romero, O. E. and Röhl, U., 2008. Onset of "Hudson Strait" Heinrich events in the eastern North Atlantic at the end of the middle Pleistocene transition ( $640 \mathrm{ka})$ ? Paleoceanography, 23, PA4218, doi:10.1029/2008PA001591.

Hönisch, B., Hemming, N. G., Archer, D., Siddall, M., McManus, J. F., 2009. Atmospheric carbon dioxide concentration across the mid-Pleistocene Transition. Science, 324: 1551-1554.

Horng, C.-S., Lee, M.-Y., Pälike, H., Wei, K.-Y., Liang, W.-T., Iizuka, Y., and Torii, M., 2002. Astronomically calibrated ages for geomagnetic reversals within the Matuyama chron. Earth Planets Space, 54, 679-690.

Houmark-Nielsen, M., 2011. Pleistocene glaciations in Denmark: A closer look at chronology, ice dynamics and landforms. Chapter 5. In: Ehlers, J., Gibbard, P.L., Hughes, P.D. (Eds.), Quaternary Glaciations - Extent and Chronology - A Closer Look. Developments in Quaternary Sciences, Elsevier, vol. 15, pp. 47-58.

Huybers, P., 2006. Early Pleistocene glacial cycles and the integrated summer insolation forcing. Science, 313, 508-511. 
Huybers, P., 2007. Glacial variability over the last two million years: an extended depthderived agemodel, continuous obliquity pacing, and the Pleistocene progression. Quaternary Science Reviews 26 (2007) 37-55.

Huybers, P., 2011. Combined obliquity and precession pacing of late Pleistocene deglaciations. Nature, 480, 229-232.

Hyodo, M., Biswas, D. K., Noda, T., Tomioka, N., Mishima, T., Itota, C., and Sato, H. 2006. Millennial- to submillennial-scale features of the Matuyama-Brunhes geomagnetic polarity transition from Osaka Bay, southwestern Japan. Journal of Geophysical Research, 111, B02103, doi:10.1029/2004JB003584.

Hyodo, M., Kitaba, I., 2015 Timing of the Matuyama-Brunhes geomagnetic reversal: decoupled thermal maximum and sea-level highstand during Marine Isotope Stage 19. Quaternary International.

Imbrie, J. and Imbrie, J.Z., 1980. Modeling the climatic response to orbital variations. Science, 207, 943-953.

Imbrie, J.Z., Imbrie-Moore, A., Lisiecki, L.E., 2011. A phase-space model for Pleistocene ice volume. Earth and Planetary Science Letters, 307: 94-102.

Jin, C.S., and Liu, Q.S., 2011. Remagnetization mechanism and a new age model for L9 in Chinese loess. Physics of the Earth and Planetary Interiors 187, 261-275.

Jin, C., Liu, Q. and Larrasoaña, J.C., 2012. A precursor to the Matuyama-Brunhes reversal in Chinese loess and its palaeomagnetic and stratigraphic significance. Geophysical Journal International, 190, 829-842.

Jin, H., Jian, Z., 2013. Millennial-scale climate variability during the mid-Pleistocene transition period in the northern South China Sea. Quaternary Science Reviews 70, 1527.

Johansson, P., Lunkka, J.P., Sarala, P., 2011. The glaciation of Finland. Chapter 9. In: Ehlers, J., Gibbard, P.L., Hughes, P.D. (Eds.), Quaternary Glaciations - Extent and Chronology - A Closer Look. Developments in Quaternary Sciences, Elsevier, vol. 15, pp. 105-116.

Kahlke, R.-D., García, N., Kostopoulos, D.S., Lacombat, F., Lister, A.M., Mazza, P.P.A., Spassov, N., Titov, V.V., 2011. Western Palaearctic palaeoenvironmental conditions during the Early and early Middle Pleistocene inferred from large mammal communities, and implications for hominin dispersal in Europe. Quaternary Science Reviews 30, $1368-1395$.

Kahlke, R.-D., 2014. The origin of Eurasian mammoth faunas (Mammuthus-Coelodonta Faunal Complex). Quaternary Science Reviews 96, 32-49. 
Kalm, V., Raukas, A., Rattas, M., Lasberg, K., 2011. Pleistocene glaciations in Estonia. Chapter 8. In: Ehlers, J., Gibbard, P.L., Hughes, P.D. (Eds.), Quaternary Glaciations Extent and Chronology - A Closer Look. Developments in Quaternary Sciences, Elsevier, vol. 15, pp. 95-104.

Karabanov, A.K., Matveyev, A.V., 2011. The Pleistocene glaciations in Belarus. Chapter 3. In: Ehlers, J., Gibbard, P.L., Hughes, P.D. (Eds.), Quaternary Glaciations - Extent and Chronology - A Closer Look. Developments in Quaternary Sciences, Elsevier, vol. 15, pp. 29-35.

Kazaoka, O., Suganuma, Y., Okada, M., Kameo, K., Head, M.J., Yoshida, T., Kameyama, S., Nirei, H., Aida, N., Kumai, H., 2015. Stratigraphy of the Kazusa Group, Boso Peninsula: an expanded and highly-resolved marine sedimentary record from the Lower and Middle Pleistocene of Central Japan. Quaternary International.

Kemp, A.E.S., Grigorov, I., Pearce, R.B., Naveira Garabato, A.C., 2010. Migration of the Antarctic Polar Front through the mid-Pleistocene transition: evidence and climatic implications. Quaternary Science Reviews 29, 1993-2009.

Kennett, J. P., Cannariato, K. G., Hendy, I. L., Behl, R.J., 2003. Methane hydrates in Quaternary climate change. The Clathrate Gun Hypothesis. American Geophysical Union, Washington D.C., p. i-vii, 1-217.

Kitaba, I., Hyodo, M., Katoh, S., Dettman, D.L., Sato, H., 2013. Midlatitude cooling caused by geomagnetic field minimum during polarity reversal. PNAS, 110 (4), 12151220.

Kitamura, A., Kawagoe, T., 2006. Eustatic sea-level change at the Mid-Pleistocene climate transition: new evidence from the shallow-marine sediment record of Japan. Quaternary Science Reviews 25, 323-335.

Kleiven, H.F, Jansen, E., Curry, W.B., Hodell, D.A. \& Venz, K.A. 2003. Atlantic Ocean thermohaline circulation changes on orbital to suborbital timescales during the midPleistocene. Paleoceanography, 18(1), 1008. DOI: 10.1029/2001PA000629.

Kutzbach, J.E., Guetter, P.J., Ruddiman, W.F., Prell, W.L., 1989. Sensitivity of climate to Late Cenozoic Uplift in Southern Asia and the American West: numerical experi- ments. Journal of Geophysical Research-Atmospheres 94, 18393-18407.

Landeck, G., Garcia, J., 2015. Jaramillo hominin presence at Untermassfeld (Thuringia, Germany) - Or the struggle against the early 20th century "Mauer mandible paradigm": Reply to M. Baales (2014). Quaternary International 355, 169-171.

Lang, N, and Wolff, E.W., 2011. Interglacial and glacial variability from the last $800 \mathrm{ka}$ in marine, ice and terrestrial archives. Climate of the Past, 7, 361-380. 
Larrasoaña, J.C., Roberts, A.P., Rohling, E.J., Winklhofer, M., Wehausen, R., 2003. Three million years of monsoon variability over the northern Sahara. Clim. Dyn. 21 (78), 689-698.

Larrasoaña, J.C., Roberts, A.P., Rohling, E.J., 2008. Magnetic susceptibility of eastern Mediterranean marine sediments as a proxy for Saharan dust supply? Marine Geology 254, 224-229.

Lawrence, K.T., Sosdian, S., White, H.E., Rosenthal, Y., 2010. North Atlantic climate evolution through the Plio-Pleistocene climate transitions. Earth and Planetary Science Letters 300, 329-342.

Lee, J.R., Rose, J., Hamblin, R.J.O., Moorlock, B.S.P., Riding, J.B., Phillips, E., Barendregt, R.W., Candy, I., 2011. The glacial history of the British Isles during the Early and Middle Pleistocene: Implications for the long-term development of the British Ice Sheet. Chapter 6. In: Ehlers, J., Gibbard, P.L., Hughes, P.D. (Eds.), Quaternary Glaciations - Extent and Chronology - A Closer Look. Developments in Quaternary Sciences, Elsevier, vol. 15, pp. 59-74.

Leonhardt, R., and K. Fabian (2007), Paleomagnetic reconstruction of the global geomagnetic field evolution during the Matuyama/Brunhes transition: Iterative Bayesian inversion and independent verification, Earth Planet. Sci. Lett., 253, 172-195, doi:10.1016/j.epsl.2006.10.025.

Lewis, M.E., Werdelin, L., 2010. Carnivoran dispersal out of Africa during the Early Pleistocene: relevance for hominins? In: Fleagle, J.G., Shea, J.J., Grine, F.E., Baden, A.L., Leakey, R.E. (Eds.), Out of Africa I: The First Hominin Colonization of Eurasia. Springer, Dordrecht, pp. 13-26.

Li, Q., Wang, P., Zhao, Q., Tian, J, Cheng, X., Jian, Z., Zhong, G., Chen, M., 2008. Paleoceanography of the mid-Pleistocene South China Sea. Quaternary Science Reviews 27 (2008) 1217-1233.

Liu, W.M., and Zhang, L.Y., 2013. Chemical magnetization in Chinese loess. Physics of the Earth and Planetary Interiors 218, 14-18.

Liu, W.M., Zhang, L.Y., and Sun, J.M., 2010. High resolution magnetostratigraphy of the Luochuan loess-paleosol sequence in the central Chinese Loess Plateau. Chinese Journal of Geophysics, 53(4), 888-894 [In Chinese with English abstract]

Liu, Q., Roberts, A. P., Rohling, E.J., Zhu, R., Sun, Y., 2008. Post-depositional remanent magnetization lock-in and the location of the Matuyama-Brunhes geomagnetic reversal boundary in marine and Chinese loess sequences. Earth and Planetary Science Letters $275,102-110$. 
Liu, Z., Cleaveland, L.C., Herbert, T.D., 2008. Early onset and origin of 100-kyr cycles in Pleistocene tropical SST records. Earth and Planetary Science Letters 265, 703-715.

Lisiecki, L. E., 2010. Links between eccentricity forcing and the 100,000-year glacial cycle. Nature Geoscience, 3: 349-352.

Lisiecki, L.E., and Raymo, M.E., 2005. A Pliocene-Pleistocene stack of 57 globally distributed benthic $\square^{18} \mathrm{O}$ records. Paleoceanography, 20, PA1003, doi:10.1029/2004PA001071.

Lisiecki, L. E., and Raymo, M. E., 2007. Plio-Pleistocene climate evolution: trends and transitions in glacial cycle dynamics. Quaternary Science Reviews 26 (2007) 56-69

Lisiecki, L. E., and M. E. Raymo (2009), Diachronous benthic $\delta^{18}$ O responses during late Pleistocene terminations, Paleoceanography, 24, PA3210, doi:10.1029/2009PA001732.

López-García, J.M., Luzi, E., Berto, C., Peretto, C., Arzarello, M., 2015. Chronological context of the first hominin occurrence in southern Europe: the Allophaiomys ruffoi (Arvicolinae, Rodentia, Mammalia) from Pirro 13 (Pirro Nord, Apulia, southwestern Italy). Quaternary Science Reviews 107, 260-266.

Lordkipanidze, D., Vekua, A., Ferring, R., Rightmire, G.P., Agusti, J., Kiladze, G., Mouskhelishvili, A., Nioradze, M., Ponce de León, M.S., Tappen, M., Zollikofer, C.P.E., 2005. The earliest toothless hominin skull. Nature 434, 717-718.

Lordkipanidze, D., Jashashvili, T., Vekua, A., Ponce de León, M.S., Zollikofer, C.P.E., Rightmire, G.P., Pontzer, H., Ferring, R., Oms, O., Tappen, M., Bukhsianidze, M., Agustí, J., Kahlke, R., Kiladze, G., Martínez-Navarro, B., Mouskhelishvili, A., Nioradze, M., Rook, L., 2007. Postcranial evidence from early Homo from Dmanisi, Georgia. Nature 449, 305-310.

Lordkipanidze, D., Ponce de León, M.S., Margvelashvili, A., Rak, Y., Rightmire, G.P., Vekua, A., Zollikofer, C.P.E., 2013. A complete skull from Dmanisi, Georgia, and the evolutionary biology of early Homo. Science, 342, 326-331.

Lourens, L.J., 2004. Revised tuning of Ocean Drilling Program Site 964 and KC01B (Mediterranean) and implications for the $\delta^{18} \mathrm{O}$, tephra, calcareous nannofossil, and geomagnetic reversal chronologies of the past 1.1 Myr. Paleoceanography, 19, PA3010, doi:10.1029/2003PA000997, 2004.

Lourens, L., Hilgen, F., Shackleton, N.J., Laskar, J., and Wilson, J., 2005a. Appendix 2. Orbital tuning calibrations and conversions for the Neogene Period. In: Gradstein, F.M., Ogg, J.G. and Smith, A.G., eds., A geologic time scale 2004. Cambridge University Press, Cambridge, p. 469-484 [Imprinted 2004]. 
Lourens, L., Hilgen, F., Shackleton, N.J., Laskar, J., and Wilson, J., 2005b. The Neogene Period. In: Gradstein, F.M., Ogg, J.G. and Smith, A.G., eds., A geologic time scale 2004. Cambridge University Press, Cambridge, p. 409-440 [Imprinted 2004].

Lozano-Fernández, I., Blain, H.-A., López-García, J.M., and Agustí, J., 2014. Biochronology of the first hominid remains in Europe using the vole Mimomys savini: Fuente Nueva 3 and Barranco León D, Guadix-Baza Basin, south-eastern Spain. Historical Biology: An International Journal of Paleobiology, DOI: 10.1080/08912963.2014.920015.

Lunkka, J.-P. et al., 2011. To be supplied.

Maasch, K.A., 1988; Statistical detection of the mid-Pleistocene transition. Climate Dynamics, 2:133-143.

Maasch, K.A., and Saltzman, B., 1990. A low-order dynamical model of global climatic variability over the full Pleistocene. Journal of Geophysical Research, 95 (D2), 19551963.

Magri, D., Palombo, M.R., 2013. Early to Middle Pleistocene dynamics of plant and mammal communities in South West Europe. Quaternary International 288, 63-72.

Maher, B.A., Mutch, T.J., Cunningham, D., 2009. Magnetic and geochemical characteristics of Gobi Desert surface sediments: implications for provenance of the Chinese Loess Plateau. Geology 37, 279-282.

Maiorano, P., Marino, M., Flores, J.-A., 2009. The warm interglacial Marine Isotope Stage 31: Evidences from the calcareous nannofossil assemblages at Site 1090 (Southern Ocean). Marine Micropaleontology 71, 166-175.

Malaizé, B., Jullien, E., Tisserand, A., Skonieczny, C., Grousset, E.F., Eynaud, F., Kissel, C., Bonnin, J., Karstens, S., Martinez, P., Bory, A., Bout-Roumazeilles, V., Caley, T., Crosta, X., Charlier, K., Rossignol, L., Flores, J.-A., Schneider, R., 2012. The impact of African aridity on the isotopic signature of Atlantic deep waters across the Middle Pleistocene Transition. Quaternary Research 77, 182-191.

Mancin, N., Hayward, B.W., Trattenero, I., Cobianchi, M., Lupi, C., 2013. Can the morphology of deep-sea benthic foraminifera reveal what caused their extinction during the mid-Pleistocene Climate Transition? Marine Micropaleontology 104, 53-70.

Manzi, G., Mallegni, F. and Ascenzi, A. 2001. A cranium for the earliest Europeans: Phylogenetic position of the hominid from Ceprano, Italy. Proceedings of the National Academy of Sciences of the United States of America 98, 10011-10016.

Markova, A.K., 2005. Eastern European rodent (Rodentia, mammalia) faunas from the Early-Middle Pleistocene transition. Quaternary International 131, 71-77. 
Marks, L., 2011. Quaternary glaciations in Poland. Chapter 23. In: Ehlers, J., Gibbard, P.L., Hughes, P.D. (Eds.), Quaternary Glaciations - Extent and Chronology - A Closer Look. Developments in Quaternary Sciences, Elsevier, vol. 15, pp. 299-303.

Marino, M., Maiorano, P., Lirer, F., 2008. Changes in calcareous nannofossil assemblages during the Mid-Pleistocene Revolution. Marine Micropaleontology 69, 7090.

Marino, M., Maiorano, P., Lirer, F., Pelosi, N., 2009. Response of calcareous nannofossil assemblages to paleoenvironmental changes through the mid-Pleistocene revolution at Site 1090 (Southern Ocean). Palaeogeography, Palaeoclimatology, Palaeoecology 280, 333-349.

Marino, M., Maiorano, P., Flower, B. P., 2011. Calcareous nannofossil changes during the Mid-Pleistocene Revolution: Paleoecologic and paleoceanographic evidence from North Atlantic Site 980/981. Palaeogeography, Palaeoclimatology, Palaeoecology 306, 58-69.

Marino, M., Bertini, A., Ciaranfi, N., Aiello, G., Barra, D., Gallicchio, S., Girone, A., La Perna, R., Lirer, F., Maiorano, P., Petrosino, P., Toti, F., 2015. Paleoenvironmental and climatostratigraphic insights for Marine Isotope Stage 19 (Pleistocene) at the Montalbano Jonico succession, South Italy. Quaternary International (in press).

Martínez, O., Coronato, A., Rabassa, J., 2011. Pleistocene glaciations in northern Patagonia, Argentina: An Updated Review. Chapter 52. In: Ehlers, J., Gibbard, P.L., Hughes, P.D. (Eds.), Quaternary Glaciations - Extent and Chronology - A Closer Look. Developments in Quaternary Sciences, Elsevier, vol. 15, pp. 729-734.

Martínez-Garcia, A., Rosell-Melé, A., Jaccard, S. L., Geibert, W., Sigman, D. M. \& Haug, G. H. 2011. Southern Ocean dust-climate coupling over the past four million years. Nature, 476, 312-315.

Martínez-Navarro, B., 2010. Early Pleistocene faunas of Eurasia and hominin dispersals. In: Fleagle, J.G., Shea, J.J., Grine, F.E., Baden, A.L., Leakey, R.E. (Eds.), Out of Africa I: The First Hominin Colonization of Eurasia. Springer, Dordrecht, pp. 207-224.

Martínez-Navarro, B., Belmaker, M., Bar-Yosef, O., 2009. The large carnivores from 'Ubeidiya' (early Pleistocene, Israel): biochronological and biogeographical implications. Journal of Human Evolution 56, 514-524.

Maslin, M.A., and Ridgwell, A.J., 2005. Mid-Pleistocene revolution and the 'eccentricity myth'. In: M.J. Head and P.L. Gibbard (Editors), Early-Middle Pleistocene transitions: the land-ocean evidence. Geological Society of London, Special Publication 247: 19-34. 
Maslin, M.A., Seidov, D., Lowe, J., 2001. Synthesis of the nature and causes of sudden climate transitions during the Quaternary In: Seidov, D., Haupt, B., and Maslin, M.A. (eds) The Oceans and Rapid Climate Change: Past, Present and Future. AGU Geophysical Monograph Series, 126, 9-52.

Maslin, M.A. Brierley, C.M., Milner, A.M., Shultz, S., Trauth, M.H., Wilson, K.E., 2014. East African climate pulses and early human evolution. Quaternary Science Reviews $101,1-17$.

Masson-Delmotte, V., Stenni, B., Pol, K., Braconnot, P., Cattani, O., Falourd, S., Kageyama, M., Jouzel, J., Landais, A., Minster, B., Barnola, J.M., Chappellaz, J., Krinner, G., Johnsen, S., Röthlisberger, R., Hansen, J., Mikolajewicz, U., Otto-Bliesner, B., 2010. EPICA Dome C record of glacial and interglacial intensities. Quaternary Science Reviews 29, 113-128.

Maul, L.C., Masini, F., Parfitt, S.A., Rekovets, L., Savorelli, A., 2014. Evolutionary trends in arvicolids and the endemic murid Mikrotia - New data and a critical overview. Quaternary Science Reviews 96, 240-258.

McClymont, E.L., Rosell-Mele, A., Haug, G.H., Lloyd, J.M., 2008. Mid-Pleistocene expansion of subarctic water masses in the northern Atlantic and Pacific Oceans and their potential modulation of northern hemisphere ice-sheet growth. Paleoceanography. doi.org/10.1029/2008PA001622.

McClymont, E.L., Sosdian, S.M., Rosell-Melé, A., Rosenthal, Y., 2013. Pleistocene seasurface temperature evolution: Early cooling, delayed glacial intensification, and implications for the mid-Pleistocene climate transition. Earth-Science Reviews 123, 173193.

Medina-Elizalde, M., Lea, D.W., 2005. The Mid-Pleistocene transition in the tropical Pacific. Science 310, 1009-1012.

Ménabréaz, L., Thouveny, N., Bourlès, D. L., Vidal, L., 2014. The geomagnetic dipole moment variation between 250 and $800 \mathrm{ka} \mathrm{BP}$ reconstructed from the authigenic ${ }^{10} \mathrm{Be} /{ }^{9} \mathrm{Be}$ signature in West Equatorial Pacific sediments. Earth and Planetary Science Letters, 385, 190-205.

Mertens, K.N., Takano, Y., Head, M.J., and Matsuoka, K. 2014. Living fossils in the Indo-Pacific warm pool: A refuge for thermophilic dinoflagellates during glaciations. Geology, 42: 531-534, doi:10.1130/G35456.1.

Meyer, M., Fu, Q., Aximu-Petri, A., Glocke, I., Nickel, B., Arsuaga, J.-L., Martínez, I., Gracia, A., Bermúdez de Castro, J.M., Carbonell, E., Pääbo, S., 2014. A mitochondrial genome sequence of a hominin from Sima de los Huesos. Nature 505, 403-406. 
Meyers, S.R., and Hinnov, L.A., 2010. Northern Hemisphere glaciation and the evolution of Plio- Pleistocene climate noise. Paleoceanography, 25, PA3207, doi:10.1029/2009PA001834.

Milliken, S., 1999. The earliest occupation of Italy. Accordia 7, 7-36.

Mochizuki, N., H. Oda, O. Ishizuka, T. Yamazaki, and H. Tsunakawa, 2011, Paleointensity variation across the Matuyama-Brunhes polarity transition: Observations from lavas at Punaruu Valley, Tahiti. Journal of Geophysical Research, 116, B06103, doi:10.1029/2010JB008093.

Möller, L., Sowers, T., Bock, M., Spahni, R., Behrens, M., Schmitt, J., Miller, H. and Fischer, H., 2013. Independent variations of $\mathrm{CH}_{4}$ emissions and isotopic composition over the past 160,000 years. Geoscience Nature, 6, 885-890. doi: 10.1038/ngeo1922

Mounier, A., Condemi, S., Manzi, G., 2011. The Stem Species of Our Species: A Place for the Archaic Human Cranium from Ceprano, Italy. PLoS ONE 6(4): e18821.

doi:10.1371/journal.pone.0018821

Mudelsee, M., Schulz, M., 1997. The mid-Pleistocene climate transition: onset of $100 \mathrm{ka}$ cycle lags ice volume build-up by $280 \mathrm{ka}$. Earth and Planetary Science Letters 151, 117123.

Mudelsee, M., Stattegger, K., 1997. Exploring the structure of the mid-Pleistocene Revolution with advanced methods of time-series analysis. Geologische Rundschau 86, 499-511.

Muttoni, G., Carcano, C., Garzanti, E., Ghielmi, M., Piccin, A., Pini, R., Rogledi, S., Sciunnach, D., 2003. Onset of major Pleistocene glaciations in the Alps. Geology 31, 989-992.

Muttoni, G., Ravazzi, C., Breda, M., Pini, R., Laj, C., Kissel, K., Mazaud, A., Garzanti, E., 2007. Magnetostratigraphic dating of an intensification of glacial activity in the southern Italian Alps during Marine Isotope Stage 22. Quaternary Research 67, 161-173.

Muttoni, G., Scardia, G., Kent, D.V., Swisher, C.C., Manzi, G., 2009. Pleistocene magnetochronology of early hominin sites at Ceprano and Fontana Ranuccio, Italy. Earth and Planetary Science Letters 286, 255-268.

Naish, T., Powell, R., Levy, R., Wilson, G. and 52 others, 2009. Obliquity-paced, Pliocene West Antarctic Ice Sheet oscillations. Nature 458, 322-328.

Nomade, S., Muttoni, G., Guillou, H., Robin, E., Scardia, G., 2011. First ${ }^{40} \mathrm{Ar} /{ }^{39} \mathrm{Ar}$ age of the Ceprano man (central Italy). Quaternary Geochronology 6, 453-457. 
Nývlt, D., Engel, Z., Tyráček, J., 2011. Pleistocene glaciations of Czechia. Chapter 4. In: Ehlers, J., Gibbard, P.L., Hughes, P.D. (Eds.), Quaternary Glaciations - Extent and Chronology - A Closer Look. Developments in Quaternary Sciences, Elsevier, vol. 15, pp. $37-46$.

Ollé, A., Mosquera, M., Rodríguez, X.P., de Lombera-Hermida, A., García-Antón, M.D., García-Medrano, P., Peña, L., Menéndez, L., Navazo, M., Terradillos, M., Bargalló, A., Márquez, B., Sala, R., Carbonell, E., 2013. The Early and Middle Pleistocene technological record from Sierra de Atapuerca (Burgos, Spain). Quaternary International 295, 138-167.

O’Regan, H. J., Turner, A. \& Wilkinson, D. M. 2002. European Quaternary refugia: a factor in large carnivore extinction? Journal of Quaternary Science, 17, 789-795.

O’Regan, H.J., Bishop, L.C., Lamb, A., Elton, S., Turner, A., 2005. Large mammal turnover in Africa and the Levant between 1.0 and 0.5 Ma In: Head, M.J. and Gibbard, P.L. (eds.), Early-Middle Pleistocene transitions: the land-ocean evidence. Geological Society of London, Special Publication 247, 231-249.

O’Regan, H.J., Turner, A., Bishop, L.C., Elton, S., Lamb, A.L., 2011. Hominins without fellow travellers? First appearances and inferred dispersals of Afro-Eurasian largemammals in the Plio-Pleistocene. Quaternary Science Reviews 30, 1343-1352.

Ottesen, D., Dowdeswell, J. A., and Bugge, T., 2014. Morphology, sedimentary infill and depositional environments of the early Quaternary North Sea Basin $\left(56-62^{\circ} \mathrm{N}\right)$. Marine Petroleum Geol 56, 123-46.

Palombo, M.R., and Valli, A.M.F., 2005. Highlighting the Early-Middle Pleistocene transition in Italian and French large-mammal faunas: similarities and faunal renewals. In: Head, M.J. and Gibbard, P.L. (eds.), Early-Middle Pleistocene transitions: the landocean evidence. Geological Society of London, Special Publication 247, 263-276.

Palombo, M.R., Raia, P., and Giovinazzo, C., 2005. Early-Middle Pleistocene structural changes in mammalian communities from the Italian peninsula. In: Head, M.J. and Gibbard, P.L. (eds.), Early-Middle Pleistocene transitions: the land-ocean evidence. Geological Society of London, Special Publication 247, 251-262.

Parés, J.M., Arnold, L., Duval, M., Demuro, M., Pérez-González, A., Bermúdez de Castro, J.M., Carbonell, E., Arsuaga, J.L., 2013. Reassessing the age of Atapuerca-TD6 (Spain): new paleomagnetic results. Journal of Archaeological Science 40, 4586-4595.

Parfitt, S.A., Barendregt, R.W., Breda, M., Candy, I., Collins, M.J., Coope, G.R., Durbidge, P., Field, M.H., Lee, J.R., Lister, A.M., Mutch, R., Penkman, K.E.H., Preece, R.C., Rose, J., Stringer, C.B., Symmons, R., Whittaker, J.E., Wymer, J.J., Stuart, A.J., 2005. The earliest record of human activity in northern Europe. Nature 438, 1008-1012. 
Parfitt, S.A., Ashton, N.M., Lewis, S.G., Abel, R.L., Coope, G.R., Field, M.H., Gale, R., Hoare, P.G., Larkin, N.R., Lewis, M.D., Karloukovski, V., Maher, B.A., Peglar, S.M., Preece, R.C., Whittaker, J.E., Stringer, C.B., 2010. Early Pleistocene human occupation at the edge of the boreal zone in northwest Europe. Nature 466, 229-233.

Parrenin, F., Barnola, J.-M., Beer, J., Blunier, T., Castellano, E., Chappellaz, J., Dreyfus, G., Fischer, H., Fujita, S., Jouzel, J., Kawamura, K., Lemieux-Dudon, B., Loulergue, L., Masson-Delmotte, V., Narcisi, B., Petit, J.R., Raisbeck, G., Raynaud, D., Ruth, U., Schwander, J., Severi, M., Spahni, R., Steffensen, J.P., Svensson, A., Udisti, R., Waelbroeck, C., Wolff, E.W., 2007. The EDC3 chronology for the EPICA Dome C ice core. Clim. Past 3, 485-497.

Pedoja, K., Husson, L., Johnson, M. E., Melnick, D., Witt, C., Pochat, S., Nexer, M., Delcaillau, B., Pinegina, T., Poprawski, Y., Authemayou, C., Elliot, M., Regard, V., Garestier, F., 2014. Coastal staircase sequences reflecting sea-level oscillations and tectonic uplift during the Quaternary and Neogene. Earth-Science Reviews, 132, 13-38.

Peeters, F.J.C., Acheson, R., Brummer, G.-J.A., de Ruijter, W.P.M., Schneider, R.R., Ganssen, G.M., Ufkes, E., Kroon, D., 2004. Vigorous exchange between the Indian and Atlantic oceans at the end of the past five glacial periods. Nature 430, 661-665.

Pickering, K.T., Souter, C., Oba, T., Taira, A., Schaaf, M., Platzman, E., 1999. Glacioeustatic control on deep-marine clastic forearc sedimentation, Pliocene-mid-Pleistocene (c. 1180-600 ka) Kazusa Group. SE Japan. Journal of the Geological Society, London $156,125-136$.

Pillans, B., 2003. Subdividing the Pleistocene using the Matuyama-Brunhes boundary (MBB): an Australasian perspective. Quaternary Science Reviews, 22: 1569-1577.

Pillans, B. and Gibbard, P.L. 2012. The Quaternary Period. In: Gradstein, F.M., Ogg, J.G., Schmitz, M.D. and Ogg, G.M. (eds) The Geologic Time Scale 2012. Vol. 2. Elsevier: Amsterdam, 980-1009.

Pisias, N.G., Moore, T.C., Jr., 1981. The evolution of Pleistocene climate: a time series approach. Earth and Planetary Science Letters, 52, 450-458.

Pollard, D., DeConto, R.M., 2009. Modelling West Antarctic ice sheet growth and collapse through the past five million years. Nature 458, 329-332.

Preece, R.C., Parfitt, S.A., 2012. The Early and early Middle Pleistocene context of human occupation and lowland glaciation in Britain and northern Europe. Quaternary International 271, 6-28.

Qiu, Z., Deng, T., Wang, B., 2004. Early Pleistocene mammalian fauna from Longdan, Dongxiang, Gansu, China. Palaeontologia Sinica, New Series C, 191, 1-198. 
Raffi, I. 2002. Revision of the early-middle Pleistocene calcareous nannofossil biochronology (1.75-0.85 Ma). Marine Micropaleontology, 45, 25-55.

Railsback, L.B., Gibbard, P.L., Head, M.J., Voarintsoa, N.R.G., Toucanne, S., 2015. An optimized scheme of lettered marine isotope substages for the last 1.0 million years, and the climatostratigraphic nature of isotope stages and substages. Quaternary Science Reviews (in press).

Raukas, A. et al., 2011. To be supplied later.

Raymo, M.E., Ruddiman, W.F., Shackleton, N.J., Oppo, D.W., 1990. Evolution of Atlantic-Pacific $\delta 13 \mathrm{C}$ gradients over the last 2.5 m.y. Earth Planet. Sci. Lett. 97, 353368.

Raymo M. E., 1994. The Himalayas, organic carbon burial, and climate in the Miocene. Paleoceanography 9, 399-404.

Raymo, M.E., 1997. The timing of major climate transitions. Paleoceanography 12, 577585.

Raymo, M.E., Oppo, D.W., Curry, W., 1997. The mid-Pleistocene climate transition: a deep sea carbon isotopic perspective. Paleoceanography 12 (4), 546-559.

Raymo M. E., Ruddiman W. F. and Froelich P. N., 1988. Influence of late Cenozoic mountain building on ocean geochemical cycles. Geology 16, 649-653.

Raymo, M. E. and Nisancioglu, K. 2003: The 41 kyr world: Milankovitch's other unsolved mystery. Paleoceanography 18, 1011-1017.

Raymo, M. E., Lisiecki, L.E., and Nisancioglu, K.H. 2006. Plio-Pleistocene ice volume, Antarctic climate, and the global $\delta^{18} \mathrm{O}$ record. Science, 313, 492-495.

Reale, V., and Monechi, S., 2005. Distribution of the calcareous nannofossil Reticulofenestra asanoi within the Early-Middle Pleistocene transition in the Mediterranean Sea and Atlantic Ocean: correlation with magneto- and oxygen isotope stratigraphy. In: Head, M.J. and Gibbard, P.L. (eds), Early-Middle Pleistocene Transitions: The Land-Ocean Evidence. Geological Society, London, Special Publications, 247, 117-130.

Renne, P.R., Mundil, R., Balco, G., Min, K., Ludwig, K.R., 2010. Joint determination of ${ }^{40} \mathrm{~K}$ decay constants and ${ }^{40} \mathrm{Ar} /{ }^{40} \mathrm{~K}$ for the Fish canyon sanidine standard, and improved accuracy for ${ }^{40} \mathrm{Ar} /{ }^{39} \mathrm{Ar}$ geochronology. Geochim. Cosmochim. Acta 74, 5349-5367. http://dx.doi.org/10.1016/j.cga.2010.06.017.

Renne, P.R., Balco, G., Ludwig, K.R., Mundil, R., and Min, K., 2011, Response to the comment by W.H. Schwarz et al. on "Joint determination of ${ }^{40} \mathrm{~K}$ decay constants and 
${ }^{40} \mathrm{Ar} * /{ }^{40} \mathrm{~K}$ for the Fish Canyon sanidine standard, and improved accuracy for ${ }^{40} \mathrm{Ar} /{ }^{39} \mathrm{Ar}$ geochronology" by P.R. Renne et al. (2010). Geochimica et Cosmochimica Acta, 75, 5097-5100.

Rial, J.A., Oh, J., Reischmann, E., 2013. Synchronization of the climate system to eccentricity forcing and the 100,000-year problem. Nature Geoscience 6, 289-293.

Richmond, G.M., 1996. The INQUA-approved provisional Lower-Middle Pleistocene boundary. In: C. Turner (Editor), The early Middle Pleistocene in Europe. Balkema, Rotterdam, pp. 319-327.

Ridgwell, A. J., and Watson, A., 2002. Feedback between aeolian dust, climate, and atmospheric $\mathrm{CO}_{2}$ in glacial time. Paleoceanography, 17(4), 1059, doi:10.1029/2001PA000729, 2002.

Rightmire, G.P. 2012, The evolution of cranial form in mid-Pleistocene Homo. South African Journal of Science 108 (3/4), Art. \#719, 10 pages.

Roberts, A.P., Tauxe, L., Heslop, D., 2013. Magnetic paleointensity stratigraphy and high-resolution Quaternary geochronology: successes and future challenges. Quaternary Science Reviews 61, 1-16.

Rodríguez, J., Alberdi, M. T., Azanza, B. \& Prado, J. L. 2004. Body size structure in north-western Mediterranean Plio-Pleistocene mammalian faunas. Global Ecology and Biogeography, 13, 163-176.

Rodríguez, J., Burjachs, F., Cuenca-Bescós, G., García, N., Made van der, J., PérezGonzález, A., Blain, H.-A., Expósito, I., López-García, J.M., García Antón, M., Allué, E., Cáceres, I., Huguet, R., Mosquera, M., Ollé, A., Rosell, J., Parés, J.M., Rodríguez, X.P., Díez, C., Rofes, J., Sala, R., Saladié, P., Vallverdú, J., Bennasar, M.L., Blasco, R., Bermúdez de Castro, J.M., Carbonell, E., 2011. One million years of cultural evolution in a stable environment at Atapuerca (Burgos, Spain). Quaternary Science Reviews 30, 1396-1412.

Roebroeks, W., Villa, P., 2011. On the earliest evidence for habitual use of fire in Europe. Proceedings of the National Academy of Sciences of the United States of America 108, 5209-5214.

Rook, L., Martínez-Navarro, B., 2010. Villafranchian: The long story of a PlioPleistocene European large mammal biochronologic unit. Quaternary International 219, 134-144.

Rose, J. et al., 2011. To come. 
Rossignol-Strick, M., Paterne, M., Bassinot, F., Emeis, K.-C. and De Lange, G. J. 1998. An unusual mid-Pleistocene monsoon period over Africa and Asia, Nature, 392, 269272.

Ruddiman, W. F., and A. McIntyre (1981), Oceanic mechanisms for amplification of the 23,000-year ice-volume cycle, Science, 212(4495), 617-627, doi:10.1126/science.212.4495.617.

Ruddiman, W. F., and A. McIntyre (1984), Ice-age thermal response and climatic role of the surface Atlantic Ocean, $40^{\circ} \mathrm{N}$ to $63^{\circ} \mathrm{N}$, Geol. Soc. Am. Bull., 95(4), 381-396, doi:10.1130/0016-7606(1984)95<381: ITRACR>2.0.CO;2.

Ruddiman, W.F., Raymo, M., and McIntyre, A., 1986. Matuyama 41,000-year cycles: North Atlantic Ocean and northern hemisphere ice sheets. Earth and Planetary Science Letters, 80, 117-129.

Ruddiman, W. F., Raymo, M. E., Martinson, D. G., Clement, B.M., and Backman, J., 1989. Pleistocene evolution: Northern Hemisphere ice sheets and North Atlantic Ocean. Paleoceanography, 4(4), 353-412.

Sagnotti, L., Scardia, G., Giaccio, B., Liddicoat, J.C., Nomade, S., Renne, P.R., Sprain, C.J., 2014. Extremely rapid directional change during Matuyama-Brunhes geomagnetic polarity reversal. Geophysical Journal International 199, 1110-1124.

Saltzman, B. and Maasch, K.A., 1988, Carbon cycle instability as a cause of the late Pleistocene ice age oscillations: Modeling the asymmetric response. Global Biogeochemical Cycles, 2, 177-185.

Sardella, R., Petrucci, M., 2012. The earliest Middle Pleistocene Crocuta crocuta (Erxleben, 1777) at Casal Selce (Rome, Italy). Quaternary International 267, 103-110.

Schefuß, E., Schouten, S., Jansen, J.H.F., Sinninghe Damsté, J.S., 2003. African vegetation controlled by tropical sea surface temperatures in the mid-Pleistocene period. Nature 422, 416-421.

Schefuß, E., Jansen, J.H.F., and Sinninghe Damsté, J.S., 2005. Tropical environmental changes at the mid-Pleistocene transition: insights from lipid biomarkers. In: Head, M.J. and Gibbard, P.L. (eds.), Early-Middle Pleistocene transitions: the land-ocean evidence. Geological Society of London, Special Publication 247, p. 35-63.

Scherer, R. P., Bohaty, S. M., Dunbar, R. B., Esper, O., Flores, J.-A., Gersonde, R., Harwood, D. M., Roberts, A. P., and Taviani, M., 2008. Antarctic records of precessionpaced insolation-driven warming during early Pleistocene Marine Isotope Stage 31. Geophysical Research Letters, 35, L03505, doi:10.1029/2007GL032254. 
Schmieder, F., von Dobeneck, T., Bleil, U., 2000. The Mid-Pleistocene climate transition as documented in the deep South Atlantic Ocean: initiation, interim state and terminal event. Earth and Planetary Science Letters 179, 539-549.

Sejrup, H.P., Haflidason, H., Aarseth, I., Forsberg, C.F., King, E., Long, D., Rokoengen, K., 1994. Late Weichselian glaciation history of the northern North Sea. Boreas 23, 1-13.

Sejrup, H.P., Aarseth, I., Haflidason, H., Løvlie, R., Bratten, A., Tjøstheim, G., Forsberg, C.F., Ellingsen, K.L., 1995. Quaternary of the Norwegian Channel; paleoceanography and glaciation history. Norsk Geologisk Tidsskrift 75, 65-87.

Sexton, P.F., Barker, S., 2012. Onset of 'Pacific-style' deep-sea sedimentary carbonate cycles at the mid-Pleistocene transition. Earth and Planetary Science Letters 321-322, 81-94.

Shackleton, N.J., 1977. Carbon-13 in Uvigerina: Tropical rainforest history and the equatorial Pacific carbonate dissolution cycles, in The Fate of Fossil Fuel $\mathrm{CO}_{2}$ in the Ocean, N.R. Anderson and A. Malahoff, eds., Plenum, New York, pp. 401-427.

Shackleton, N.J., Berger, A., and Peltier, W.R., 1990. An alternative astronomical calibration of the lower Pleistocene timescale based on ODP Site 677. Transactions of the Royal Society of Edinburgh: Earth Sciences, 81, 251-261.

Shackleton, N.J., Opdyke, N.D., 1976. Oxygen-isotope and paleomagnetic stratigraphy of Pacific core V28-239: Late Pliocene to latest Pleistocene. Geological Society of America Memoir 145, 449-464.

Shackleton, N. J., Hall, M. A., and Vincent, E., 2000. Phase relationships between millennial- scale events 64,000-24,000 years ago, Paleoceanography 15, 565-569, doi:10.1029/2000PA000513.

Shackleton, N. J., Fairbanks, R. G., Chiu, T.- C., and Parrenin, F., 2004. Absolute calibration of the Greenland time scale: Implications for Antarctic time scales and for $\mathrm{D}^{14}$ C, Quat. Sci. Rev., 23, 1513-1522, doi:10.1016/j.quascirev.2004. 03.006.

Short, D. A., J. G. Mengel, T. J. Crowley, W. T. Hyde, and G. R. North (1991), Filtering of Milankovitch cycles by Earth's geography, Quaternary Research, 35(2), 157-173, doi:10.1016/0033-5894(91)90064-C.

Singer, B.S., 2014. A Quaternary geomagnetic instability time scale. Quaternary Geochronology 21, 29-52.

Singer, B.S., Hoffman, K.A., Coe, R.S., Brown, L.L., Jicha, B.R., Pringle, M.S., Chauvin, A., 2005. Structural and temporal requirements for geomagnetic field reversal deduced from lava flows. Nature 434, 633-636. 
Sirakov, N., Guadelli, J.-L., Ivanova, S., Sirakova, S., Boudadi-Maligne, M., Dimitrova, I., Fernandez, P., Ferrier, C., Guadelli, A., Iordanova, D., Iordanova, N., Kovatcheva, M., Krumov, I., Leblanc, J.-C., Miteva, V., Popov, V., Spassov, R., Taneva, S., Tsanova, T., 2010. An ancient continuous human presence in the Balkans and the beginnings of human settlement in western Eurasia: a Lower Pleistocene example of the Lower Palaeolithic levels in Kozarnika cave (North-western Bulgaria). Quaternary International 223-224, 94-106.

Skinner, L.C., and Shackleton, N.J., 2005. An Atlantic lead over Pacific deep-water change across Termination I: implications for the application of the marine isotope stage stratigraphy. Quaternary Science Reviews 24, 571-580.

Snedden, J.W., and Liu, C., 2010. A compilation of Phanerozoic sea-level change, coastal onlaps and recommended sequence designations. Search and Discovery, article \#40594.

Song, Y., Fang, X., King, J.W., Li, J., Naoto, I., An, Z., 2014. Magnetic parameter variations in the Chaona loess/paleosol sequences in the central Chinese Loess Plateau, and their significance for the middle Pleistocene climate transition. Quaternary Research $81,433-444$.

Sosdian, S., and Rosenthal, Y., 2009. Deep-sea temperature and ice volume changes across the Pliocene-Pleistocene climate transitions. Science, 325, 306-310.

Sosdian, S., and Rosenthal, Y., 2010. Response to comment on "Deep-sea temperature and ice volume changes across the Pliocene-Pleistocene climate transitions" Science, $328,1480-d$.

Spassov, S., Heller, F., Evans, M.E., Yue, L.P., von Dobeneck, T., 2003. A lock-in model for the complex Matuyama-Brunhes boundary record of the loess/palaeosol sequence at Lingtai (Central Chinese Loess Plateau). Geophys. J. Int. 155, 350-366.

Stewart, J.R., Stringer, C.B., 2012. Human evolution out of Africa: the role of refugia and climate change. Science 335, 1317-1321.

Stout, D., Apel, J., Commander, J., Roberts, M., 2014. Late Acheulean technology and cognition at Boxgrove, UK. Journal of Archaeological Science 41, 576-590.

Stringer, C., 2012. The status of Homo heidelbergensis (Schoetensack 1908). Evolutionary Anthropology 21, 101-107.

Suc, J.-P., Popescu, S.-M., 2005. Pollen records and climatic cycles in the North Mediterranean region since 2.7 Ma. In: Head, M.J. and Gibbard, P.L. (Eds.), EarlyMiddle Pleistocene transitions: the land-ocean evidence. Geological Society of London, Special Publication 247, 147-158. 
Suc, J.-P., Bertini, A., Combourieu-Nebout, N., Diniz, F., Leroy, S., Russo-Ermolli, E., Zheng, Z., Bessais, E., Ferrier, J. 1995. Structure of West Mediterranean vegetation and climate since 5.3 Ma. Acta Zoologica Cracoviensa, 38, 3-16.

Suganuma, Y., Yokoyama, Y., Yamazaki, T., Kawamura, K., Horng, C.-S., Matsuzaki, H., 2010. ${ }^{10}$ Be evidence for delayed acquisition of remanent magnetization in marine sediments: Implication for a new age for the Matuyama-Brunhes boundary. Earth and Planetary Science Letters 296, 443-450.

Suganuma, Y., Okuno, J., Heslop, D., Roberts, A.P., Yamazaki, T., Yokoyama, Y., 2011. Post-depositional remanent magnetization lock-in for marine sediments deduced from ${ }^{10} \mathrm{Be}$ and paleomagnetic records through the Matuyama-Brunhes boundary. Earth and Planetary Science Letters 311, 39-52.

Suganuma, Y., Okada, M., Horie, K., Kaiden, H., Takehara, M., Senda, R., Kimura, J.-I., Kawamura, K., Haneda, Y., Kazaoka, O., Head, M.J., 2015. Age of Matuyama-Brunhes boundary constrained by $\mathrm{U}-\mathrm{Pb}$ zircon dating of a widespread tephra. Geology.

Sun, Y., Clemens, S.C., An, Z., Yu, Z., 2006. Astronomical timescale and palaeoclimatic implication of stacked 3.6-Myr monsoon records from the Chinese Loess Plateau. Quaternary Science Reviews 25, 33-48.

Sun, Y., An, Z., Clemens, S.C., Bloemendal, J., Vandenberghe, J., 2010. Seven million years of wind and precipitation variability on the Chinese Loess Plateau. Earth and Planetary Science Letters 297, 525-535.

Toggweiler, J.R., Russell, J.L., Carson, S.R., 2006. Midlatitude westerlies, atmospheric CO2, and climate change during the ice ages. Paleoceanography 21, PA2005. http://dx.doi.org/10.1092/2005PA001154.

Toro-Moyano, I., Martínez-Navarro, B., Agustí, J., Souday, C., Bermúdez de Castro, J.M., Martinón-Torres, M., Fajardo, B., Duval, M., Falguères, C., Oms, O., Parés, J.M., Anadón, P., Julià, R., García-Aguilar, J.M., Moigne, A.-M., Espigares, M.P., RosMontoya, S., Palmqvist, P., 2013. The oldest human fossil in Europe, from Orce (Spain). Journal of Human Evolution 65, 1-9.

Trauth, M.H., Larrasoaña, J.C., Mudelsee, M., 2009. Trends, rhythms and events in PlioPleistocene African climate. Quaternary Science Reviews 28 (2009) 399-411.

Tripati, A. K., Roberts, C. D., Eagle, R. A., Gaojun Li, 2011. A 20 million year record of planktic foraminiferal $\mathrm{B} / \mathrm{Ca}$ ratios: Systematics and uncertainties in $p \mathrm{CO}_{2}$ reconstructions. Geochimica et Cosmochimica Acta 75, 2582-2610.

Tzedakis, P.C., Hooghiemstra, H., Pälike, H., 2006. The last 1.35 million years at Tenaghi Philippon: revised chronostratigraphy and long-term vegetation trends. Quaternary Science Reviews 25, 3416-3430. 
Tzedakis, P.C., Raynaud, D., McManus, J. F., Berger, A., Brovkin, V., and Kiefer, T., 2009. Interglacial diversity. Nature Geoscience 2, 751-755.

Tzedakis, P. C., 2010. The MIS 11-MIS 1 analogy, southern European vegetation atmospheric methane and the early anthropogenic hypothesis. Clim. Past 6, 131-144.

Tzedakis, P. C., Channell, J. E. T., Hodell, D. A., Kleiven, H. F., Skinner, L. C., 2012. Determining the natural length of the current interglacial. Nature Geoscience 5, DOI: 10.1038/NGEO1358.

Urdea, P., Onaca, A., Ardelean, F., Ardelean, M., 2011. New evidence on the Quaternary glaciation in the Romanian Carpathians. Chapter 24. In: Ehlers, J., Gibbard, P.L., Hughes, P.D. (Eds.), Quaternary Glaciations - Extent and Chronology - A Closer Look. Developments in Quaternary Sciences, Elsevier, vol. 15, pp. 305-322.

van den Bergh, G. D., de Vos, J. \& Sondaar, P. Y. 2001. The Late Quaternary palaeogeography of mammal evolution in the Indonesian Archipelago. Palaeogeography, Palaeoclimatology, Palaeoecology 171, 385-408.

van de Wal, R. S. W., de Boer, B., Lourens, L. J., Köhler, P. and Bintanja, R. 2011. Reconstruction of a continuous high-resolution $\mathrm{CO}_{2}$ record over the past 20 million years. Climate of the Past, 7, 1459-1469.

van der Made, J., 2013. First description of the large mammals from the locality of Penal, and updated faunal lists for the Atapuerca ungulates - Equus altidens, Bison and human dispersal into Western Europe. Quaternary International 295, 36-47.

van Husen, D., 2011. Quaternary glaciations in Austria. Chapter 2. In: Ehlers, J., Gibbard, P.L., Hughes, P.D. (Eds.), Quaternary Glaciations - Extent and Chronology - A Closer Look. Developments in Quaternary Sciences, Elsevier, vol. 15, pp. 15-28.

Van Kolfschoten, T., 2014. The Palaeolithic locality Schöningen (Germany): A review of the mammalian record. Quaternary International 326-327, 469-480.

Van Kolfschoten, T., \& Markova, A.K., 2005. Response of the European mammalian fauna to the mid-Pleistocene transition. In: Head, M.J. and Gibbard, P.L. (eds.), EarlyMiddle Pleistocene transitions: the land-ocean evidence. Geological Society of London, Special Publication 247, 221-229.

Valet, J.P., Bassinot, F., Bouilloux, A., Bourlès, D., Nomade, S., Guillou, V., Lopes, F., Thouveny, N., and Dewilde, F., 2014. Geomagnetic, cosmogenic and climatic changes across the last geomagnetic reversal from Equatorial Indian Ocean sediments. Earth and Planetary Science Letters, 397, 67-79. 
Vance, D., Teagle, D. A. H. and Foster, G. L. (2009) Variable Quaternary chemical weathering fluxes and imbalances in marine geochemical budgets. Nature 458, 493-496.

Venuti, A., Florindo, F., Michel, E., Hall, I.R., 2007. Magnetic proxy for the deep (Pacific) western boundary current variability across the mid-Pleistocene climate transition. Earth and Planetary Science Letters 259, 107-118.

Villa, G., Persico, D., Wise, S.W., Gadaleta, A., 2012. Calcareous nannofossil evidence for Marine Isotope Stage 31 (1 Ma) in Core AND-1B, ANDRILL McMurdo Ice Shelf Project (Antarctica). Global and Planetary Change 96-97, 75-86.

Wagner, G.A., Krbetschek, M., Degering, D., Bahain, J.-J., Shao, Q., Falguères, C., Voinchet, P., Doloe, J.-M., Garciae, T. and Rightmire, G.P., 2010. Radiometric dating of the type-site for Homo heidelbergensis at Mauer, Germany. Proceedings of the National Academy of Sciences, USA 107, 19726-19730.

Wang, D. J., Wang, Y.C., Han, J.T., Duan, M.G., Shan, J.Z., Liu, T.S., 2010. Geomagnetic anomalies recorded in L9 of the Songjiadian loess section in southeastern Chinese Loess Plateau. Chinese Science Bulletin, 55 (6), 520-529. doi: 10.1007/s11434009-0565-9.

Wang, X., Løvlie, R., Yang, Z., Pei, J., Zhao, Z., Sun, Z., 2005. Remagnetization of Quaternary eolian deposits: A case study from SE Chinese Loess Plateau. Geochemistry Geophysics Geosystems, 6, Q06H18, doi:10.1029/2004GC000901.

Wang, X., Løvlie, R., Chen, Y., Yang, Z., Pei, J., Tang, L., 2014. The MatuyamaBrunhes polarity reversal in four Chinese loess records: high-fidelity recording of geomagnetic field behavior or a less than reliable chronostratigraphic marker? Quaternary Science Reviews 101, 61-76.

Wara, M.W., Ravelo, A.C., Delaney, M.L., 2005. Permanent El Niño-like conditions during the Pliocene warm period. Science 309, 758-761.

Watson, A. J., Bakker, D. C. E., Ridgwell, A. J., Boyd, P. W., and Law, C. S., 2000. Effect of iron supply on Southern Ocean $\mathrm{CO}_{2}$ uptake and implications for glacial atmospheric $\mathrm{CO}_{2}$, Nature, 407, 730-733.

Weirauch, D., Billups, K., Martin, P., 2008. Evolution of millennial-scale climate variability during the mid-Pleistocene. Paleoceanography 23, PA3216. doi:10.1029/ 2007PA001584.

Woodward, J.C., Hughes, P.D., 2011. Glaciation in Greece: A new record of cold stage environments in the Mediterranean. Chapter 15. In: Ehlers, J., Gibbard, P.L., Hughes, P.D. (Eds.), Quaternary Glaciations - Extent and Chronology - A Closer Look. Developments in Quaternary Sciences, Elsevier, vol. 15, pp. 175-198. 
Wright, A.K., and Flower, B.P., 2002. Surface and deep ocean circulation in the subpolar North Atlantic during the mid-Pleistocene revolution. Paleoceanography, 17 (4), 1068, doi:10.1029/2002PA000782, 2002.

Wu, B., and Wu, N.Q., 2011. Terrestrial mollusc records from Xifeng and Luochuan L9 loess strata and their implications for paleoclimatic evolution in the Chinese Loess Plateau during marine Oxygen Isotope Stages 24-22. Climate of the Past 7, 349-359.

Yang, T., Hyodo, M., Yang, Z., Li, H., and Maeda, M. (2010), Multiple rapid polarity swings during the Matuyama-Brunhes transition from two high- resolution loesspaleosol records, Journal of Geophysical Research, 115, B05101, doi:10.1029/2009JB006301.

Ziegler, M., Lourens, L. J., Tuenter, E., and Reichart, G.-J., 2010. High Arabian Sea productivity conditions during MIS 13 - odd monsoon event or intensified overturning circulation at the end of the Mid-Pleistocene transition? Climate of the Past, 6, 63-76.

Yin, Q., 2013. Insolation-induced mid-Brunhes transition in Southern Ocean ventilation and deep-ocean temperature. Nature, 494, 222-225.

Zachos, J., Pagani,M., Sloan, L., Thomas, E., Billups, K., 2001. Trends, rhythms, and aberrations in global climate $65 \mathrm{Ma}$ to present. Science, 292, 686-693.

Zelčs, V., Markots, A., Nartišs, M., Saks, T., 2011. Pleistocene glaciations in Latvia. Chapter 18. In: Ehlers, J., Gibbard, P.L., Hughes, P.D. (Eds.), Quaternary Glaciations Extent and Chronology - A Closer Look. Developments in Quaternary Sciences, Elsevier, vol. 15, pp. 221-229.

Zhamoida, A. I. 2004. Some key problems of the International Stratigraphic Scale. Report of the Chairman of the Interdepartmental Stratigraphic Committee of Russia in the session of the International Commission on Stratigraphy and Subcommission on Stratigraphic Classification. A. P. Karpinsky All Russian Geological Research Institute. VSEGEI Press, St. Petersburg, 19 pp.

Zhao, H., X. Qiang, and Y. Sun (2014), Apparent timing and duration of the MatuyamaBrunhes geomagnetic reversal in Chinese loess, Geochemistry, Geophysics, Geosystems, 15, doi:10.1002/ 2014GC005497.

Zheng, F., Li, Q., Li, B., Chen, M., Tu, X., Tian, J., Jian, Z., 2005. A millennial scale planktonic foraminiferal record of mid-Pleistocene climate transition in the northern South China Sea. Palaeogeography, Palaeoclimatology, Palaeoecology 223, 349-363.

Zhou, L.P., and Shackleton, N.J., 1999. Misleading positions of geomagnetic reversal boundaries in Eurasian loess and implications for correlation between continental and marine sedimentary sequences. Earth and Planetary Science Letters, 168: 117-130. 
Zhou, S., Li, J., Zhao, J., Wang, J., Zheng, J., 2011. Quaternary glaciations: extent and chronology in China. Chapter 70. In: Ehlers, J., Gibbard, P.L., Hughes, P.D. (Eds.), Quaternary Glaciations - Extent and Chronology - A Closer Look. Developments in Quaternary Sciences, Elsevier, vol. 15, pp. 981-1002.

\section{Figure Captions}

Figure. 1. Stratigraphic correlation table for the last 2.7 million years. (From Cohen and Gibbard, 2011).

Figure 2. Major events during the Early-Middle Pleistocene transition updated from Head et al. (2008, fig. 1) and using the marine benthic foraminiferal $\delta^{18} \mathrm{O}$ stack of Lisiecki and Raymo (2005). For the magnetostratigraphy: $\mathrm{B}=$ Blake Event, $\mathrm{E}=$ Emperor Event, $\mathrm{J}=$ Jaramillo Subchron, $\mathrm{C}=$ Cobb Mountain Event, $\mathrm{G}=$ Gilsa Event, $\mathrm{O}=$ Olduvai Subchron (top only).

\section{Tables}

Table 1. Various published estimates for the duration and mid-point age (in parentheses where duration is given) of the Matuyama-Brunhes boundary (ka), relationship to the marine isotope stratigraphy, location, and estimated sedimentation rate across the boundary. The duration of the polarity reversals represents the length of time for which the VGP latitudes are less than $45^{\circ}$.

\begin{tabular}{|c|c|c|c|c|c|}
\hline Author & \multicolumn{2}{|l|}{ Age (ka) } & \multicolumn{2}{|c|}{ Relationship to MIS } & Sedimentation rate \\
\hline Shackleton et al. (1990) & 780 & & base MIS 19 & ODP 677, eastern equatorial Pacific & $4.3 \mathrm{~cm} / \mathrm{kyr}$ \\
\hline Bassinot et al. (1994) & $775 \pm 10$ & & uppermost MIS 19 & MD90-0963, equatorial Indian Ocean & $3.65 \mathrm{~cm} / \mathrm{kyr}$ \\
\hline Horng et al. (2002) & $781 \pm 3$ & & just above MIS 19.3 & MD972143, western Philippine Sea & $1 \mathrm{~cm} / \mathrm{kyr}$ \\
\hline Capraro et al. (2005) & & & mid-MIS 19 & southern Italy & $13 \mathrm{~cm} / \mathrm{kyr}$ \\
\hline Channell et al. (2004) & $777(773.5) 770$ & 7 & MIS 19.3-MIS 18.4 & ODP 984, Bjorn Drift, N. Atlantic & $9 \mathrm{~cm} / \mathrm{kyr}$ \\
\hline Channell \& Kleiven (2000) & $775(772.5) 770$ & 5 & MIS 19.3-MIS18.4 & ODP 983, Gardar Drift, N. Atlantic & $14 \mathrm{~cm} / \mathrm{kyr}$ \\
\hline Channell et al. (2004) & $775(772.5) 770$ & 5 & MIS 19.3-MIS18.4 & ODP 983, Gardar Drift, N. Atlantic & $14 \mathrm{~cm} / \mathrm{kyr}$ \\
\hline Lisiecki \& Raymo (2005) & 780 & & within MIS 19 & Mean of up to 8 Atlantic and Pacific sites & \\
\hline Lourens et al. (2005a) & 781 & & & Based on Shackleton et al. (1990), Horng & et al. (2002) \\
\hline Dreyfus et al. (2008) & $776(770) 764$ & 12 & upper MIS 19 & EPICA Dome $\mathrm{C}$ ice core based on ${ }^{10} \mathrm{Be}$ pe & \\
\hline Head et al. (2008) & 773 & & & Follows Channell et al. (2004) & \\
\hline Channell et al. (2010) & $774.8(773.1) 771.3$ & 3.5 & upper MIS 19 & ODP 980, Feni Drift, N. Atlantic & $4 \mathrm{~cm} / \mathrm{kyr}$ \\
\hline Channell et al. (2010) & $775.0(772.7) 770.4$ & 4.6 & upper MIS 19 & ODP 983, Gardar Drift, N. Atlantic & $14 \mathrm{~cm} / \mathrm{kyr}$ \\
\hline Channell et al. (2010) & $776.5(773.4) 770.3$ & 6.2 & upper MIS 19 & ODP 984 , Bjorn Drift, N. Atlantic & $9 \mathrm{~cm} / \mathrm{kyr}$ \\
\hline Channell et al. (2010) & $775.0(772.7) 770.4$ & 4.6 & upper MIS 19 & ODP 1063 , Bermuda Rise, N. Atlantic & $11 \mathrm{~cm} / \mathrm{kyr}$ \\
\hline Channell et al. (2010) & $775.0(773.5) 772.0$ & 2.9 & upper MIS 19 & IODP U1308, central N. Atlantic & $6 \mathrm{~cm} / \mathrm{kyr}$ \\
\hline Channell et al. (2010) & $775.3(773.1) 770.9$ & 4.4 & upper MIS 19 & Mean reversal age of the five N. Atlantic & cores \\
\hline Grützner \& Higgins (2010) & 773 & & (Non-isotope orbital proxy & IODP U1314, Gardar Drift, N. Atlantic & $5.5 \mathrm{~cm} / \mathrm{kyr}$ \\
\hline Suganuma et al. (2010) & $770 \pm 6$ & & upper MIS 19 & MD972143, western Philippine Sea & $0.99 \mathrm{~cm} / \mathrm{kyr}$ \\
\hline Hilgen et al. (2012) & 781 & & & Follows Lourens et al. (2005a) & \\
\hline Pillans \& Gibbard (2012) & 781 & & & Follows Lourens et al. (2005a) & \\
\hline Valet et al. (2014) & $777(772) 767$ & 10 & upper MIS 19 & MD90-0961, equatorial Indian Ocean & $4.7 \mathrm{~cm} / \mathrm{kyr}$ \\
\hline Sagnottoi et al. (2014) & $786.1 \pm 1.5 \mathrm{ka}$ & & & Sulmona, Italy $\left({ }^{40} \mathrm{Ar} /{ }^{39} \mathrm{Ar}\right.$-dated tephras $)$ & $20 \mathrm{~cm} / \mathrm{kry}$ \\
\hline Suganuma et al. (2015) & $770.2 \pm 7.3 \mathrm{ka}$ & & upper MIS 19 & Chiba section, Japan (U-Pb dated tephra) & $32 \mathrm{~cm} / \mathrm{kyr}$ \\
\hline Accepted in this paper & $\sim 773$ & & upper MIS 19 & Channell et al. (2010), Valet et al. (2014) & , Suganuma et al. (2015) \\
\hline
\end{tabular}

Table 2. Various published age estimates for the base and top of the Jaramillo Subchron (ka), relationship to the marine isotope stratigraphy, location, and estimated sedimentation rate across the subchron where known. 
Author

Shackleton et al. (1990)

Horng et al. (2002)

Channell et al. (2002)

Channell and Raymo (2003)

Lisiecki \& Raymo (2005)

Lourens et al. (2005a)

Channell et al. (2008, fig. 5)

Grützner \& Higgins (2010)

Hilgen et al. (2012)

Accepted in this paper
Age base (ka)

1070 (mid-MIS 31)

1072 \pm 2 ka (MIS 31)

1068 (base MIS 31)

1060 (top MIS 31)

1075 (MIS 31)

1072

1070 (mid-MIS 31)

1074

1072

1070 (mid-MIS 31)
Age top (ka)

990 (mid-MIS 27)

$988 \pm 3$ ka (MIS 27)

987 (base MIS 27)

987 (mid-MIS 27)

991 (MIS 28)

988

988 (MIS 28)

987

988

988 (MIS 28)
Site / location Sedimentation rate

ODP 677, eastern equatorial Pacific $\quad 3.9 \mathrm{~cm} / \mathrm{kyr}$ MD972143, western Philippine Sea $1.5 \mathrm{~cm} / \mathrm{kyr}$ ODP 983,984, N. Atlantic

ODP 980, Feni Drift, N. Atlantic $4 \mathrm{~cm} / \mathrm{kyr}$

Mean of up to 8 Atlantic and Pacific sites

Based on Shackleton et al. (1990), Horng et al. (2002)

IODP U1308, central North Atlantic $7 \mathrm{~cm} / \mathrm{kyr}$

IODP U1314, Gardar Drift, N. Atlantic $7.5 \mathrm{~cm} / \mathrm{kyr}$

Follows Lourens et al. (2005a)

Following Channell et al. (2008, fig. 5). 